Old Dominion University ODU Digital Commons

Winter 2014

\title{
The Impacts of In-State Procurement Preference Policies on the Economy of South Carolina
}

Sawsan A. Abutabenjeh

Old Dominion University

Follow this and additional works at: https://digitalcommons.odu.edu/publicservice_etds

Part of the Finance Commons, Public Administration Commons, Public Policy Commons, and the Regional Economics Commons

\section{Recommended Citation}

Abutabenjeh, Sawsan A.. "The Impacts of In-State Procurement Preference Policies on the Economy of South Carolina" (2014). Doctor of Philosophy (PhD), dissertation, , Old Dominion University, DOI: 10.25777/9nnr-tw66

https://digitalcommons.odu.edu/publicservice_etds/18 inclusion in School of Public Service Theses \& Dissertations by an authorized administrator of ODU Digital Commons. For more information, please contact digitalcommons@odu.edu. 


\title{
THE IMPACTS OF IN-STATE PROCUREMENT PREFERENCE
}

\section{POLICIES ON THE ECONOMY OF SOUTH CAROLINA}

\author{
by \\ Sawsan A. Abutabenjeh \\ B.S. June 2004, The Hashemite University \\ MBA. June 2006, The Hashemite University \\ A Dissertation Submitted to the Faculty of \\ Old Dominion University in Partial Fulfillment of the \\ Requirements for the Degree of \\ DOCTOR OF PHILOSOPHY \\ PUBLIC ADMINISTRATION AND URBAN POLICY \\ OLD DOMINION UNIVERSITY \\ December 2014
}

Approved by:

Berhanu Mengistu (Director)

Stephén B. Gordon (Member)

David Selover (Member)

Clifford McCue (Member) 
ABSTRACT

THE IMPACTS OF IN-STATE PROCUREMENT PREFERENCE POLICIES ON THE ECONOMY OF SOUTH CAROLINA

Sawsan A. Abutabenjeh, 2014

Old Dominion University

Director: Professor Berhanu Mengistu

This research examined the impact of South Carolina's in-state preference policies on the economy of the state. To achieve this purpose, the research sought to answer the question: what are the impacts of implementing the in-state procurement preference policies on the economy of the state of South Carolina? The question was answered by using seven economic indicators: jobs, personal income, real disposable income, output (sales), Gross State Product (GSP), value added and state's population. The data related to the in-state preference policies were collected from the South Carolina Procurement Services Office. The data was then analyzed using the Regional Economic Model Policy Insight (REMI PI+) for economic-forecasting and policy-analysis.

The results revealed the existence of quantitative differences between the baseline, which represents the values of the economic indicators without implementing the preference policies, and the alternative forecast, which represents the values of the economic indicators when implementing the policies. Specifically, the results showed that implementing in-state preference policies presented economic benefits to the state and its communities in the form of additional jobs, income, GSP, value added, population and sales. From 2010 until 2017, the total economic impact of implementing preference policies generated $\$ 17$ million in total output, 135 total job- years, $\$ 10.22$ 
million in GSP, \$10.27 million in value added, $\$ 7.52$ in income and $\$ 5.14$ million in real disposable personal income. The impact on the wholesale trade industry was over $\$ 5$ million in total industry output and approximately 27 jobs. The manufacturing sector had a total impact of over $\$ 4$ million in total industry output and approximately 17 jobs. The impact on the construction industry was approximately $\$ 3$ million in total industry output and approximately 30 jobs. Over 100 people were predicted to relocate to the state within the next 8 years. Although the values of the economic indicators are very small compared to the size of the state economy, they outweighed the direct cost of preferences. The direct cost of preferences represents the extra dollars that government pays when they award the contracts based on preferences. Overall, implementing the in-state preference policies contributed to South Carolina's economy. However, further research is warranted to account for the total costs of implementing the preference policies. 
This dissertation is dedicated to

My husband, Ra'ed, who gave me the motivation, support, encouragement, and strength to complete my dissertation while pursuing his own Ph.D.

My dad, Ali, who always believed that

I can do anything I put my mind to.

My mom, Rima, without her prayers I would not be here.

My brothers, Ala', Ehab, and Ahmad, for their endless support and love.

My sister, Rana, for always being there for me.

My daughter, Kenda, without her being the queen of terrible twos, I would not have been challenged to complete this dissertation. 


\section{ACKNOWLEDGMENTS}

This dissertation could not have been completed without the continued effort and support from faculty, friends, and colleagues. I would like to take this opportunity to thank Dr. Berhanu Mengistu, my committee chair, for his steady support and encouragement through the process of completing not only my dissertation but also my doctoral studies. I extend many thanks to Dr. Stephen Gordon for being my mentor and father figure. Dr. Gordon believed in me and my passion toward public procurement. We started talking about my dissertation topic almost one year before he formally joined Old Dominion University in 2011 . I would like to thank my other committee members, Dr. David Selover and Dr. Clifford McCue, for their guidance during the dissertation process. I am thankful for my committee members for reading, editing, and providing feedback for many drafts.

I would like to thank the Regional Economic Models, Inc. (REMI) for providing access to the economic forecasting and policy analysis model for South Carolina. Very special thanks to Mr. Chris Brown from REMI for answering all my questions regarding the model.

I am also thankful to Norma Hall for providing the data and the information related to South Carolina preference policies and practices, so I could complete the dissertation analysis. Ms. Hall works at the Division of Procurement Services in the South Carolina Budget and Control Board. 
I would like to convey thanks to the Department Urban Studies and Public Administration, the Department of Accounting and Finance, and the Master of Business Administration Department for providing financial assistance during my study at Old Dominion University. Ms. Toni Zemken deserves acknowledgment for treating me in a special way the last two years. She has been a good listener and a valuable helper.

Special thanks also to Anne Geyer for proofreading and editing my writings through my doctoral study. She read and learned the subject matter to help me. I deeply thank her for being a good friend to me, providing encouragement and positive comments all the time, and sharing long chats at coffee shops.

I would also like to acknowledge my classmates in the doctoral program, especially Dr. Getachew Melkie and Shawn Hirano. I appreciate their time and advice when we attended classes, studied for comprehensive exams, and worked on our prospectuses and dissertations. Thank you for the memories that I gathered when we consumed many cups of coffee trying to help each other.

I am in indebted to my husband, Ra'ed, who always provided extreme love and support. We started our educational adventure more than ten years ago, and although we went through hard times and challenges, here we are completing our doctoral studies. Ra'ed was a handy helper and a Super Dad to our daughter, Kenda, who added a lot of joy and challenges to our life. Kenda, almost three years old now, hates it when I go to school and she always says "mommy...are you going to school...to study...stay home mommy... want to be with you". I would like to thank her deeply for her patience 
with me and ask her to forgive me for not spending enough time with her. 1 am also thankful for my good friends who babysat Kenda so I could complete my degree.

Finally, I am deeply grateful to my family who supported me during my PhD study. Thank you to my father and mother who being thousands of miles away from me did not stop them from providing unlimited love, support, and prayers. They are the ones who taught me to be true to my dreams and believe in myself. I am grateful to my brothers and sister for all the shared and warm love that they have for me. 


ABSTRACT

Chapter

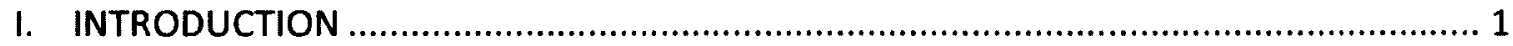

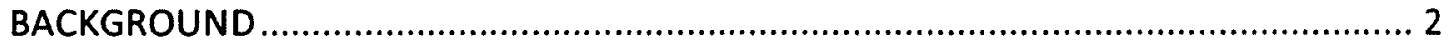

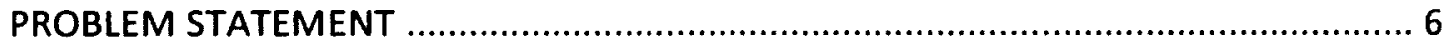

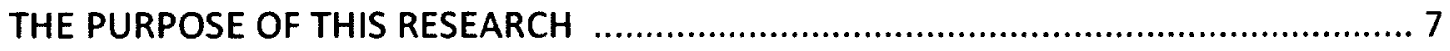

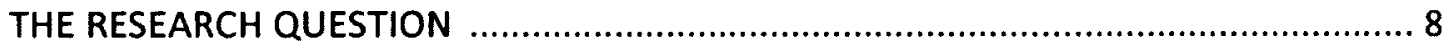

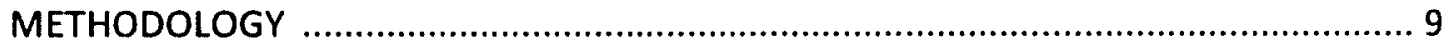

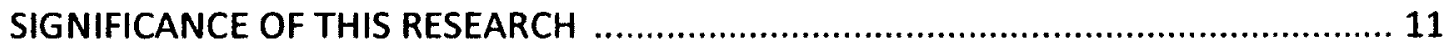

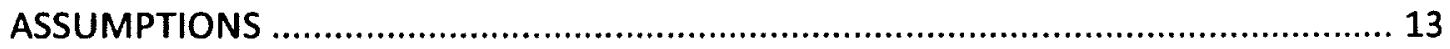

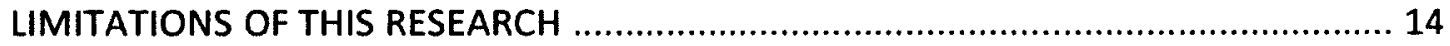

ORGANIZATION OF THIS RESEARCH

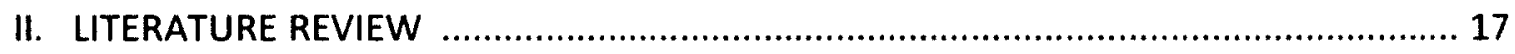

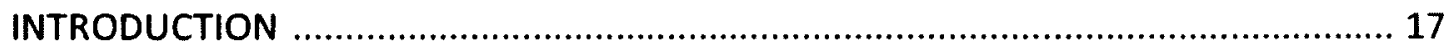

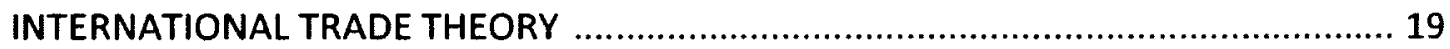

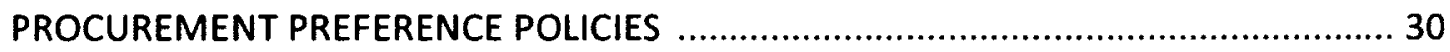

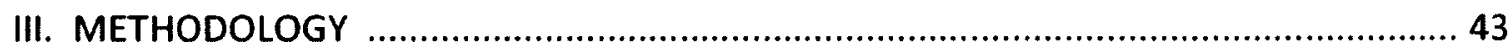

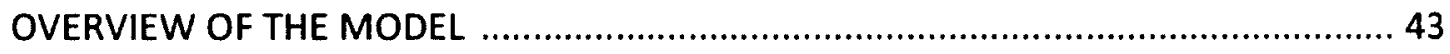

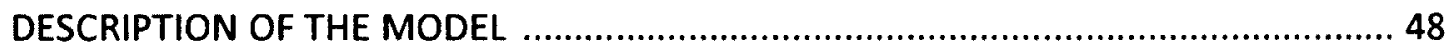

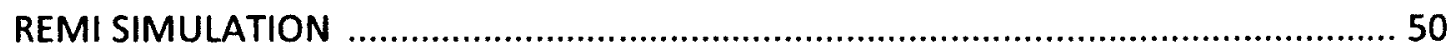

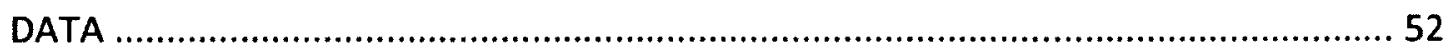

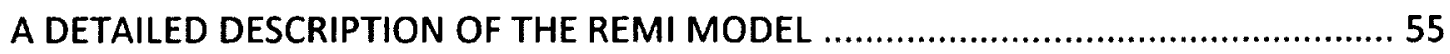

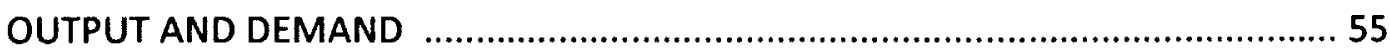

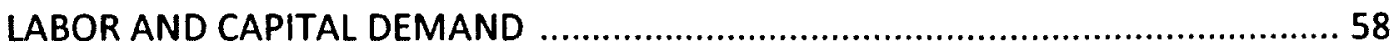




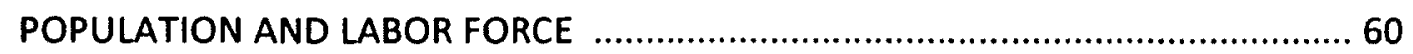

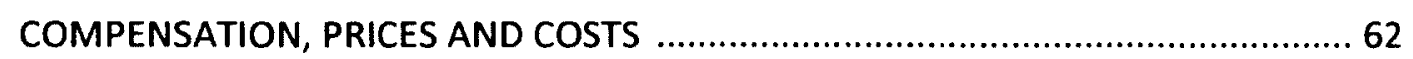

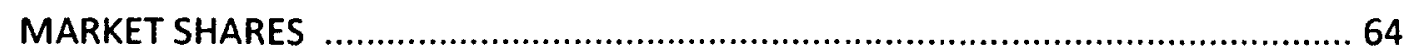

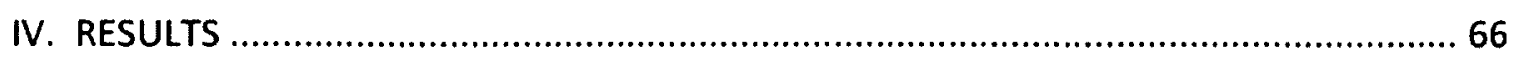

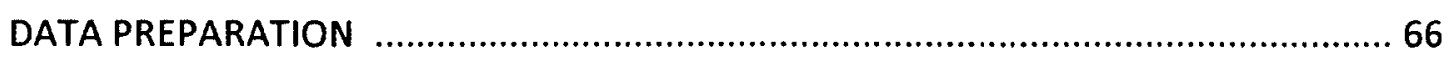

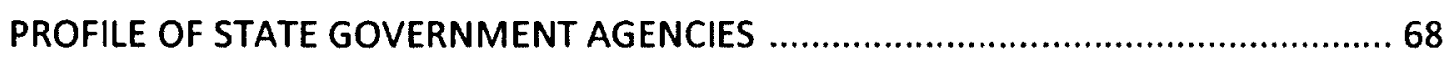

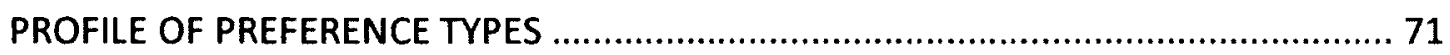

PROFILE OF INDUSTRIES BENEFITING FROM PROCUREMENT CONTRACTS .............. 73

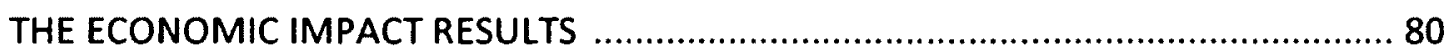

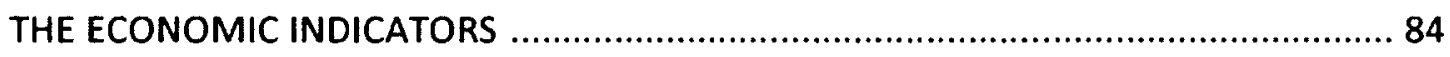

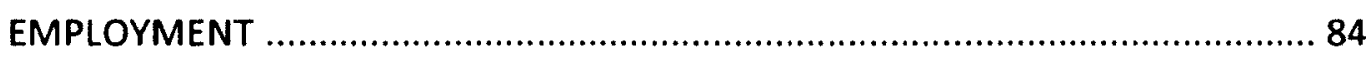

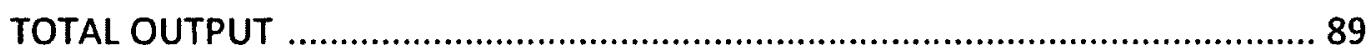

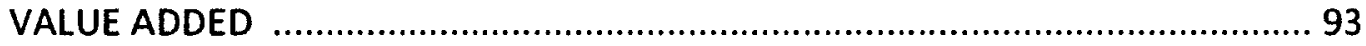

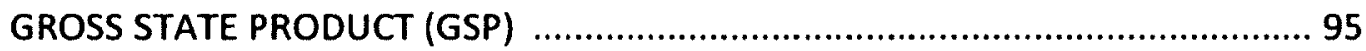

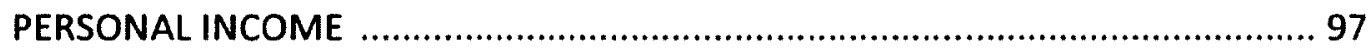

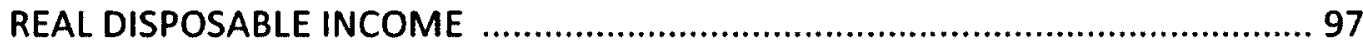

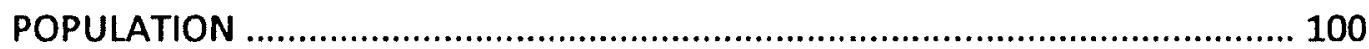

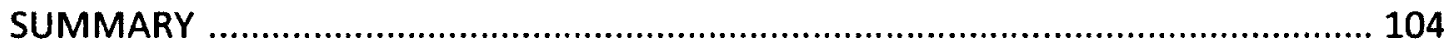

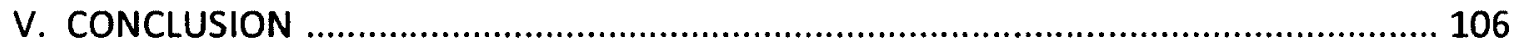

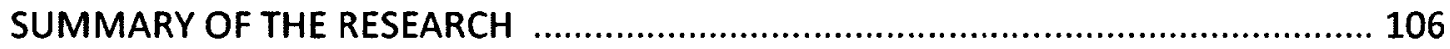

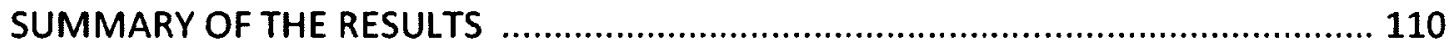

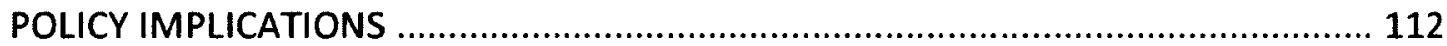

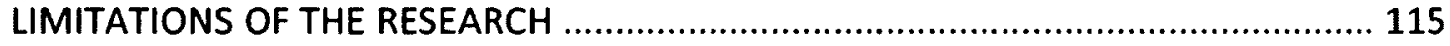

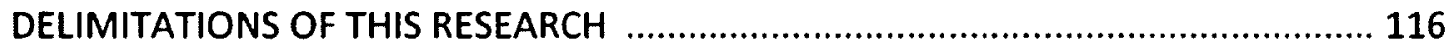

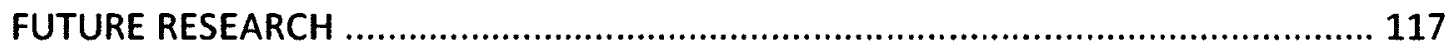

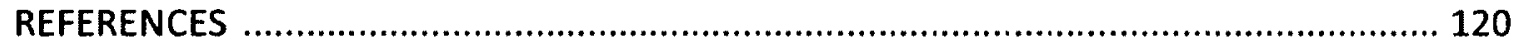

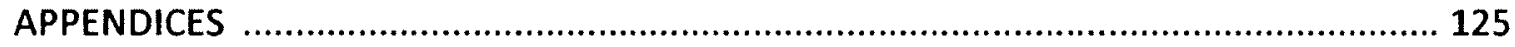

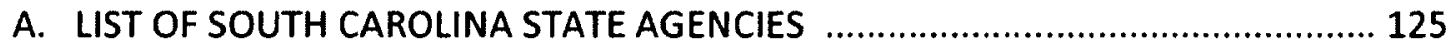

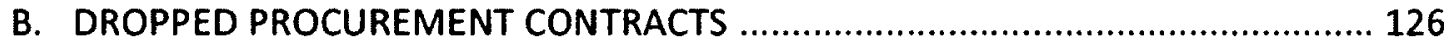

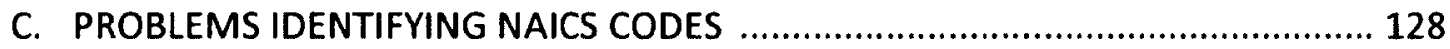

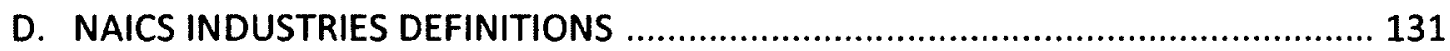

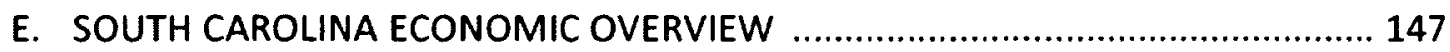

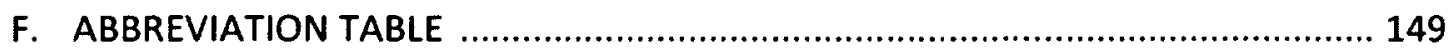

VITA 


\section{LIST OF TABLES}

Table Page

1.1 States that have Vendor-Based (Non-Geographical-Based) Price Preferences .... 4

2.2 Percentage Preference 38

3.1 Total Number of Contracts Dictated by Preferences and the Preference Cost .. 54

4.1 Profile of Industries Benefiting from Procurement Contracts 77

4.2 Difference in Economic Indicators Compared to the Baseline Values 83 


\section{LIST OF CHARTS}

Chart Page

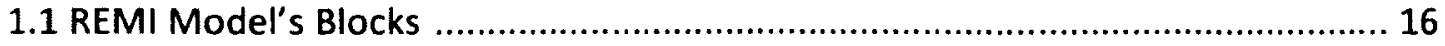

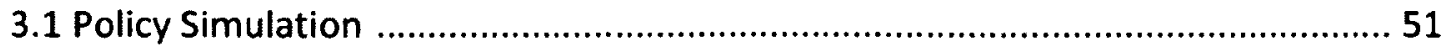

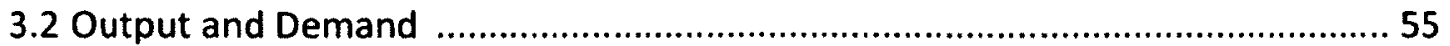

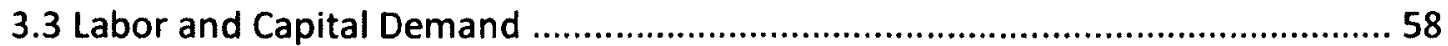

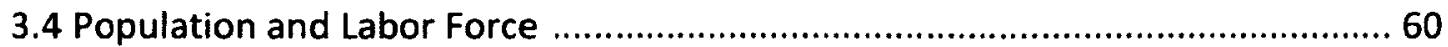

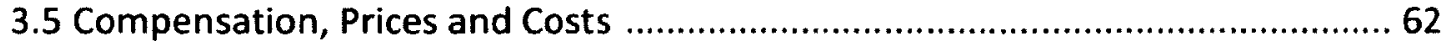

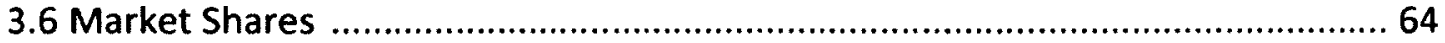

4.1 State Agencies that Implemented the In-State Preference Policies ................... 70

4.2 Type of Preference Policies ................................................................... 72

4.3 The Percentage of Procurement Contracts by Industry .................................... 78

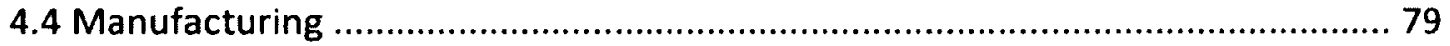

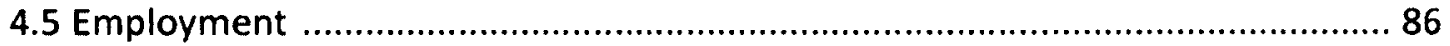

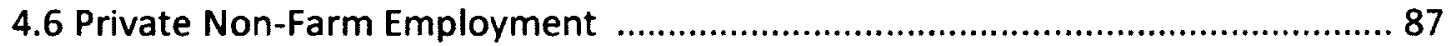

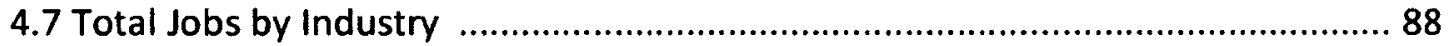

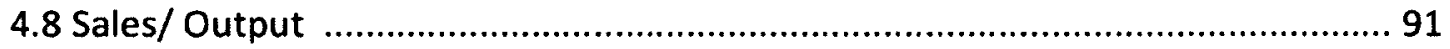

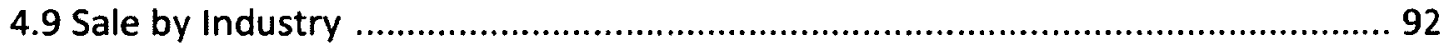

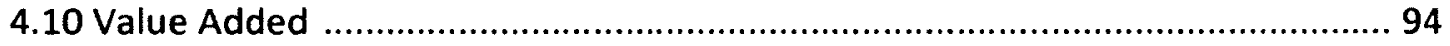

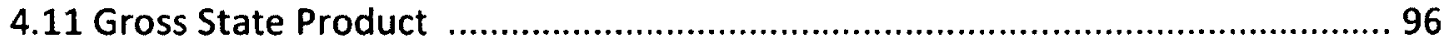

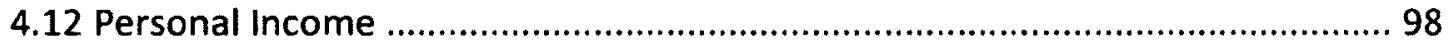

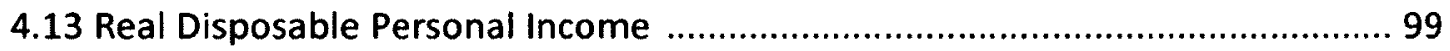

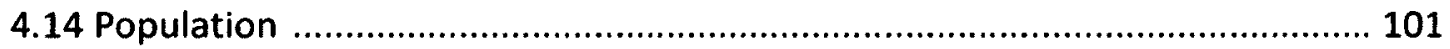

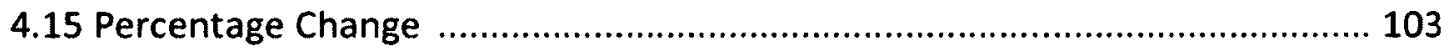




\section{LIST OF APPENDICES}

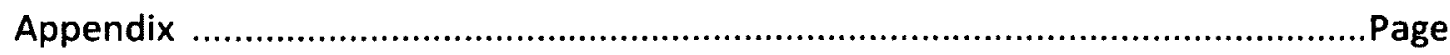

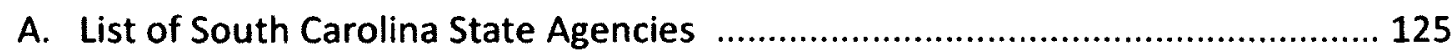

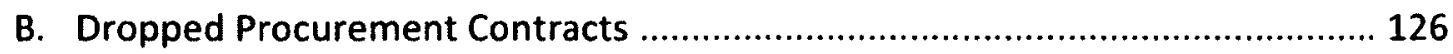

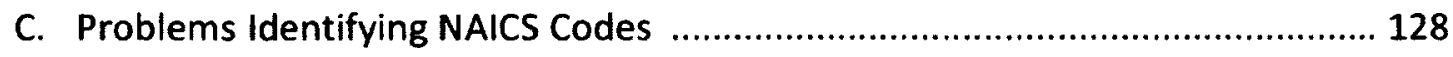

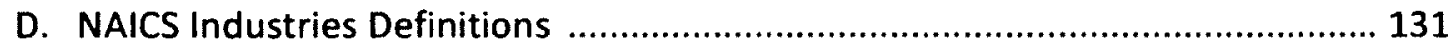

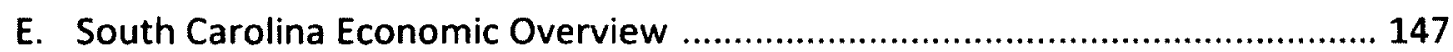

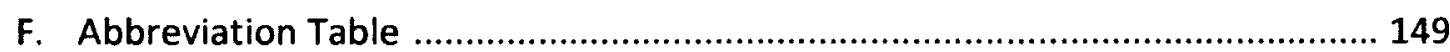




\section{CHAPTER I}

\section{INTRODUCTION}

For much of the twentieth century, public procurement has been used as a policy tool to achieve various political, economic, and social objectives (Martin, 1996; McCrudden, 2007; Pitzer \& Thai, 2009; Rolfstam, 2008; Thai, 2001). Policy makers have made federal, state, and local government procurement officials responsible for the implementation of a variety of procurement policies not related to what they are seeking to acquire in a particular procurement. Procurement officials in many states have been required to grant preferences to in-state suppliers and/or goods and services produced within the boundaries of the state's jurisdiction (McCrudden, 2007; Qiao, Thai, \& Cummings, 2009); these policies are hereafter referred to as in-state preference policies, and they are the focus of this research.

The primary purpose of in-state preferences is to create economic opportunity for in-state businesses by protecting them from out-of-jurisdiction competitors and to encourage them to engage in productive economic activities for the benefit of their state's economy and its residents as a whole (Hefner, 1996; Krasnokutskaya \& Seim, 2008; McCrudden, 2007; Moreland, 2012; Qiao et al., 2009). In the literature, there is a lack of studies to document the economic benefits of the in-state preference policies, and this creates a significant gap, which this researcher aims to begin the process of filling. 
The purpose of this study is to lay a foundation for the investigation of the economic impacts of in-state preference policies on the economy of a single state, namely, South Carolina. This chapter introduces the nature of the research by providing background information, stating the problem, and explaining the purpose and the significance of the research. Following this, the research question, the methodology, and the assumptions are presented. The last part of this chapter describes the limitations of the research.

\section{Background}

Government has always used its purchasing power to achieve particular economic, social and political objectives (Qiao et al., 2009). The literature shows that procurement policies are used to create employment opportunities, to provide fair payment to vendors and employees, to promote conditions conducive to working, as well as to protect the environment (Pitzer \& Thai, 2009). Studies further reveal that public procurement also has been used to provide preference to local vendors, small businesses, and women and minority owned businesses. As a whole, the variety of policies through which policy makers seek to grant an advantage to specified categories of vendors - no matter the basis for granting the preference in a particular instance falls under the umbrella of procurement preference policies.

The literature points to the existence of two broad categories of procurement preference policies: those based on geographical preference laws and those based on non-geographical preference laws (Qiao et al., 2009; Short, 1992). Geographical 
preferences are based on the "geographical location" of a vendor or where a product or a service is "produced" or construction is performed. Representative of these policies based on geographical location are the Buy American Act at the federal level, in-state preferences, and buy local preferences. In-state preferences, which are the focus of this study, are granted to in-state vendors because of their geographical location or because their goods and/or services are produced within the boundaries of the state's jurisdiction. The second type of procurement preference programs is mandated by nongeographical preference laws which are based on the socioeconomic classification of vendors. Using these non-geographical preference laws, governments award procurement preferences to small, minority, women, disabled, veteran and disadvantaged businesses. For example, the Small Business Act of 1953 was enacted to help small, minorities, and other disadvantaged businesses by giving them opportunities to expand their own businesses (Qiao et al., 2009). In addition "the Federal Acquisition Streamlining Act (FASA) of 1994...established a new 5\% government-wide procurement goal for women-owned business" (Qiao et al., 2009, p. 376).

The practice of using various preference policies is widespread in the U.S. The National Association of State Procurement Officials (NASPO) released a 2011-2012 Survey of State Government Purchasing Practices that consisted of 28 sections examining public procurement practices. In the section on state preference policies, the survey showed that twenty-five states provide preferences to in-state bidders or products that are not necessarily based on minority or women ownership or other criteria, and that in seventeen of the twenty-five states, the preferences are mandatory 
(NASPO, 2012). The NASPO survey also reported that several states have adopted preferences based on the socioeconomic classification of a vendor. Table 1.1 lists the number of states that have vendor-based price preferences based on a variety of socioeconomic classifications.

Table 1.1 States that Have Vendor-Based (Non-Geographical-Based) Price Preferences

\begin{tabular}{|l|c|}
\hline Vendor-Based Price Preferences & Number of States \\
\hline Women-owned business enterprise & 4 \\
\hline Minority-owned business enterprise & 6 \\
\hline Small business enterprise & 11 \\
\hline Disabled-owned business enterprise & 6 \\
\hline Sheltered workshop & 18 \\
\hline Veteran-owned business enterprise & 6 \\
\hline Service-disabled veteran owned business & 6 \\
\hline
\end{tabular}

Source: 2011-2012 NASPO Survey of State Procurement Practices

Rationales for adopting procurement preference policies are many and varied. At the 2 nd International Procurement Conference of the Americas held in 2005, some scholars argued in favor of using preference policies to promote socioeconomic objectives (Qiao et al., 2009). Some of the most common reasons cited in the literature are a state's desire to increase competition in a specific industry and to engage and support local, small, minority, and disadvantaged businesses in the market place 
(Krasnokutskaya \& Seim, 2008; Moreland, 2012; Qiao et al., 2009). A further rationale argued by some scholars is that procurement preference policies would enhance social equity by reserving some government contracts for minority and disadvantaged groups (Frederickson, 1990). Another important goal pertaining to economic growth and related mainly to in-state preference policies is that they encourage local businesses to stay in their home state, thus creating more jobs, keeping the current jobs in the economy, and increasing local tax returns by paying the tax dollars to the state (Hefner, 1996; Krasnokutskaya \& Seim, 2008; McCrudden, 2007; Moreland, 2012; Qiao et al., 2009).

Although supporters provide rationales that appear to have some merit, the procurement preference policies have generated controversy in government and business circles as well as in academia. Critics invariably argue that preferential treatment "violate[s] the basic principles of public purchasing, equity, impartiality, open competition, and the least cost to the taxpayers" (Qiao et al., 2009, p. 379). In view of these deficiencies, preferential treatment policies run contrary to the free market principles and undermine competition in the market place. For example, The National Institute of Governmental Purchasing (NIGP) and NASPO, two groups that vigorously oppose procurement preference policies, argue that all types of preference laws and practices are inconsistent with the free enterprise system and impede competition in the market place (Moreland, 2012; Qiao et al., 2009; Short, 1992; Strayer, 2011). At the state level, critics further contend that preference policies that constrain/discourage competition and protect state vendors are likely to lead to higher taxes, higher product 
prices, and reduced efficiencies (Hefner, 1996). Critics also say that protecting in-state vendors from competition will limit their motivation to enhance labor productivity and develop cost saving strategies (Hefner, 1996). In addition to the previous criticisms of implementing preferences, there are legal challenges for implementing in-state preference policies. The basis for these challenges includes asserted violations of the U.S. Constitution's Privileges and Immunities, Commerce, and Equal Protection clauses. Two cases that related to these challenges are citied in Chapter II of this dissertation.

In summary, the existence of opposing views raises concerns regarding the appropriateness of procurement preference policies that some states pursue vigorously (Krasnokutskaya \& Seim, 2008). In light of the unresolved disputes or controversies between supporters and opponents about the benefits of procurement preference policies, it is important and proper to examine what the economic benefits from procurement preference policies are.

\section{Problem Statement}

When considering in-state preferences, policy makers must resolve what often appears to be a fundamental tension between those in favor of and those opposed to preferences. Taking advantage of the opportunities that in-state preference policies offer requires meeting the challenges presented by those opposed to the policies, and this dilemma has generated considerable debate among politicians, businesses, and academics. The debates surrounding in-state preference policies revolve in large part 
around a couple of issues such as whether in-state preference policies promote or hinder competition in the market place and provide economic gains or losses for the state. As noted previously, opponents of in-state preference policies invoke the principles of the free market economic system arguing that government interference distorts the functioning of the free market and undermines competition leading to inefficiencies, low productivity, and related economic malaise (Qiao et al., 2009). Because of these questions and concerns, procurement preference programs have been " a very important and controversial issue and ... research on many of its facets is limited" (Qiao et al., 2009, pp. 396-397). The controversies will continue unabated until more research provides evidence-based answers to help understand the economic impact of in-state preference policies.

The Purpose of this Research

The purpose of this research is to investigate the economic impacts of South Carolina's in-state procurement preference policies on the state economy. As indicated in the preceding section, both supporters and opponents of procurement preference policies make contradictory claims. Yet, there is a lack of studies to support their respective claims. This lack of investigation to determine the economic benefits of instate preference policies creates an important gap in the literature. This research attempts to begin to fill the current gap in the literature by examining the economic impacts from adopting procurement preference policies. It is important to emphasize 
that the intent of this scholarly research is not to explain the reasons behind preference policies since "their existence is more likely to be due to the political power of certain interest groups" (McAfee \& McMillan, 1989, p. 292). Instead, this research primarily contributes to the area of preference policies because "a longitudinal review of [the policies'] results is never conducted" (Qiao et al., 2009, p. 397).

\section{The Research Question}

Research has shown that some states in the U.S. adopt procurement preference policies to promote important social and economic goals that include helping state businesses, protecting state vendors, creating more jobs, and increasing tax revenues for the state (Krasnokutskaya \& Seim, 2008; Qiao et al., 2009). The purpose of this research is to examine the benefits the state of South Carolina could achieve by implementing the in-state preference policies for an eight-year period (2010-2017). To achieve this purpose, the research must answer the question: what are the impacts of implementing the in-state procurement preference policies on the economy of the state of South Carolina? Using the case of South Carolina's preference policies, this research utilizes the Regional Economic Model Policy Insight (REMI PI+) for economic-forecasting and policy-analysis to estimate the economic impact of the South Carolina preference policies on the state economy. 


\section{Methodology}

This research employs the Policy Insight Model (REMI PI+) developed by Regional Economic Model (REMI), Inc. Specifically, the Policy Insight, version 1. 5.2, also known by its abbreviation, $\mathrm{PI+}$, is the version utilized in this research. The researcher uses the name REMI PI+ or simply PI+ interchangeably throughout this study. Researchers, practitioners and professionals from several private, public and nonprofit organizations have used the REMI model for structural forecasting and policy analysis for over thirty years. The REMI PI+ model is a useful analytical tool to examine in-state preference policies. Further details about the model's usage will be discussed in Chapter III of this dissertation. The researcher will use this model in this study to answer the research question and achieve the purpose of this research, which is to examine South Carolina's preference policies and their impacts on the economy of the state. Essentially, PIt answers the question "What if...?" any change in a policy would affect the regional and local economies and adjust to those changes which will occur on a year-by-year basis (REMI, 2007). Below is a brief description of the selected model.

The overall structure of the REMI PI+ is divided into five major blocks. The blocks are output and demand, labor and capital demand, population and labor force, compensation, prices and costs, and market shares (see Chart 1.1 on page 16). Each block consists of economic variables. There is a high level of interaction and connection among these variables. For example, a small change in one variable will indeed affect 
other variables in the same block and other blocks as well. The component parts of each block are:

- The output and demand block- consists of output, demand, consumption, investment, government spending, exports, and imports.

- The labor and capital demand block-includes labor intensity, labor productivity, and demand for labor and capital.

- The population and labor supply block-consists of labor force participation rate and migration equations.

- The compensation, prices, and costs block- consists of composite prices, determinants of production costs, the consumption price deflator, housing prices, and the compensation equations.

- The market shares block-consists of the proportion of local, inter-regional, and export markets captured by each region.

By utilizing $\mathrm{PI}+$, the researcher attempts to find out if implementing in-state preference policies can benefit the state's economy by creating more jobs, increasing personal income, real disposable personal income, value added, the state's population, Gross State Product (GSP), and output in the case of the state of South Carolina from 2010 until 2017. South Carolina's procurement contract data are used as an input to the selected model. The data consists of a policy variable that is measured by the dollar amount of the industry sales. The dollar values of the state of South Carolina's procurement spending that was impacted by the in-state preference policies during the 
period 2010-2012 and the values of other economic variables explained in the five blocks in the previous paragraphs will be embedded in the PIt. The researcher obtained the data from the Office of Audit and Certification, a subdivision of the Procurement Services Office in South Carolina Budget and Control Board. For the years 2013-2017, the average spending will be calculated and used to forecast the economic impact. REMI's staff developed the model and collected the data for the other variables included in the PI+ from the Bureau of Economic Analysis, the Bureau of Labor Statistics, the Department of Energy, and the Census Bureau.

\section{Significance of this Research}

Studies have shown the importance of government intervention in the economy on certain occasions to improve the welfare of a segment of society (Krueger, 1991; Reinert, 1999; World Trade Organization, 2012). Even though public procurement is a frequently used method to intervene in the economy, little has been written on this topic (MacManus, Watson, \& Blair, 1992; McCue \& Gianakis, 2001; Snider \& Rendon, 2008; Thai, 2001). Snider and Rendon (2008) have emphasized that scholars need to give sufficient attention and efforts in terms of conceptualizing and developing theoretical frameworks that can allow researchers and students alike to understand the complexities involved in making procurement policies. Similarly for in-state preference policies, scholars and researchers have emphasized the importance of conducting more research because "the practical impact of preferences is worthy of much more analysis" 
(Qiao et al., 2009, p. 397). Therefore, the contribution of this research is to establish the linkage between the conceptual (theoretical) knowledge and the practical application in the area of preference policies.

This research also will contribute to the body of knowledge of public procurement by enhancing the knowledge base of policymakers, voters and taxpayers. As Qiao et al. (2009, p. 398) asserted "procurement has always been and will continue to be used as an important policy tool for a wide range of socioeconomic and political purposes". In view of this assertion, research can help voters and taxpayers become more informed and gain the knowledge to understand the benefits of implementing preference policies. Furthermore, the results will provide an information base for policymakers, which could influence their perspectives and decisions pertinent to preferential policies. If the results show that procurement preference policies contribute to the economic goals, policy makers and public administrators should continue implementing these policies. In contrast, if the research findings show that South Carolina's preference policies are not achieving the desired goals, then the state policymakers may need to rethink implementing procurement preference policies. In either case, policymakers and public officials should give more attention to the costs associated with implementing the preference policies

This research provides database information about the state of South Carolina's preference policies specifically and preference policies in general. The data from the quarterly procurement preference reports will help to determine the type of goods and services and the industry used when implementing in-state preference policies. 
Furthermore, this data set will help decision makers learn more about the rules and procedures associated with applying for in-state preference policies. This research will move the field forward because it will establish a foundation for future investigation into the study of the economic impact on each of the 24 states applying in-state preferences. Other research areas could include a comparative study to increase understanding of the differences and the similarities among the in-state preference policies in the states. Comparing the economic impact between the 25 states will add a new perspective to the analysis and stands as a topic for future research. Finally, this study also highlighted the need to investigate reciprocal preferences.

Assumptions

Assumptions are essential for research, and four assumptions provide the basis for this study. First, the dollar values of the procurement contracts awarded based on preference policy were considered the sales variable. This study assumed that increases in sales in the economy sectors are due to implementing the in-state preference policies. Second, South Carolina state agencies reported to the South Carolina Budget and Control Board the procurement contracts awarded based on the in-state preference policies, and this study assumed that all the reported data are complete and correct. 
Third, after the South Carolina Budget and Control Board received the data about the procurement contracts, the Board compiled the data into Quarterly Preference reports. The assumption is that the reports contained accurate and correct data. Fourth, the researcher assumed that the North American Industry Classification System's (NAICS) identification for the procurement contracts is correct.

\section{Limitations of this Research}

Although twenty-five states have adopted in-state procurement preference laws in one form or another, this investigation is limited to the state of South Carolina. The researcher chose South Carolina because that state's central procurement office agreed to provide access to relevant procurement preference data. In addition, REMI Inc. has provided access to $\mathrm{PI}+$ for the state of South Carolina for the purpose of this research; however, due to lack of funding, the researcher was not able to purchase additional versions of the model. The findings of this research, which focuses only on one state, cannot be generalized to other states, and this constitutes a limitation of this research. Another limitation is that the accuracy of the data collected from the Office of Audit and Certification, a subdivision of the Procurement Services Office in the South Carolina Budget and Control Board, and the values of all the variables embedded in the REMI PI+ model cannot be verified. In addition, the economic costs (except the direct preference cost) and the social benefits of the preference policies are not analyzed in this study, 
and this constitutes a limitation of this research. The final limitation is that this analysis will not factor in the effect of reciprocal policies on South Carolina vendors when they bid on contracts in states that apply reciprocal policies. The effect of reciprocal policies on South Carolina vendors could be significant, meaning that the findings of this initial research could be misleading.

\section{Organization of this Research}

This research consists of five chapters. Chapter I introduced the background of this research and presented the problem, the purpose of the research and the research question in addition to the methodology, the assumptions, the significance and the limitations of the research. Chapter II provides a literature review that draws on theoretical perspectives related to international trade, national welfare, and social equity arguments. The previous studies and research presented in Chapter II help to understand the context of this research. Chapter III covers the methodology used in this research and includes an overview of the utilized PI+ and a description of all the model's variables and the data provided. Chapter IV discusses the analysis of the data and presents the results of the model. Chapter $V$ summarizes the research and the results, the research implications, future research and limitations of the research. 


\section{Chart 1.1: REMI Model's Blocks}

(1) Output and Demand

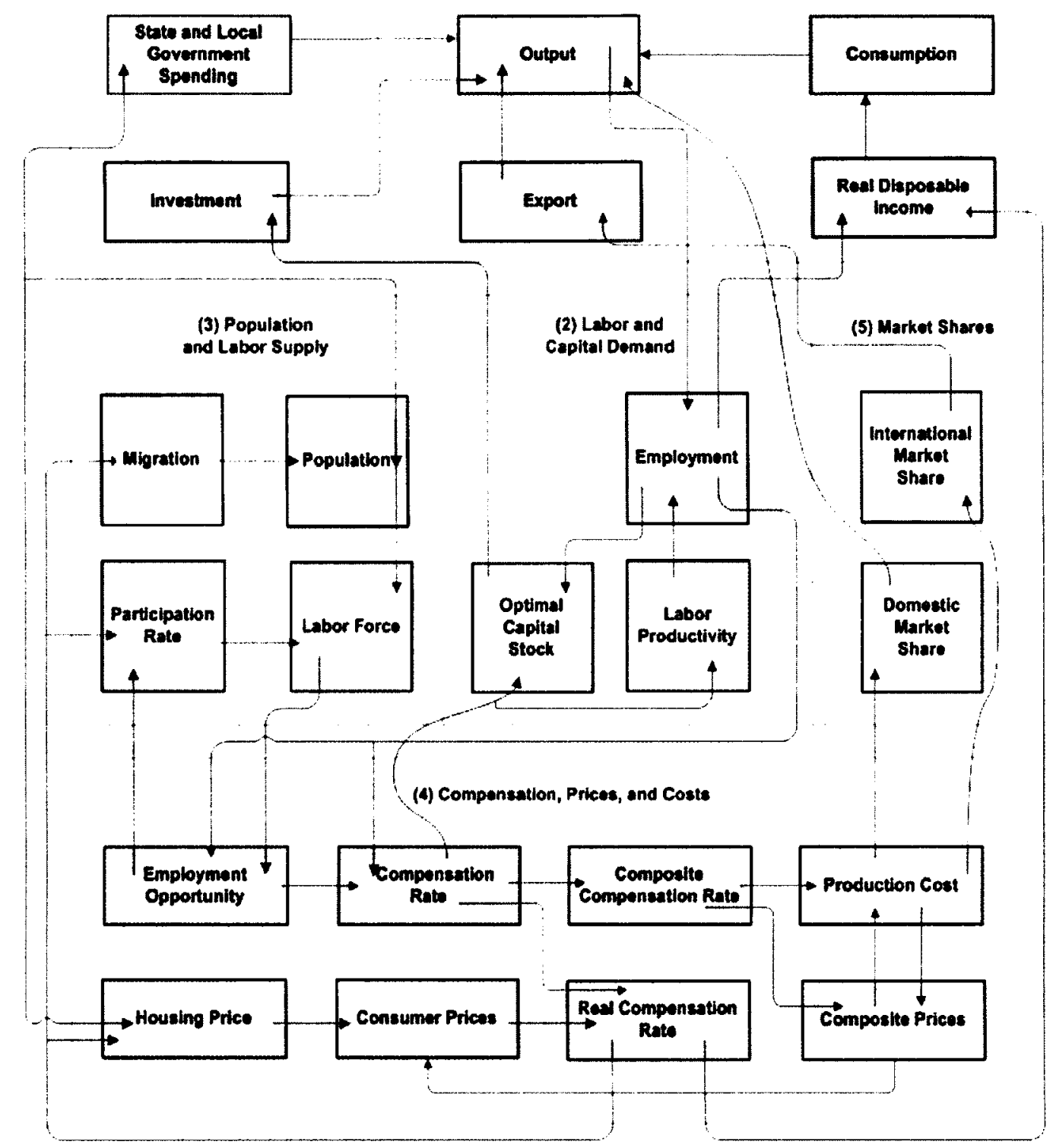

Source: REMI (2011) 


\title{
CHAPTER II
}

\section{LITERATURE REVIEW}

\author{
Introduction
}

Public procurement has an important role in delivering goods and services to citizens. Even though one of the government's main responsibilities is to buy goods and services, a related responsibility is to achieve a variety of social, economic and environmental objectives through adopting a variety of policies such as state preference policies. State governments use in-state preference policies to grant an advantage to instate vendors when awarding procurement contracts. The implied main purpose of instate preferences is to create economic opportunity and to encourage in-state businesses to engage in productive economic activities for the benefit of the state's residents as a whole (Hefner, 1996; Krasnokutskaya \& Seim, 2008; Qiao et al., 2009).

To study the impact of in-state preference policies on the state's economy, this research utilizes the international trade literature focusing on protectionist arguments. The international trade literature provides an overarching explanation to help understand what the state could predict as the result of applying the in-state preferences. Within the international trade context, governments use a variety of strategies such as tariffs, import quotas, subsidies and formal policies to intervene in trade. Formal policies represent a government's action to discriminate against foreign competitors and firms, and they are "often considered to be a non-tariff barrier to 
trade" (Trionfetti, 1999, p. 235). Since these formal policies "can be considered a part of a whole gamut of economic policies (such as tariffs, subsidies, exchange restrictions, and quotas)" (Lowinger, 1976, p. 451), studies have argued that the formal policies (nontariff barriers) would have a "protective effect" similar to the other tariff barriers (Lowinger, 1976; McAfee \& McMillan, 1989).

In many respects, the rationales used by governments to intervene in international trade are strikingly similar to the rationales a state government employs for the adoption of in-state procurement preference policies. Like the international preference policies, state preference policies are formal policies that policy makers seek to use as non-tariff barriers within the state context. Therefore, this study argues that the theoretical arguments for or against a variety of discriminatory policies and strategies in international trade could help understand what the impact of in-state procurement preference policies would be in the context of the domestic economy.

This chapter will start with an overview of international trade theories and explain a variety of intervention strategies as instruments to trade. After the overview, there will be a discussion of general procurement preference policies followed by a specific focus on the preference policies implemented by the state of South Carolina. 
International Trade Theory

Governments around the world spend a significant amount of money to buy goods, services, and construction. Through their purchasing power, governments affect and stimulate the economic growth of their countries. A study by Trionfetti "estimate[s] [that] the size of the government procurement market ... ranges between 8 and 12 per cent of GSP for industrialized countries" (Trionfetti, 2000, p. 73). Governments have the choice to purchase the needed products and services from local sources or from foreign countries. International trade policies are guided by international trade policies, and governments use these policies as a way to intervene in the economy.

Interventionism is an old idea that extends back to ancient times. As far back as the mid-sixteenth century, mercantilists sought to build national wealth through the accumulation of gold and silver by exporting more and importing less (Hill, 2011), which was in essence a restriction of free trade and a form of protectionism. But, subsequent theoretical developments, from Adam Smith's absolute advantage to Ricardo's comparative advantage, to Heckscher-Ohlin theory, to the development of new trade theory in recent times, have offered arguments for the continued use and promotion of trade between and among nations because of a strong belief that there are gains to be made from trade. Charles Hill, for example, provides the following historical anecdote regarding the start of free trade: 
The theoretical case for free trade dates to the late eighteenth century and the work of Adam Smith and David Ricardo. Free trade as a government policy was first officially embraced by Great Britain in 1846, when the British Parliament repealed the Corn Laws that placed a high tariff on imports of foreign corn. The objectives of the Corn Laws were to raise government revenues and to protect British corn producers (Hill, 2011, p. 222).

Even though the development of trade theories helps explain the international trade patterns in the world, "they lack agreement in their recommendations for government policy" (Hill, 2011, p. 163). As such, governments use a variety of strategies to intervene in trade such as tariffs, import quotas, and subsidies. A tariff is a type of tax imposed on imports or exports. Tariffs are levied in two forms, either as a fixed percentage on each imported good or as a part of the value of the imported good. Import quotas impose restrictions on the imported quantity to the country, while government provides subsidies in the form of cash, low-interest loans, and tax breaks.

Although these strategies differ in many respects, they still all constitute governmental intervention in trade. In addition to these strategies, governments employ formal and informal policies as barriers to trade. Formal policies require governments to give preference to specific products, services, or industries. For example, the U.S. government implements the Buy American Act, which gives preference to American products in awards of contracts by the U.S. government and recipients of grants-in-aid from the U.S. federal government. Other countries use informal policies to put up rules/barriers to restrict trade among other countries. France's demand that all videotape recorders imported from Japan enter the country from a point located far from the nearest shipping port is a clear example of an informal policy to restrict trade. 
As with all instruments and policies of trade, the question becomes why nations engage in discriminatory or preferential trade practices. Governments provide a variety of arguments to justify their interventions such as social, political, and economic reasons. Governmental decisions to grant preferential trade treatment are motivated by a desire to build strong relations between the countries to achieve some specified social or human rights objective. For example, prior to China joining the WTO in 2001, the United States granted Most Favored Nation (MFN) status to China to try to improve the human rights policies in that country (Green, 1993; Pregelj, 2001; Ward, 2000). MFN status allowed China to export goods to the United States at an average of 8 percent tariffs; without MFN, the tariffs would have been about 40 percent (Hill, 2011).

Of the various objectives countries hope to gain from applying preferential trade policies, the literature shows that protectionism overshadows the other motivations for governments' intervention (Hill, 2011). Governments protect consumers from dangerous products, protect the defense industry for reasons of national security, and protect jobs and industries from foreign competition.

On economic grounds, the oldest reason for protectionism was the infant industry argument (Hill, 2011; Hoekman, 1998). The infant industry argument was by far the most popular argument among developing nations (Shafaeddin, 2000) and had considerable influence in developed countries as well. The rationale was clear in that developing countries needed time to build their manufacturing sector so that the sector could compete with established industries in developed countries. Shafaeddin $(2000, \mathrm{p}$. 2) argued "that infant industry protection is necessary for countries at the early stages 
of industrialization if some countries outdistanced others in manufactures".

Aside from the infant industry argument that was primarily applicable to developing countries, many developed nations have implemented different policies to erect protectionism against imports that threaten the survival of their domestic industries. Examples of protectionist policies adopted by many nations around the world including the United States and the European Union (EU) abound in the literature. One such example is the EU's establishment of the Common Agricultural Policy (CAP). The intent of the CAP policy was to protect the jobs of Europe's politically powerful farmers by restricting imports and guaranteeing prices, but studies showed that the consequence was higher prices for consumers.

In the case of the United States, there are many instances where the government resorted to protectionism on economic and/or political grounds. Historical accounts reveal that during the height of the Great Depression, the U.S. Congress passed the Smoot-Hawley Act in 1930 to deal with the rising level of unemployment by protecting domestic industries and restricting imports. The tariff was increased by about 60 percent on more than 3000 products and 900 American import duties were created (Boffa \& Olarreaga, 2012; Hill, 2011; The Economist, 2009).

The Smoot-Hawley Act is a case in point that provides an example that even economically advanced nations such as the United States, that are expected to gain the most from free trade, do sometimes resort to protectionism because of economic imperatives at a given historical juncture. According to some studies, while the SmootHawley Act appeared to protect the local industries at the time, the Act nonetheless 
caused a retaliatory response from nearly 60 countries, and world trade plummeted; this retaliatory response was believed to be the primary contributor to a seventy percent reduction in world trade by 1933 (Boffa \& Olarreaga, 2012). Latter time economists and other writers alike characterized the Smoot-Hawley Act as a failure because it had a damaging effect on employment abroad, which in turn, forced other countries to react to the U.S. action by raising their own tariff barriers, commonly referred to in the literature as "a beggar thy neighbor policy". As a result, U.S. exports tumbled in response, and the world slid further into the Great Depression. Hill (2011, p. 223) emphasized the fact that the Act "erected an enormous wall of tariff barriers. Almost every industry was rewarded with its 'made-to- order' tariff".

Literature shows that there were instances where the United States also intervened in international trade to protect U.S. farmers. For example, in 2000, President George W. Bush signed $\$ 180$ billion subsidies for U.S. farmers, and a bill containing $\$ 286$ billion in subsidies for 10 years was signed in 2007 (Hill, 2011). In addition, in 2002, the U.S. placed tariffs on imports of foreign steel to give competitive advantage to American steel industries so that American jobs could be protected (Hill, 2011).

While strong economic arguments can be made in support of subsidies and tariffs, the actions nonetheless represent protectionism and contradict the principles of free international trade (Ferrini, 2012; Hickok, 1985; Hill, 2011; Hufbauer, Berliner, \& Elliott, 1986; Tarr \& Morkre, 1984; Wood \& Mudd, 1978). To fight protectionism and advocate for unrestricted free trade, a variety of international agreements such as the 
General Agreement on Tariffs and Trade (GATT), the Government Procurement Agreement (GPA), and a series of Directives from the European Union (EU) have continued to play an important role in ensuring the free flow of goods and services across national borders.

Many nations embrace the principles of free trade and accept the rules of the World Trade Organization (WTO), the successor of GATT. In 1947, the U.S. led the establishment of GATT and by 2003,159 nations had signed the multilateral agreement which regulates trade among countries and mainly aims to reduce any type of protectionist instruments or policies. As an effort to extend the basic principles of GATT, the Government Procurement Agreement (GPA) was signed in 1979 and entered into force in 1981 as a "plurilateral" agreement. Today, 15 countries have signed the GPA and three countries are considering the adoption of the rules (OUSTR, 2012).

The GPA is perhaps one of the most important international agreements pertaining to government procurement regulation today. GPA generally prohibits discriminatory policies favoring domestic firms and encourages competitive tendering procedures. However, GPA also has provisions that allow countries to engage in negotiations as the quotation below demonstrates.

Although in principle the GPA prohibits signatories from discriminating in favor of domestic firms, developing countries negotiate mutually acceptable exclusions from the rules on national treatment for certain entities, products, or services. Such negotiations may also be initiated after signing the procurement agreement. That option, however, is limited to certain entities, products or services, and the scope to pursue such policies is therefore inherently limited by the relative negotiating power of the country seeking to apply them (Hoekman, 1998, pp. 252-253). 
In addition to GATT and GPA, the European Union (EU) also has made important contributions in terms of adopting a series of procurement directives that affected the development of the previous GPA principles (Gordon, Rimmer, \& Arrowsmith, 1998) . The EU and the GPA have common objectives regarding their approach to procurement regulations and markets. For example, the EU has a "public procurement legislation [that] sets out procedures and practices to which central and local government and other public bodies must adapt their award procedures, where the value of the contract as estimated under the rules meets the relevant threshold" (Achille, 2011, p. 2). In general, all the EU directives imply that public procurement markets should be open among all competitors without discrimination. "The basic principles [are], notably nondiscrimination, equal treatment and transparency in the publicity of proposed procurement contracts, design of technical specifications; choice of procurement procedure; qualification and selection of candidates and tenderers [and] award of contracts" (OECD, 2011, p. 3).

The impact and effectiveness of the EU procurement rules have been examined in the literature (Cox \& Furlong, 1995; Erridge, Fee, \& Mcllroy, 1998; Gelderman, Ghijsen, \& Brugman, 2006; Madsen, 2002; Nielsen \& Hansen, 2001). Gordon et al. (1998) analyzed a study by the European Commission that investigated the impact of the European procurement rules on the effectiveness of the EU'S procurement policy from 1987 to 1994 . The results of the analysis showed that apart from a very few sectors the EU's desired objectives against protectionism were largely not achieved due primarily to "the problem of effective enforcement, lack of clarity in the rules, the 
existence of structural market obstacles, and lack of response on the supply side" (Gordon et al., 1998, p. 185).

However, other studies have reported positive results about the direct impact of the EU's procurement policies. For example, the European Commission (2004) prepared a study to evaluate the impact of EU's rules and directives for the period 1995-2002 on the transparency of procurement procedures, the prices of goods and services, and the cross-border activity in public procurement markets. The analysis indicated the existence of "positive developments in market transparency, increased cross border competition and price savings derived from the implementation of public procurement directives (European Commission, 2004, p. 1). The report also pointed to overwhelming evidence supporting the active contributions of current directives to reform the public procurement markets (European Commission, 2004).

The decisions made and the actions taken to erect barriers to free trade are not without consequences; there are indeed impacts and effects associated with the policies of protectionism that seek to protect domestic industries by creating trade barriers. Researchers began to study the economic impact of discriminatory procurement practices on international trade flow in the 1970s (Audet, 2002; Baldwin, 1982; Baldwin \& Richardson, 1972; Lowinger, 1976). The work by Baldwin and Richardson (1972) is considered to be the starting point for research into discriminatory procurement practices within the international trade context.

Basing their investigation on the assumptions that the market is perfectly competitive, and that the imported commodities are identical to the commodities 
produced domestically, Baldwin and Richardson (1972) and Baldwin (1970, 1982) set up a model to analyze the impact of the discriminatory policies on imports, output, and domestic prices, and then used the model to estimate the impact of the Buy American Act of 1933 on imports. Their model is based on demand and supply curves and inputoutput tables. According to their analysis, they found that the effect of giving preference to domestic producers is varied. After imposing the preference, government demand shifted from foreign products to local products, and as a result the prices of domestic products rose above the foreign prices and shifted private demand from domestic to foreign procurers. In this case, if government demand is less than the domestic supply, there is no effect from the preferences. If government demand is larger than domestic supply, the domestic prices increase, the output of domestic producers increases and the price of imports decreases.

On the basis of the previous discussion, Baldwin and Richardson (1972) and Baldwin $(1970,1982)$ concluded that the Buy American Act reduced total U.S. imports between $\$ 76$ million to $\$ 110$ million, which is considered to be a small impact compared to U.S. total imports. They concluded that when government demand for domestic product shifts, the private sector's imports shift as well in an equal and opposite direction. Reaching a similar conclusion Deltas and Evenett (1997) found that the extra procurement costs offset the extra welfare gains from implementing the discriminatory procurement policies. 
Following Baldwin and Richardson's assumption that the market is perfectly competitive, Herander (1982) investigated the impact of discriminatory policies on domestic output, consumption, the price of the good in the importing country, and the level of imports. He investigated the impact between two countries using a partial equilibrium model. When Herander analyzed three scenarios depending on whether government demand is larger, smaller, or equal to the domestic supply, he found that when the government demand is larger than or equal to the domestic supply, imports decrease, and domestic output and prices increase. However, when government demand is less than the domestic supply, the discriminatory policy is ineffective.

In addition to the previous studies, Lowinger (1976) used input-output tables to compare government imports and private sector imports during the 1970 s for the U.S., U.K. and EU member countries. He based his analysis on the assumption that the quantitative difference between the countries' imports equals the impact of discriminatory policies. He concluded that the U.S.'s degree of discrimination is the highest and has the largest effect on imports. So, when the U.S. reduces its discriminatory policies, its imports are expected to increase six or seven times the actual level of imports.

Expanding Lowinger's work, Deardorff and Stern (1981) studied the impact of the reduced tariffs discussed at the Tokyo Roundtable on exports, employment, economic welfare, exchange rates and imports. By using demand and supply models for several developed and developing countries, they concluded that reducing tariffs would result in "relatively small but beneficial economic effects for practically all the major 
industrialized countries and for some of the major developing countries" (Deardorff \& Stern, 1981, p. 148).

In conclusion, beginning in the 1970 s, economists conducted research to study one or more aspects of the impact of discriminatory policies on international trade and trade flow. However, overtime, scholars have failed to address some aspects of the policy, and have identified caveats in the previous work and attempted to address them by adding more dimensions to their research. Audet (2002, pp. 157-158) summarized the progression of the research from the 1970s to current times:

This brief survey of academic research on the impact of government procurement on international specialization and trade highlights the inherently complex task of conceptualizing multiple and intertwined factors into a theoretical modeling exercise, particularly in conceptualizing implicit forms of discriminatory practices. Greater understanding of several related aspects, such as transparency and non-discriminatory provisions, bidders' behavior, informational asymmetries, distribution effects and the dynamic effects of procurement preferences, could usefully provide additional policy underpinning and insights.

Generally, the results of research show that the impacts of favoring local vendors in the international trade theory context depend on the setting, the assumptions made, and the methods used in the analysis, and therefore, the impacts of preference policies on the economy are mixed. However, this research argues that the trade framework still does provide a theoretical base for studying in-state preferences. The following section gives an overview of procurement preference policies. 
Procurement Preference Policies

As the previous discussion indicated, national governments intervene in trade mainly to protect their own country's vendors and suppliers. Similarly, state governments use procurement preference policies to protect in-state businesses from being undermined or undercut by large conglomerates that may come from within the state or from neighboring states (McCrudden, 2007; Qiao et al., 2009). So, the rationale for adopting procurement preference policies in the domestic context is similar to the rationale presented in support of government intervention in international trade.

Governments apply preference policies to protect vendors and achieve a variety of social, economic and political goals. Preference policies may stimulate the economy and as a result improve the welfare of disadvantaged members of society as well as advance the collective interests of the citizens of the country. Another rationale for the adoption of preference policies is a state's desire to increase competition in a specific industry (Hefner, 1996; Krugman \& Obstfeld, 1991). On the state and local levels, preference policies help to engage and protect local businesses in the market place thus serving as incentives for local businesses to stay, grow, and thrive in the state, as well as to create more jobs and expand the state's tax base.

Some scholars support the view that procurement preference policies are an appropriate tool to promote economic goals, and it is common to see policymakers at all levels of government use preference policies even though critics point to the potential problems associated with them. However, opponents of preferential treatments argue 
against the use of preference policies claiming that preferential treatment runs contrary to the free market principles, increases cost to government, and undermines competition in the market place (Krasnokutskaya \& Seim, 2008; McCrudden, 2007; Qiao et al., 2009; Short, 1992). For example, NIGP vigorously opposes preference policies arguing that all types of preference laws and practices are inconsistent with the free enterprise system and impede competition in the market place (Achille, 2011). In a similar vein, NASPO opposes procurement preference policies arguing that businesses and special interest groups are likely to exercise undue influence in the promotion of preference laws. NASPO stated, "preference provisions and practices should be eliminated from public purchasing. Government bodies and legislatures must recognize that preference is promoted by business and special interest groups, that the net effect is costly, and that efforts to establish or maintain preference need to be resisted" (as citied in Qiao et al., 2009, p. 379). Critics further contend that preference policies constrain/discourage competition and protect local vendors and are likely to lead to higher taxes, higher product prices, and reduced efficiencies (Strayer, 2011). They also feel that protecting local vendors from competition will limit their motivation to enhance labor productivity and to develop cost saving strategies (Hefner, 1996).

Furthermore, opponents point out that the preference laws have been challenged on the basis of the Equal Protection Clause in different states (Hefner, 1996; Qiao et al., 2009). For example, Smith Setzer \& Sons, Inc. challenged the in-state preference laws in South Carolina when they submitted a bid to supply concrete culvert pipe in South Carolina. Smith Setzer \& Sons, Inc. provided the lowest bid on 15 out of 47 
sub-bids for the pipe contract, but they were not qualified to claim the in-state preferences. So as a result, the corporation was awarded only two contracts and consequently sued South Carolina for violating the Equal Protection Clause. After going through the courts, "it was conceded that the preference scheme would withstand an equal protection challenge, so long as the challenge drawn is rationally related to a legitimate state interest" (Hefner, 1996, p. 34). Similarly, in an award involving a racial preference rather than a preference based on the location of a bidder, the city of Richmond was challenged under the Equal Protection Clause when it awarded a city construction procurement project based on the city's minority business preference policies (Chambers, 1991; Gregg \& Karen, 1990; Qiao et al., 2009). In this case, the court concluded that "the [city] plan was not narrowly focused since it permitted minorities from outside the Richmond area to participate in an absolute preference over other citizens purely on race" (as citied in Qiao et al., 2009, p. 380).

The variety of procurement preferences are categorized under two types: geographical and non-geographical preference laws (Qiao et al., 2009; Short, 1992). The geographical preferences are based on the "geographical location" of a vendor or where a product or service is "made". There are three types of geographical preferences based on the level of the government implementing the preference; the three preferences are the Buy American Act at the federal level, in-state preferences at the state level, and buy local preferences at the local level. 
In 1933, Congress passed the Buy American Act which was enacted to protect the American economy by requiring the U.S. government to purchase U.S.-made products and provide employment opportunities for American workers (Pitzer \& Thai, 2009; Qiao et al., 2009). At the state level, the in-state preferences are granted to instate vendors because of their geographical location, and/or because their goods and/or services are produced within the boundaries of the state's jurisdiction. Buy local preferences also require local procurement officials to follow a formal and/or informal competitive bidding process to give advantage to local vendors over non-local vendors when local governments are in need of products and/or services.

There are five types of laws to grant the geographical preferences. First, the tie bid preference gives preference to in-jurisdiction bidders only if their bids are identically priced with the other non-local bidders. Second, a percentage preference applies a fixed percentage of the bid price to the out-of-jurisdiction firm's bid price; the in-jurisdiction bidder is then considered the low bid if the adjusted bid is less than the actual bid price of the out-of-jurisdiction bidder. Third, the absolute preference policy requires the purchasing office of the jurisdiction " to buy certain goods or services from vendors [located] within a designated area" (Qiao et al., 2009, p. 374). Fourth, general preference law gives a wide range of preference to serve the interest of the state (Qiao et al., 2009; Short, 1992); however "due to its administrative ambiguousness, it is difficult to document or assess this type of preference law" (Qiao et al., 2009, p. 373). Lastly, the reciprocal preference laws add a percentage to the out-of-state vendors when their own states impose preferences on the out-of-state vendors, so they work in 
the opposite direction of in-state preference policies. Thirty-five states apply reciprocal preference laws to achieve equal treatment for their interested vendors against the bidders who get preference treatment in their own states.

In addition to the previous preferences based on geographical criteria, the second type of preference programs comprises those in which governments have adopted non-geographical preferences. These preferences are based on the socioeconomic classification of vendors and are awarded to small, minority, women, disabled, veteran and disadvantaged businesses. Scholars have argued that reserving some government contracts for a specific part of the society would indeed enhance social equity (Frederickson, 1990; Hefner, 1996; Krasnokutskaya \& Seim, 2008; Qiao et al., 2009). Thus, preference policies could be used in the economic sphere to reduce severe income inequality.

Historical accounts reveal that underserved businesses "have historically been uninvolved in the contracting and procurement activities of government agencies and authorities" (Rice, 1991, p. 114). To correct this past discrimination, governments at the federal and state level have passed laws requiring government agencies to reserve or set aside some procurement contracts for a certain segment of businesses to encourage them to participate in the local economy (Enchautegui, Fix, Loprest, Lippe, \& Wissoker, 1997) and to overcome the "continuing effects of past discrimination" (Svara \& Brunet, 2004, p. 100). According to Enchautegui et al. (1997), at least at the federal level, there were many acts that required the federal government to give advantages to minorities and small businesses such as the 1997 Small Business Reauthorization Act. The authors 
thus remarked: "No doubt the set-aside provision has enhanced social equity" (Enchautegui et al., 1997, p. 15). To defend the set-aside programs, disparity studies that focused on the effect of past discrimination in federal government contracts against minority-owned businesses have been conducted and documented (Bates, 2001). For example, according to Rice (1991), the city of Atlanta conducted a disparity study to provide evidence of discrimination against minority entrepreneurs, and the results showed that discrimination had occurred in many areas of economic activities including construction, real estate, architectural, and energy industries. Statistical data also documented discriminatory practices in the financial sector between black-owned and white-owned businesses (Rice, 1991).

Nevertheless, some studies reveal that set-aside programs have been criticized for violating the fundamental principles of equity. Critics point out that the granting of public contracts based on a set of rules or criteria that favor certain socioeconomic classes or groups of individuals is fundamentally flawed and runs contrary to the equity principles that involve fairness, efficiency, justice and equal treatment in public service delivery and public policy implementations (Qiao et al., 2009; Short, 1992).

Although it is possible to question the results of granting preferences, a NASPO survey conducted in 2012 nevertheless found that 25 states provide in-state preference policies for local vendors and/or local products. This research focuses on the in-state preference policies of South Carolina, one of the states identified in the NASPO survey. The South Carolina General Assembly rewrote the previous law about in-state preferences and provided expanded legal authority to the state government to use 
preference policies. "The General Assembly finds that it is crucial to this state's economic recovery to purchase goods manufactured and produced in the State, maintain the circulation of the funds of the citizens of this State within this State, and encourage and facilitate job development and economic growth" (2009 Act No. 72, p. 3).

According to Act No. 72 enacted by the South Carolina General Assembly, vendors should request the in-state preference for solicitation and provide documents to prove that they qualify for the preferences. South Carolina has two types of preferences: commodity contract preferences and service contract preferences. The commodity contract preferences include United States end-product preference (USEPP), South Carolina end-product preference (SCEPP), and resident vendor preference (RVP). The commodity contract preferences apply to specific end-products and require companies to meet specific requirements. For example, the 2009 Act No. 72 stipulates that to apply for the RVP, the vendors must maintain an office or location in South Carolina at the time of the bid. In addition to maintaining an office, vendors should meet other criteria such as having either an inventory of commodities on which the award will be made with a value of fifty thousand dollars $[\$ 50,000]$ or an amount equal to the annual amount of the contract or having a manufacturer headquartered in South Carolina with an annual payroll of at least one million dollars (2009 Act No. 72). To qualify for the SCEPP, vendors should bid a South Carolina end-product, and to qualify for USEPP, vendors should bid a U.S. end-product. U.S. or South Carolina end-product means that products must have been manufactured or grown in the United States of 
America or in South Carolina. After determining the eligibility requirement to receive the preference, the procurement officer lowers the price for that line item before comparing the price to other vendors. Subsequently, the price is decreased by a certain percentage depending on the preferences for which the bidder qualifies. This is done for evaluation purposes only. In the end, the lowest bidder wins the bid.

The following summary provided by the South Carolina Budget and Control Board illustrates the bidding process. "Vendor A and Vendor B both submit bids for a single line item of equipment. Vendor A bids $\$ 12,000$. Vendor B bids $\$ 11,500$. Vendor A's equipment qualifies for the SCEPP. Vendor B's equipment does not. For purposes of evaluation, Vendor A's price will be decreased by seven percent $(7 \%)$, down to $\$ 11,160.00$. Vendor A wins the bid and the South Carolina government pays the $\$ 12,000$ to vendor A" (South Carolina Budget and Control Board, 2009, para 29-30). If the vendors qualify for more than one type of preference, the cumulative amount is capped not to exceed a certain amount. Essentially, there are two types of caps. One of the caps refers to the cumulative benefit of all preferences applied to the price of a line item and is capped not to exceed ten percent $(10 \%)$ or $\$ 500,000$ for a single award. The second type limits the amount of the cap to $\$ 50,000$ for a single award with a total potential value in excess of $\$ 500,000$.

In addition to the commodity/product contract preferences, the state offers contract preferences for services that are designated as resident contractor preference $(R C P)$ and resident subcontractor preference (RSCP). Like the preferences mentioned above, vendors must also meet certain requirements in order to qualify for either of 
these contract preferences. To qualify for the RCP, a vendor must "maintain an office" in South Carolina, hire employees "domiciled" in the state and have labor costs that exceed fifty percent of the total bid price. The requirement to qualify for the resident subcontractor preference (RSCPs) is far more stringent than for RCP. To qualify for RSCP, a vendor must "have a documented commitment from a single proposed first-tier subcontractor to perform some portion of the services expressly required by the solicitation", hire employees "domiciled" in the state, have vendor labor costs exceeding twenty percent of the total bid price, and "identify the subcontractor that will perform the work, the work the subcontractor is to perform, and [the] factual basis for concluding that the subcontractor's work constitutes the required percentage of the work to be performed in the procurement" (South Carolina Budget and Control Board, 2009 , para 37). A summary of the percentages for each type of preference is presented in Table (2.2) below.

Table (2.2): Percentage Preference

\begin{tabular}{|c|c|}
\hline Preference & Percentage Preference \\
\hline USEPP & $2 \%$ \\
\hline SCEPP & $7 \%$ \\
\hline RVP & $7 \%$ \\
\hline RCP & $7 \%$ \\
\hline RSCP-2\% & $2 \%$ (each sub) \\
\hline RSCP-4\% & $4 \%$ (each sub) \\
\hline
\end{tabular}

Source: South Carolina Budget and Control Board 
After an extensive survey of the literature, the researcher found that there is a lack of studies attempting to show the relationship between procurement preference policies and economic benefits at the state and local level. Only a few relevant studies were identified in the literature. In 1996, economist Hefner conducted research in the context of the state of South Carolina. In his study, Hefner (1996) sought to measure the economic impact of not applying procurement preference to a concrete pipes contract in the state of South Carolina. The concrete pipes award was challenged on a legal basis in the court. By using the Regional Input-Output Modeling System (RIMS II), Hefner estimated how many jobs, how much earning (personal incomes), and how much income taxes (individual, corporate, retail sales taxes) the state economy would lose if the preference was not implemented. The results showed that South Carolina's economy would lose 27 job opportunities, $\$ 650,000$ in personal income and $\$ 32,500$ in income taxes. He concluded that awarding the contract by implementing the policy would help the state economy.

In another study involving a case in South Carolina, Lowenstein (2011) provided an extensive overview of preference policies in Horry County, South Carolina. By employing the economic background and rationale for the preference policies, Lowenstein introduced a framework that shows how local preference would be applied in the county. Using the economic multiplier for Horry County and assuming that $90 \%$ of government purchases are local, Lowenstein concluded that "a local purchasing preference could potentially generate nearly $\$ 158$ million in economic activity, creating/retaining a minimum of 160 jobs" (Lowenstein, 2011, p. 53). 
A further study discussing preference policies and economic benefits was done by Jensen (2011). Using qualitative data, he investigated how North Carolina's local governments practice preferences and also extended the study to neighboring states (South Carolina and Georgia) to review their preference policies. Combining and analyzing data from surveys, phone interviews, and documents, the analysis showed a variety of findings. First, North Carolina local governments have no formal local preference policies, although they do practice informal local preferences. Second, when participants were asked why their local governments practice preferences, "promotion of local businesses was the most frequently cited answer. Following was job creation, increased tax base, sustainability and wealth creation" (Jensen, 2011, p. 3) . Finally, in regard to the neighboring states, Jensen's results showed that South Carolina and Georgia practice local preferences formally and apply them differently from North Carolina.

In addition to the previous studies specific to South and North Carolina, the literature review showed several studies that have examined the benefits of local business to the economy within their jurisdictions. For example, Rodriguez and Houston (2007) compared the impact of Wist Office Products (Wist) and Office Max Contract (Office Max) on the economy of the state of Arizona. Both businesses represent different degrees of locality. Wist is described to be "a true local supplier" (Rodriguez \& Houston, 2007, p. 10) because all the offices, employees, warehouse, distribution, and administration are local, but Office Max has only a warehouse and small staff locally. Labor, profit, procurement, and charity represented the four elements to calculate how 
much money was kept in the state economy. According to the findings, $33.4 \%$ of Wist's total revenue remains in the local economy, but $11.6 \%$ of Office Max's total revenue remains. The study concluded that:

Local suppliers generate dramatically greater economic activity than their chain competitors. In the case at hand, using the most locally invested of the national chain suppliers, one with a sizeable physical presence in the Phoenix area, the local firm generates nearly three times the economic impact (Civic Economics, 2007, p. 12).

In another study undertaken by Civic Economics Center, the researchers analyzed the economic impact of local businesses in Grand Rapids, Michigan. They concluded that $10 \%$ increases in consumer purchasing to local business would add approximately $\$ 140$ million in new economic activity, generate over 1600 new jobs, and provide over $\$ 50$ million in new wages.

The literature also revealed that some studies focused on other aspects related to procurement preference policies. For example, researchers have studied the impact of preferences on government procurement costs, on the bidding behavior of vendors, and on participation decisions of vendors (Baldwin \& Richardson, 1972; De Silva, Dunne, Kosmopoulou, \& Lamarche, 2011; Krasnokutskaya \& Seim, 2008; Marion, 2007; McAfee \& McMillan, 1989; Trionfetti, 2000).

The arguments for and against preferences policies offer conflicting but powerful arguments. Each approach has sought to inform state procurement preference policies, but the debates continue. Research can help to confirm if the procurement preferential policies achieve the desired economic goals. As the review of the literature indicates, 
some state governments have used procurement preference policies to stimulate the economy and expand the tax bases. One such state is South Carolina, and this study seeks to examine the impact of South Carolina's procurement preference policies on the economy of the state.

The first part of this chapter presented an overview of international trade literature and discussed a variety of protectionist policies. The second part of this chapter focused on the preference policies implemented by the state of South Carolina. The next chapter will propose the methodology for this research. 
CHAPTER III

Methodology

Research has shown that many states exert considerable effort to affect social and economic objectives through procurement policies such as in-state preference policies (NASPO, 2012). According to NASPO (2012), there are 25 states including South Carolina that have provided in-state preference for state vendors and/or state products. South Carolina has implemented the in-state preference policies to help the state recover from its economic crisis (2009 Act No. 72). This research employs the Regional Economic Models, Inc. (REMI) Policy Insight (PI+) Model to estimate the impact of South Carolina's in-state preference policies on the economy of the state for the years 2010 through 2017. This chapter presents an overview of the model, description of the model, REMI simulation model, data, and a detailed description of the REMI model.

\section{Overview of the Model}

This section describes the rationales and justifications for the selection of the Regional Economic Models, Inc. (REMI) Policy Insight (PI+) Model to answer the proposed research question, which is what are the impacts of implementing the in-state procurement preference policies on the economy of the state of South Carolina? PI+ involves the use of a simulation model that has been utilized by researchers for over thirty years to conduct economic impact analysis. $\mathrm{PI}+$ provides quantifiable results with numerical values to answer the research question. 
There are several compelling reasons for selecting the REMI PI+ model for this research. One of the main reasons for selecting $\mathrm{REMI} \mathrm{PI+} \mathrm{is} \mathrm{because} \mathrm{it} \mathrm{integrates} \mathrm{the}$ three models that economists have used to study the impact of either adding or eliminating protectionist instruments (i.e. tariffs and non-tariffs) within the trade theory. Since trade theory was used as an overarching theory in this research, it seemed appropriate to select REMI as a research tool. A review of the trade literature reveals that the three models are: input-output models (Deardorff \& Stern, 1981; Lowinger, 1976), supply-demand equations (Baldwin, 1982; Baldwin \& Richardson, 1972; Breton \& Salmon, 1996; Herander, 1982), and computable general equilibrium model (Deardorff \& Stern, 1981). These models consist of embedded mathematical equations that explain the relationships and the linkages among a variety of economic variables. A "run" or simulation of these models represents a "shock" to the economy such as imposing a tariff. The embedded relationships within these models trace the economic impacts generated by the shock and provide quantifiable values for the impacts.

A second reason for selecting this model is that the research question of this research aligns closely with the stated goals of REMI PI+. One of the main goals of REMI PI+ is "understanding how government actions...affect the world around us" (REMI, n.d., p. 2). More specifically, the goal is to help "government decision-makers [to] test the economic effects of their policies" (REMI, n.d., p. 2). Given these similarities, the REMI PI+ seemed an appropriate model to use.

The third reason for choosing the REMI PI+ model is that it can be customized for any specific geographic region such as a state, county or city. In this research, REMI PI+ 
will be customized for the state of South Carolina. Repeatability is the final reason for selecting the REMI PI+. The repeated use of the model for economic impact analysis establishes confidence over time and adds more reliability to the model to conduct this analysis (Cassing \& Giarratani, 1992). PI+ has been in existence for more than 30 years and has been used in a wide variety of situations by many scholars, researchers, practitioners and professionals from several private, public and nonprofit organizations. The model simulations in $\mathrm{PI}+$ are also used to assess "economic and demographic effects in wide-ranging initiatives such as: economic impact analysis; policies and programs for economic development, infrastructure, environment, energy and natural resources; and state and local tax changes" (REMI, 2012, para 2). The findings from these studies were published in various journals such as the American Economic Review, the Review of Economic Statistics, the Journal of Regional Science, and the International Regional Science Review (REMI, 2012).

Researchers have examined the validity of the REMI model in a variety of scholarly works (Cassing \& Giarratani, 1992; Rose, Wei, \& Dormady, 2011; Treyz, Rickman, \& Shao, 1991). To validate the estimation ability of the model, Cassing and Giarratani (1992) calculated the post-sample period forecasts for all fifty states and Washington, D.C. by using actual historical values. The Mean Absolute Percentage Error (MAPE) was then calculated to represent the difference between the predicted values and the actual values, and the results showed "that the REMI model produces very good forecasts over a short period of time beyond the historical data sample. As expected for all forecasting models, prediction accuracy deteriorates as the forecasting period 
lengthens. Studies also indicated that REMI can predict major changes in the direction of economic activity for larger industries" (Rose et al., 2011, p. 359). By using multivariate econometric analysis, Rose et al. (2011, p. 358) evaluated "the explanatory power of the REMI model and consistency of its output with regard to policy variables". The analysis "confirm[s] the close proximity between the combination of direct and indirect macroeconomic impacts and the direct impact assessments of stakeholders...the results represent a strong validation of the application of the REMI model to the analysis in this paper" (Rose et al., 2011, p. 374). Moreover, Rickman and Schwer (1995) compared the multipliers of the REMI model with two other input-output models, the Impact Analysis for Planning (IMPLAN) and the Regional Input-Output Modeling System (RIMS II). To compare the three models, the authors created benchmarked versions of the three models to account for the difference in techniques used to calculate national inputoutput coefficients. The results showed that there is no significant difference among the multipliers for the three models. Rickman and Schwer suggested that this conclusion could help researchers and practitioners to be more confident in using ready-made models in their research.

At the state level, the REMI model is used because it is "the most widely used state-level economic modeling software package in the U.S." (Rose, Wei, \& Prager, 2010, p. 9). Almost every state government agency has applied a REMI Model (Rose et al., 2010). Some of these states are: Florida, Pennsylvania, Michigan, California and New Mexico. In Florida, the model was used to investigate the impacts of the Florida Energy and Climate Change Action Plan (FECCAP) on the state's economy (Rose \& Wei, 2012) 
while in Michigan, the model was used to analyze the macroeconomic impact of the Michigan Climate Action Plan (Miller, Wei, \& Rose, 2010). Pennsylvania used the model to evaluate the impacts of the Pennsylvania Climate Action Plan on the state's economy for the period of 2009-2020 (Rose et al., 2011).

Although REMI PI+ is a commonly used model, it has some limitations. First, as is the case with other economic impact models, it is possible that REMI could be viewed as a black box by those who are not familiar with the model. However, to withstand this limitation REMI Inc. has provided documents on their website to review all assumptions, equations and data sources. The second limitation is that REMI PI+ is not capable of providing tax revenue as a separate output; thus, the researcher cannot capture the impact of tax revenue on the state economy. Third, REMI PI+ can estimate the economic impacts for only three consecutive years $(2010$ - 2012) because of the way the model is built. The model does not run simulations in years with actual historical data, and the last year of historical data is 2009.

In spite of the limitations noted above, the REMI model estimates the impact of in-state preference policies by measuring the most commonly reported economic indicators: output (sales), employment, personal income, real disposable personal income, Gross State Product (GSP), and state's population. Output, which can be thought of as sales, is measured by the amount of production sold to the intermediate and final consumers. Employment is the total number of full-time and part-time jobs in government and the private sector. Private sector employment is determined by the value added which represents the difference between output and intermediate inputs 
by industry. Income represents the sum of income that is received by all persons from all sources. GSP is a comprehensive measure of economic activity in a state. Population is the difference between the net natural change (caused by births and deaths) and the migration change (REMI, 2011). Because the REMI model is grounded in neoclassical economics, the anticipated impacts included are: additional jobs as a result of implementing the policy, an increase in labor personnel and real disposable income, an increase in the state's population, and an increase in output (sales) that local businesses experience as a result of the government buying their products or services.

\section{Description of the Model}

The $\mathrm{PI}+$ is flexible and can be customized to account for geographic or regional differences in assessing the impacts of economic changes in the target states, cities and/or localities (Avalos \& Birdyshaw, 2007). In this case, PI+ is customized to be a mathematical representation of the South Carolina economy to investigate the impact of implementing the procurement preference policies. The dollar amount of the preference contracts (industry sales) are input into the PI+ which calculates the total changes in output due to the policy changes resulting from the implementation of the in-state preference policy.

PI+ uses simulation equations and economic variables. The number of equations varies depending on "the extent of industry, demographic, demand, and other details in the specific model being used" (REMI, 2007, p. 3). The model integrates four methodological approaches: input-output, computable general equilibrium, 
econometric and economic geography methodologies. Each one of these methodological approaches has its own strengths and weaknesses if used alone; however, the REMI model combines the strengths of each of these approaches into the model (REMI, 2007). The four approaches are explained below.

First: input-output model. The REMI model represents "the inter-industry relationships found in input-output models. Changes that affect industry sectors that are highly interconnected to the rest of the economy will often have a greater economic impact than those for industries that are not closely linked to the regional economy" (REMI, 2012, para 2).

Second: computable general equilibrium. General equilibrium focuses on the balance between supply and demand in an economy with many interacting markets. The balance occurs in the long run when prices, production, consumption, imports, exports, and other changes are in equilibrium and stabilize the economy. "For example, if real wages in a region rise relative to the U.S., this will tend to attract economic migrants to the region until relative real wage rates equalize". The purpose of general equilibrium theory is to help "evaluate changes such as tax policies that may have an effect on regional prices and competitiveness" (REMI, 2012, para 3).

Third: econometric model. Econometric model is a tool that economists and researchers use "to forecast future developments in the economy" (Hymans, 2008, para 1). In this model, past relationships among variables are estimated to predict "how changes in some variables will affect the future course of others" (Hymans, 2008, para 1). 
Fourth: economic geography model.

The new economic geography features represent the spatial dimension of the economy. Transportation costs and accessibility are important economic determinants of interregional trade and the productivity benefits that occur due to industry clustering and labor market access. Firms benefit from having access to a large, specialized labor pool and from having access to specialized intermediate inputs from supplying firms. The productivity and competitiveness benefits of labor and industry concentrations are called agglomeration economies, and are modeled in the economic geography equations (REMI, 2012, para 5).

As shown in Chart 1.1 (page 16), the overall structure of the REMI model consists of five major blocks with each block consisting of several economic variables.

Connections among the variables in each block are represented as linkages within and between the five blocks. The blocks and the variables are:

- Output and demand block (B1) - includes output, consumption, investment, government spending, real disposable income and export concepts

- Labor and capital demand block (B2) - includes labor productivity, labor intensity, and the optimal capital stocks.

- Population and labor force block (B3) - includes population, migration, participation rate, and labor force.

- Compensation, prices, and costs block (B4) - includes delivered prices, production costs, equipment cost, the consumption deflator, consumer prices, the price of housing, and the wage equation

- Market shares block (B5) - includes the proportion of local and export markets that are captured by each industry.

\section{REMI Simulation}

Chart 3.1 illustrates how the policy simulation in the REMI PI+ model works. As shown in the figure, a series of steps must be taken to run the simulation. First, the researcher formulates the policy question, which in this case is "what are the economic impacts of implementing the in-state preference policies?". Second, the researcher 
determines the external variable that represents the effects of the policy (in this case, sales that represent the dollar value for the procurement contract). By using the baseline value for the variables, the model creates the control forecast (the regional forecast). To create the control forecast, REMI PI+ employs the recent available data (i.e. 2009) for the South Carolina region. Third, the researcher puts the data into the model through the policy variable industry sales, which represent the direct effect of the sales variable on the economy of the state. Fourth, the model generates an alternative forecast. Finally, the impact of the policy variable is measured by comparing the alternative and the control forecasts.

Chart (3.1) Policy Simulation

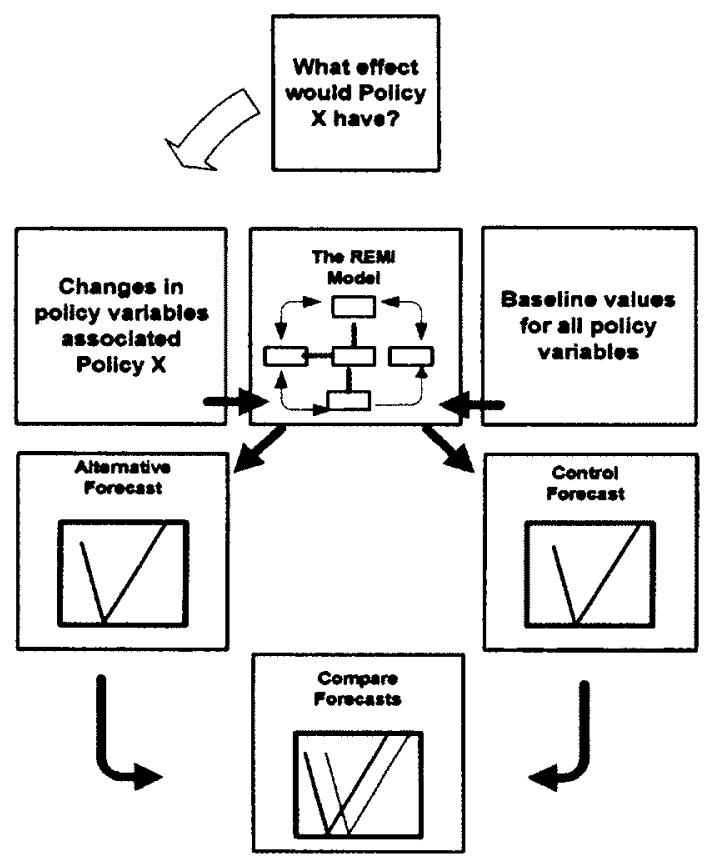

Source: REMI (2011) 
The case of South Carolina's preference policies for the years 2010 through 2017 will be the focus of this research. The selection of the state of South Carolina is dictated by data availability. The period of this research is eight years; the dollar value of procurement contracts for the first three years $(2010-2012)$ will be input into the PI+. REMI cannot run simulations for more than three years in the past because the model cannot run simulations in years that have historical data. The PI+'s last year of history is 2009. There is a two-year lag in the procurement contracts data because the year must first end, and then it takes another year for the sources to compile and report the data. The average spending will be calculated and used to forecast the economic impact for the years 2013- 2017.

The researcher will employ two types of data in this research. The first type of data to be used includes the values of the economic variables, which are represented in all the underlying economic linkages, equations and estimated relationships of the economic structure in the PIt. These relationships and linkages are built into the software, and REMI staff will develop the model and provide the economic data which it gathers from various sources. REMI collects primary historical data from various sources including the Bureau of Economic Analysis (BEA), the Bureau of Labor Statistics (BLS), and County Business Patterns (CBP); its national forecast data is collected from BLS (forecast data and occupation data) and Research Seminar in Quantitative Economics (RSQE) from the University of Michigan. 
In addition to the data set described above, the second type of data the researcher will use includes the dollar values of the contracts awarded to South Carolina firms given the in-state preference policy. For each contract, the spending (the dollar value of the contracts) is compiled into the North American Industry Classification System (NAICS) to account for the differential impacts by type of sector, and these dollar values will be input into the $\mathrm{PI}+$. The preference data is obtained from the Office of Audit and Certification, a subdivision of the Procurement Services Office in South Carolina Budget and Control Board, which is the central administrative agency for South Carolina state government. The Office of Audit and Certification prepared quarterly procurement preference reports which provided the dollar amount of the procurement preference contracts.

Each of the quarterly reports also includes the name of the South Carolina agencies that have awarded the contracts, the solicitation numbers, descriptions, NIGP commodity codes, lowest response amount, award amount, preference expenses, and preference categories. All procurement contracts involved the use of invitations for competitive sealed bids. The contracts are classified into the following categories: the United States end-product preference, South Carolina end-product preference, and resident vendor preference. In addition to the commodity/product contract preferences, the state offers contract preferences for services that are designated as resident contractor preference and resident subcontractor preference (more details about the categories are provided in Chapter II). 
Table 3.1 below represents the combined data from the quarterly reports. The table shows that in the 2010 fiscal year, 20 competitive sealed bids were awarded by agencies in the state of South Carolina using preference policies for a total of $\$ 1,031,605$, while in the 2011 fiscal year 49 competitive sealed bids were awarded by agencies in the state of South Carolina using preference policies for a total of $\$ 1,748,391$. In the 2012 fiscal year, 49 competitive sealed bids were awarded by agencies in the state of South Carolina using preference policies for a total of $\$ 1,519,655$. The dollar value of each of the 118 contracts will be input in the model according to the respective North American Industry Classification System (NAICS) industry for each contract. The table also shows that the direct cost of awarding the preference contracts is $\$ 179,332$, meaning that the state agencies paid an extra $\$ 179,332$ to award the contracts based on a variety of preference types. Thirty state agencies implemented the in-state preference policies during 2010 and 2012. A list of the state agencies is provided in Appendix A.

Table 3.1 Total Number of Contracts Dictated by Preferences and the Preference Cost

\begin{tabular}{|c|c|c|c|c|}
\hline Year & $\begin{array}{l}\text { Lowest } \\
\text { Response }\end{array}$ & $\begin{array}{l}\text { Award } \\
\text { Amount }\end{array}$ & $\begin{array}{l}\text { Preference } \\
\text { Cost }\end{array}$ & $\begin{array}{l}\text { Number of } \\
\text { Contracts }\end{array}$ \\
\hline 2010 & $\$ 996,375$ & $\$ 1,031,605$ & $\$ 35,230$ & 20 \\
\hline 2011 & $\$ 1,670,035$ & $\$ 1,748,391$ & $\$ 78,355$ & 49 \\
\hline 2012 & $\$ 1,448,731$ & $\$ 1,519,655$ & $\$ 70,924$ & 49 \\
\hline Total & $\$ 4,484,834$ & $\$ 4,664,166$ & $\$ 179,332$ & 118 \\
\hline
\end{tabular}




\section{A Detailed Description of the REMI Model}

A South Carolina version of the REMI P1+ model was applied to estimate the economic impacts of preference policies on output, personal and real disposable income, value added, Gross State Product (GSP), population, and employment in South Carolina for 2010 and 2017. Each of the five major blocks is summarized below.

1. Output and Demand (B1)

Chart (3.2): Block 1 Output and Demand

(1) Output Block

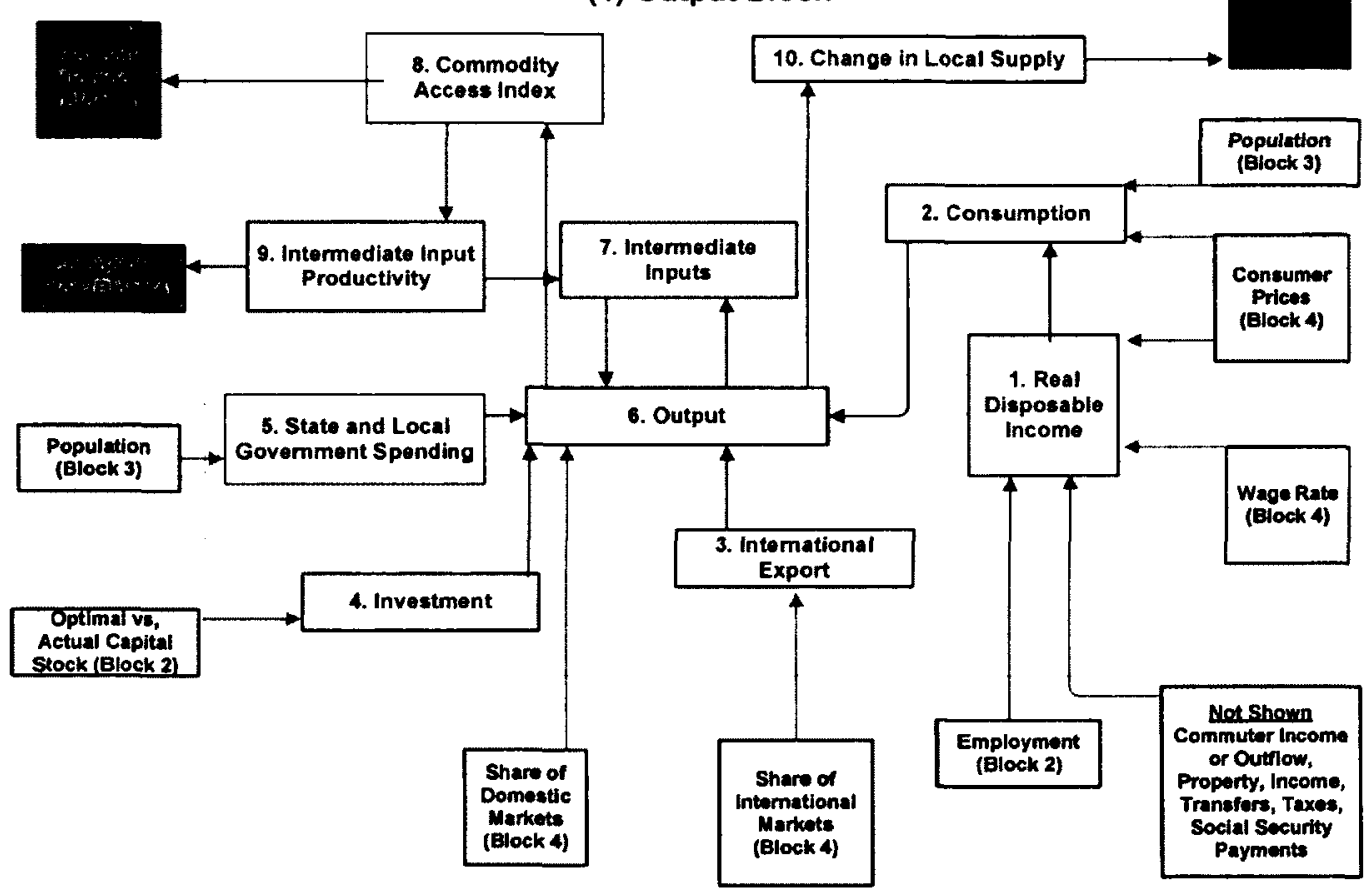

Source: REMI (2011) 
The output and demand block (Chart 3.2) consists of output, demand, consumption, investment, government spending, exports, and imports, "as well as feedback from output change due to the change in the productivity of intermediate inputs" (REMI, 2011, p. 6). Three variables affect the output for each industry in the home region: industry demand in all regions in the nation, the home region's share of each market, and international exports from the region. In block 5, economic geography methods determine the shares of home and other regions' markets. Final demand drives the output block. For each industry, the final demand consists of the amount of output, consumption, investment, and capital demand on that industry (REMI, 2011). The sources of demand are defined below:

- Output is the amount of production, including all intermediate goods purchased as well as value added (compensation and profit). Output also can be thought of as sales or supply.

- Consumption is a function of real disposable income per capita, relative prices, differential income elasticities, and population. When population increases, consumption increases.

- Real disposable income drives consumption, which is determined by compensation (B4), employment (B2), non-compensation income, and the personal consumption expenditure price index. Labor income depends on employment and the compensation rate, described in blocks 2 and 4, respectively. Non-compensation income includes commuter income, property income, transfers, taxes, and social security payments (REMI, 2011). 
- Investment is "the difference between optimal and actual capital stock for residential, non-residential, and equipment investment" (REMI, 2011, p. 9) and it is driven by optimal capital stock adjustment process.

- Government spending is used to provide services for citizens and it is related to revenue resources. Government spending depends on population (B3), housing prices (B4), and the overall size of the economy (GRP). "The government spending equation takes into account regional differences in per capita and per GSP government spending, as well as differential government spending levels across localities within a larger region" (REMI, 2011, p. 9).

- The demand for the intermediate inputs is driven by "the requirements of industries that use inputs from other sectors. These inter-industry relationships are based on the input-output table for the economy" (REMI, 2011, p. 9). The intermediate inputs are determined by productivity which is determined by the commodity access index. 
2. Labor and Capital Demand (B2)

Chart (3.3): Block 2 Labor and Capital Demand

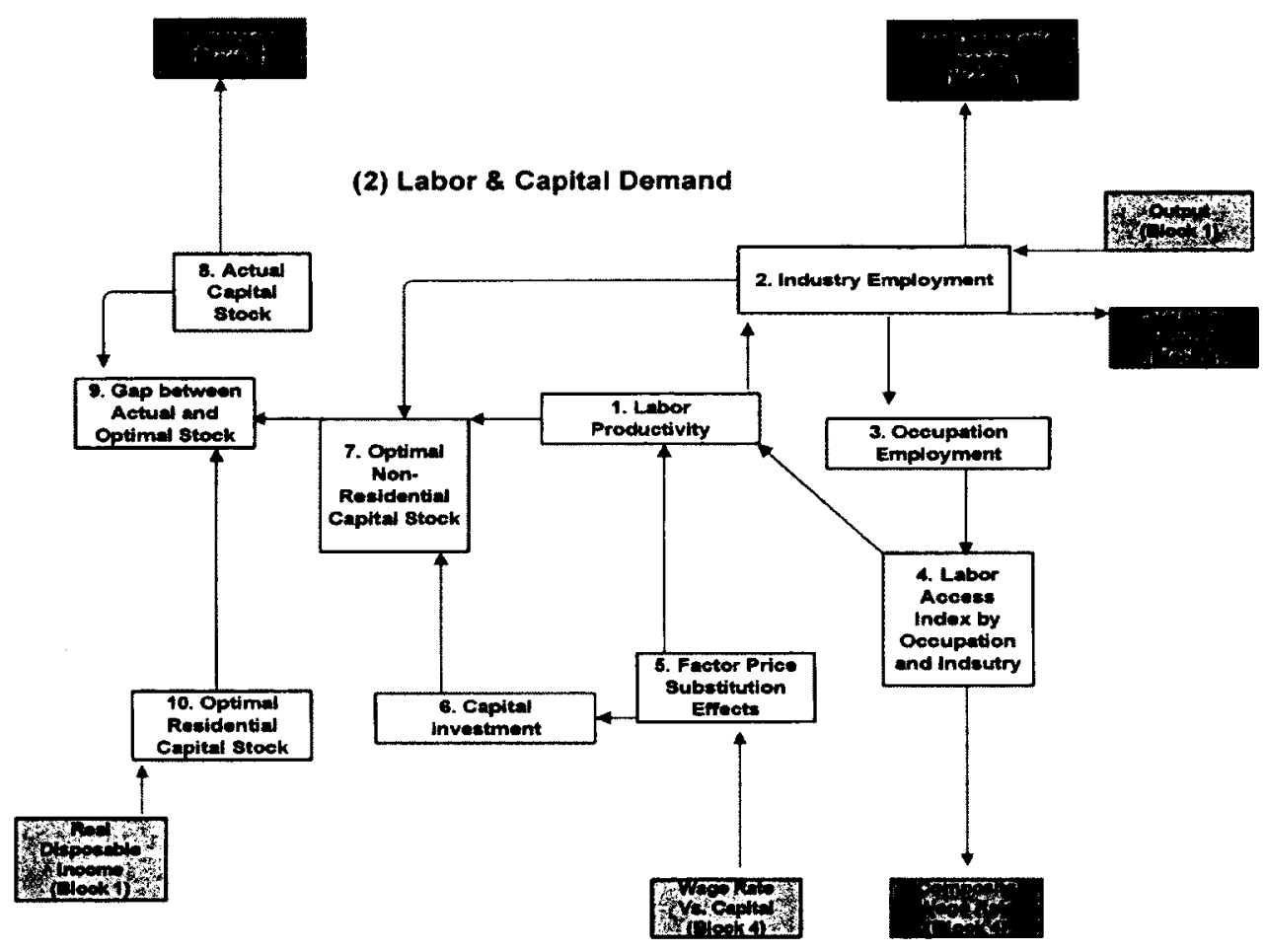

Source: REMI (2011)

The second block (B2) is "the labor and capital demand block" which includes employment, labor intensity, labor productivity, and the substitution among labor, fuel and capital (Chart 3.3).

- Employment includes farm, government, and private non-farm employment.

"Employment in private non-farm industries depends on employment demand and the number of workers needed to produce a unit of output. The 
employment per dollar of output is driven by the national employment per dollar of output, the cost of other factors, and the access to specialized workers" (REMI, 2011, p. 14).

- Labor productivity for each industry depends on "the availability of workers with differentiated skills for the occupations used in each industry" which is equal to the output per employee (output/employment). Chart 3.3 indicates the following relationships: labor productivity is driven by industry employment. Industry employment is driven by occupation employment. Occupation employment is driven by the labor access index by occupation and industry. The index derives labor productivity.

- Labor intensity: "is determined by the cost of labor relative to the other factor inputs, capital and fuel" (REMI, 2011, p. 14). Labor intensity measures the use of labor relative to other factors.

- "The substitution between labor, capital, and fuel is based on a Cobb-Douglas production function, which implies constant factor shares. Labor intensity is calculated for each industry" (Rose et al., 2010, p. 12).

- "Demand for capital is driven by the optimal capital stock equation for industries and for housing. The optimal level of capital is determined for non-residential structures and equipment for each industry. The regional optimal capital stock is based on the industry size measured in capital-weighted employment terms, the cost of capital relative to labor, and a measure of the optimal capital stock on the national level. (REMI, 2011, p. 14). 
- The optimal level of capital for residential housing is determined by the real disposable income in the region relative to the nation, the optimal residential capital stock for the nation, and the price of housing.

3. Population and Labor Force (B3)

Chart (3.4): Block 3 Population and Labor Supply

(3) Population Labor Supply

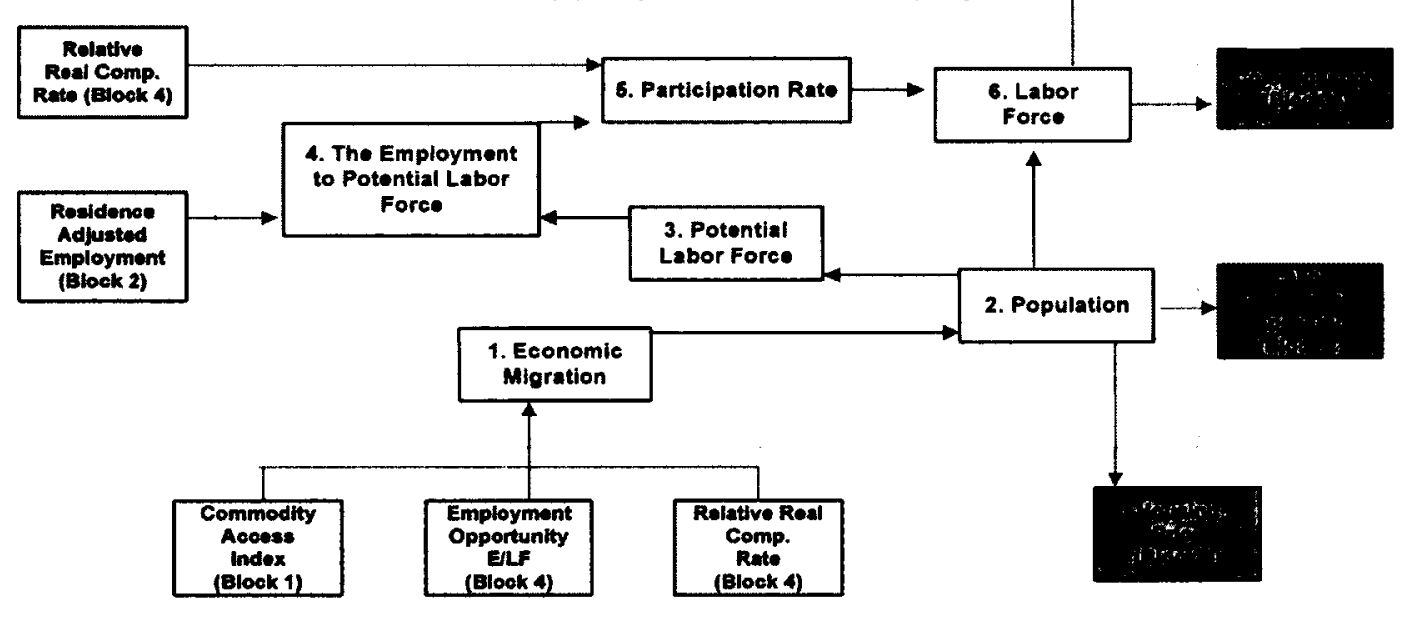

Source: REMI (2011)

Population, labor force, participation rate, and migration equations are the components of the third block, "the population and labor supply", as shown in Chart

3.4. Generally, this block gives demographic information about the region and it consists of the following: 
- Population is available by age, gender, and ethnic category, with birth and survival rates for each group. Populations for every year equal the net natural change (caused by births and deaths) and the migration change (migration occurs for economic and non-economic reasons) to the previous year's population(REMI, 2011).

- Migration includes retirement, military, international, and economic migration", and it varies widely across population groups. It is measured/ determined by " the relative real after-tax compensation rate, relative employment opportunity, and consumer access to variety" (REMI, 2011, p. 6). The model assumes that the changes in migration are not caused by any changing regional economic conditions.

- Labor force includes unemployed and employed workers. Labor force participation rate is "thus the proportion of each population group that is working or looking for work" (REMI, 2011, p. 16). Labor supply is determined by the size and labor force participation rate of each group. "These participation rates respond to changes in employment relative to the potential labor force and to changes in the real after-tax compensation rate. Demand for labor from block 2 and labor force supply from block 3 interact to determine compensation (wage) rates (REMI, 2011). 
Chart (3.5): Block 4 Compensation, Prices, and Costs

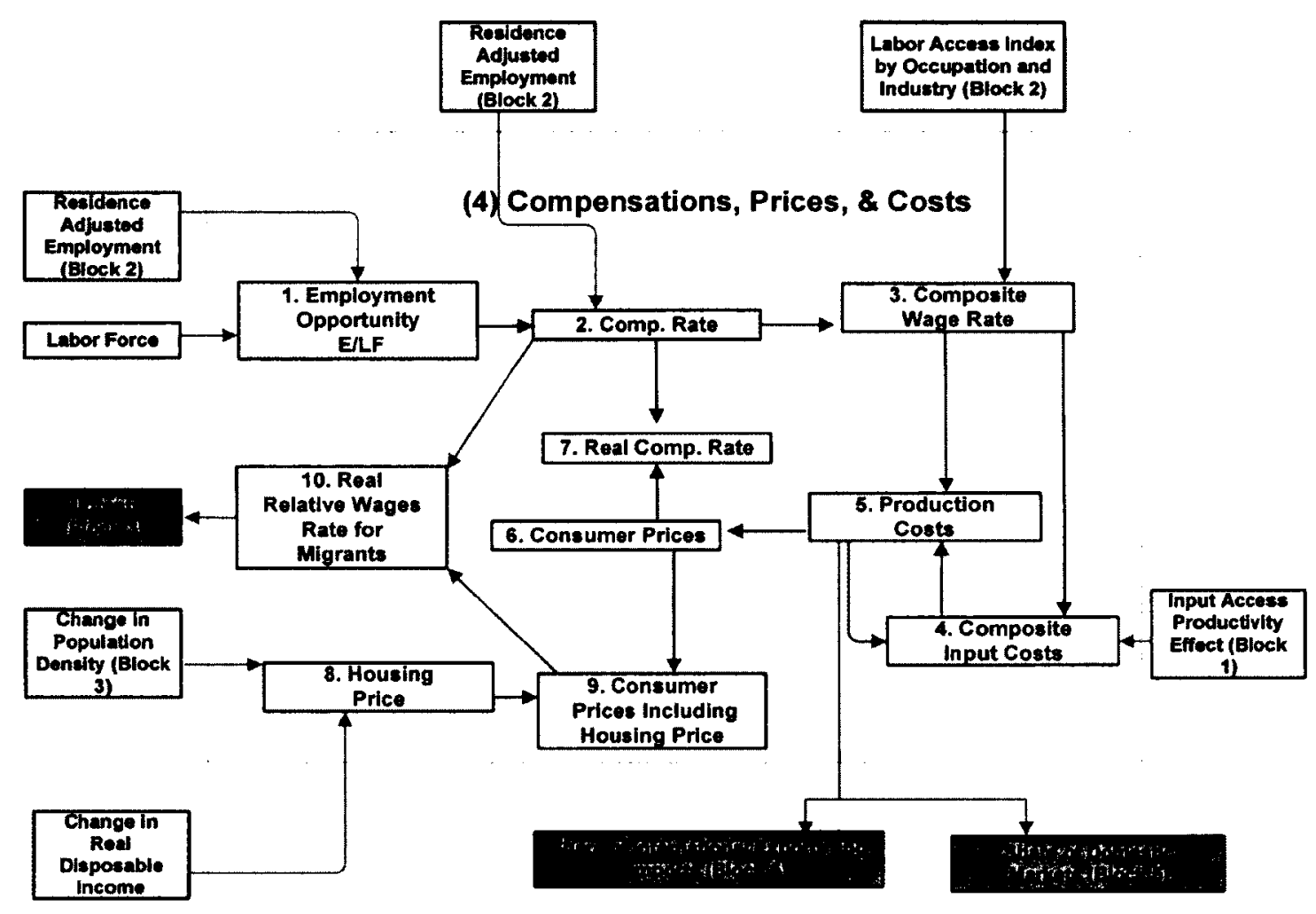

Source: REMI (2011)

The compensation, prices, and costs block (B4) consists of consumer prices,

housing prices, and composite wages and input costs, composite prices, determinants of production costs, the consumption price deflator, and the compensation equation (Chart 3.5). Compensation, prices, and costs are "determined by the labor and housing markets". The labor market is central to the regional economy, and compensation 
differences are the primary source of price and cost differentials between regions" (REMI, 2011, p. 14). Demand for labor (B2) and labor force supply (B3) interact to determine compensation rates. Housing prices depend on changes in population density and changes in real disposable income. The components are discussed below.

- Composite prices are derived by the production costs of supplying regions, the effective distance to these regions, and the index of access to the variety of outputs in the industry relative to the access by other uses of the product (REMI, 2011).

- Determinants of production costs are the cost of labor, capital, fuel, and intermediate inputs. Labor costs "reflect a productivity adjustment to account for access to specialized labor, as well as underlying compensation rates" (REMI, 2011, p. 17). Capital costs include costs of non-residential structures and equipment, while fuel costs incorporate electricity, natural gas, and residual fuels.

- Composite compensation rate is determined by the labor access index from block 2 as well as the nominal compensation rate.

- The composite cost of production depends on the productivity-adjusted compensation rate of the region, costs of structures, equipment, and fuel, and the delivered price of intermediate inputs (REMI, 2011).

- "The consumption deflator converts industry prices to prices for consumption commodities" (REMI, 2011, p. 17). 
Compensation changes are due to changes in the labor supply and demand conditions and changes in the national compensation rate. Changes in employment opportunities relative to the labor force and occupational demand changes determine the compensation rates by industry (REMI, 2011).

5. Market Shares (B5)

Chart (3.6): Block 5 Market Shares

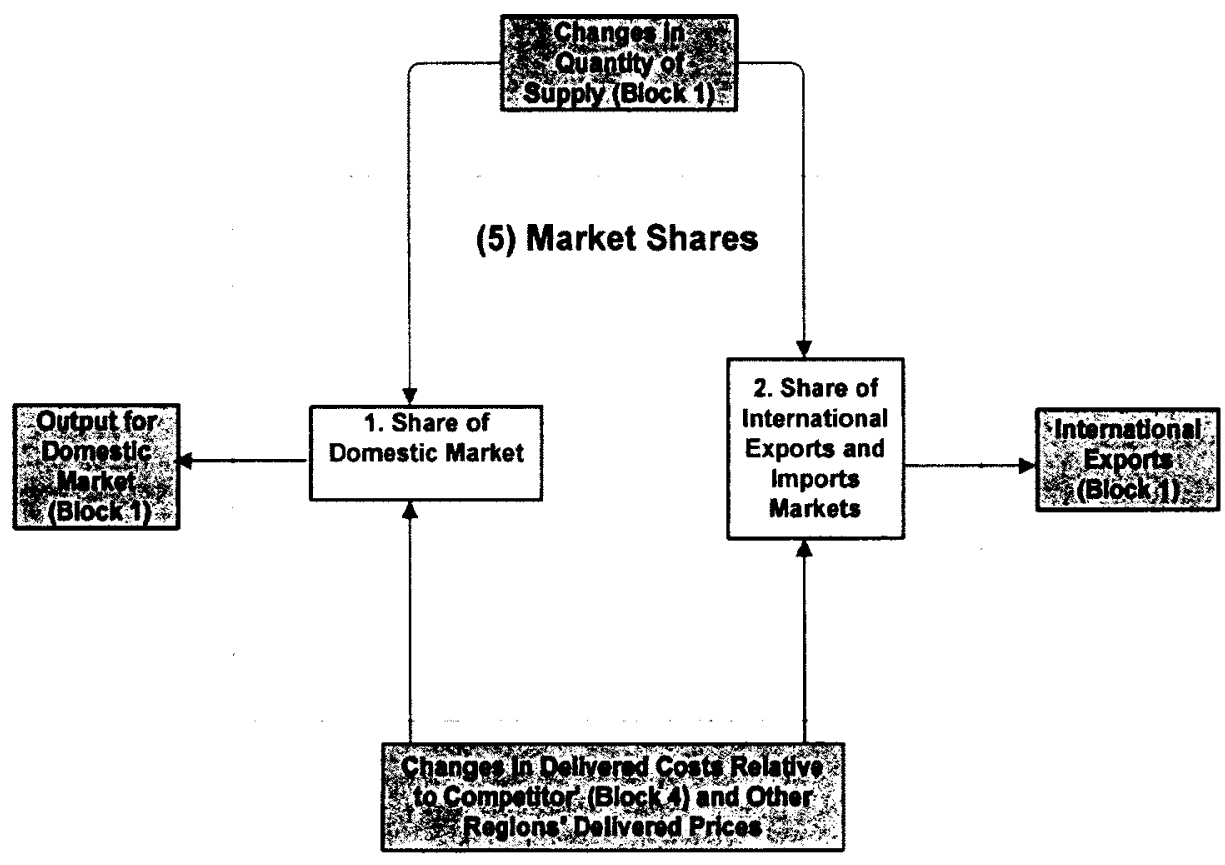

Source: REMI (2011)

The last block is "the market shares block" which includes the proportion of local, inter-regional, and export markets captured by each region, so the block represents "the ability of the region to sell its output within the local region, to other regions in the nation, and to other nations"(REMI, 2011, p. 17). This block is affected by 
three factors: "relative production costs, the estimated price elasticity of demand, and the effective distance between the home region and each of the other regions" (REMI, 2011, p. 18). Change in a product's quantity (output) and price (production cost) compared with other competitors drives the change in share of a specific area in any region (Chart 3.6).

When prices increase (production cost), market shares will be lower. A higher quantity (output) raises market shares. "Market shares rise with output increases, since higher output is better able to meet local and other regions' demand for goods and services by providing more choices". "The share of local and external markets then drives the exports from and imports to the home economy" (REMI, 2011, p. 18).

This chapter discussed the rationales for choosing REMI PI+ to estimate the impact of South Carolina's in-state preference policies on the economy of the state. In addition, the chapter presented a description of the data to be analyzed as well as the model and its relationships. 


\section{Chapter IV}

\section{Results}

Chapter III presented an overview of the REMI model, a REMI simulation, data, and a detailed description of the REMI model. The purpose of Chapter IV is to present the data analysis and report the results. This chapter is divided into five sections: data preparation, profiles of state government agencies, industries benefiting from procurement contracts, preference types, and economic impact results. The chapter concludes with a summary of the information presented.

\section{Data Preparation}

The procurement contracts awarded to South Carolina firms given the in-state preference policy were carefully examined in detail to prepare the data for the analysis. The total number of the contracts was 124 , but 6 contracts were dropped from the data because 1) the available data was not sufficient to identify the correct industry, 2) a public purchasing officer deemed the data provided on the preference reports was not accurate or 3 ) the dollar value of the contracts was very low (more details regarding these cases are provided in Appendix B).

Prior to inputting the dollar values of the 118 contracts into the REMI model, the dollar value (the spending) for each contract was classified into the North American Industry Classification System (NAICS). The purpose of the classification is to account for 
the differential economic impacts on output (business sales), total employment (includes the private non-farm employment), personal income, real disposable personal income, Gross State Product (GSP), value added, and state's population by the type of industry. To identify the respective industry, the South Carolina Procurement Services Office provided the following data: the solicitation numbers, the solicitation descriptions, the National Institute of Governmental Purchasing (NIGP) commodity codes, and preference categories.

The appropriate NAICS industry was identified in three ways. First, the description of each contract was compared with the detailed description of the NAICS numbering system provided on the NAICS website. The two descriptions were then matched to identify the most appropriate industry code. Second, since the corresponding NIGP code for every contract is provided, the NIGP code staff helped to convert the NIGP codes to NAICS codes. Third, the NIGP code staff provided the researcher online access to the description of NIGP codes to help identifying NAICS.

After identifying the appropriate NAICS industry, the researcher reviewed each contract's description and matched it with the description of NIGP codes. The NIGP codes were then matched with the NAICS codes. During the process of identifying the NAICS codes, the type of preference that the state agency applied to every contract was taken into consideration. For example, if the preference type is resident vendor preference, the sales from the specific contract contribute to the wholesale trade industry or retail industry. But, if the preference type is resident vendor and South Carolina end-product, the sales from the specific contract contribute to the 
manufacturing industry because the product is manufactured in the state of South Carolina.

After identifying the NAICS by each approach, the corresponding NAICS codes were compared. In a few cases, there were disagreements on the identified NAICS codes. In these cases, the researcher checked the South Carolina Budget and Control Board website to find more details about the specific solicitations. If the information was not available on the website, the researcher either emailed or called the state agency that awarded the contracts, provided the solicitation numbers and asked for more details about the specific contract to help determine the appropriate industry. (Appendix $\mathrm{C}$ includes additional information regarding these cases.)

\section{Profile of State Government Agencies}

There are ninety-five state agencies in the government of the state of South Carolina. These agencies represent a variety of organizations, such as educational institutions like Clemson University and the University of South Carolina, government departments such as the Department of Transportation and the Department of Parks, Recreation and Tourism, and commissions like the Public Service Commission and Arts Commission. Nearly $30 \%$ of the state agencies implemented the in-state preference policies within the period of 2010-2012. The types of preferences include Resident Vendor, South Carolina End Product, Resident Vendor and South Carolina End Product, Resident Vendor and US End Product, Resident Contractor, and Resident Contractor and 
Subcontractor(s). The next section provides more information about the percentages of each type of preference policy implemented by the state agencies.

Chart 4.1 identifies the names of the top thirteen state agencies that implemented the preference policies. For the most part, vendors claimed a variety of preferences when they bid on higher education institutions' contracts. For example, Clemson University bought fire equipment and protective gear, a Polaris Ranger Vehicle, and materials for repairing a floor. The University of South Carolina installed computer servers, provided a switchgear for the Eugene Stone Stadium, and bought surveillance cameras for the Law Enforcement and Safety Department. Lander University bought emergency phone towers for campus and mattresses for residence halls, and printed view books for their colleges. Coastal Carolina University bought treadmills and requested landscaping services and printing of the winter issue of the alumni magazine.

In addition to higher education institutions, other government agencies implemented the state preference policies within the period of 2010-2012. The Transportation Department awarded a contract to buy safety vests, total stations, and multimeters; the Public Safety Department awarded a contract to a resident vendor to provide janitorial services and to buy golf carts; the Parks, Recreation and Tourism Department awarded a contract based on resident vendor and South Carolina product to buy heat pumps for Givhans Ferry State Park and playground equipment for Lake Wateree State Park; the South Carolina Department of Juvenile Justice awarded a resident contractor a solicitation for maintenance and repair of generators. 
Chart (4.1): State Agencies that Implemented the In-State Preference Policies (2010-2012)

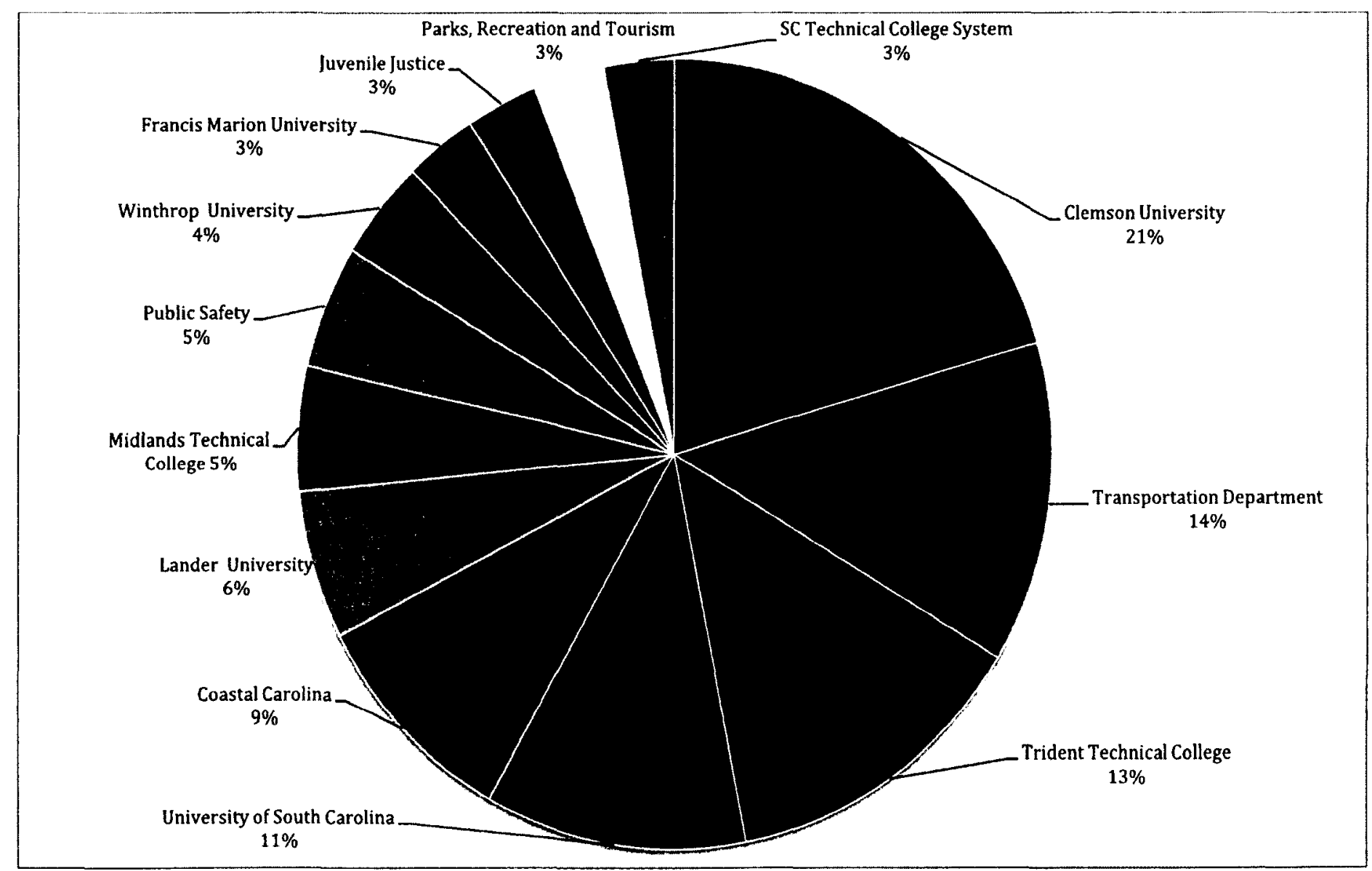




\section{Profile of Preference Types}

Chart 4.2 shows the type of preference policies that vendors claimed when South Carolina agencies sent invitations for bid within the three-year period from 20102012. As mentioned in Chapter II, South Carolina has two types of preferences: commodity contract preferences and service contract preferences. The commodity contract preferences are the preferences claimed by South Carolina vendors because they sell or manufacture a product in the state. The service contract preferences are preferences claimed by South Carolina vendors because they provide services in the state. The commodity contract preferences include the United States end-product preference, South Carolina end-product preference, and resident vendor preference. In addition to the commodity/product contract preferences, the state offers contract preferences for services that are designated as resident contractor preference and resident subcontractor preference. As shown in Chart 4.2, thirty-four percent of the vendors claimed that they qualified for resident vendor and South Carolina end-product preference, which means that their products are sold by South Carolina vendors and are made, manufactured, or grown in South Carolina. Twenty-seven percent of the vendors proved that they qualified for resident vendor preference policy. Twenty-seven percent represents 28 contracts awarded to South Carolina vendors. Twenty-nine percent of the contracts were awarded based on resident vendor and US end product. Chart 4.2 also shows that there were few contracts (less than $6 \%$ of the contracts) awarded based on resident contractors and subcontractors preferences and South Carolina end-product preferences. 
Chart (4.2): Type of Preference Policies

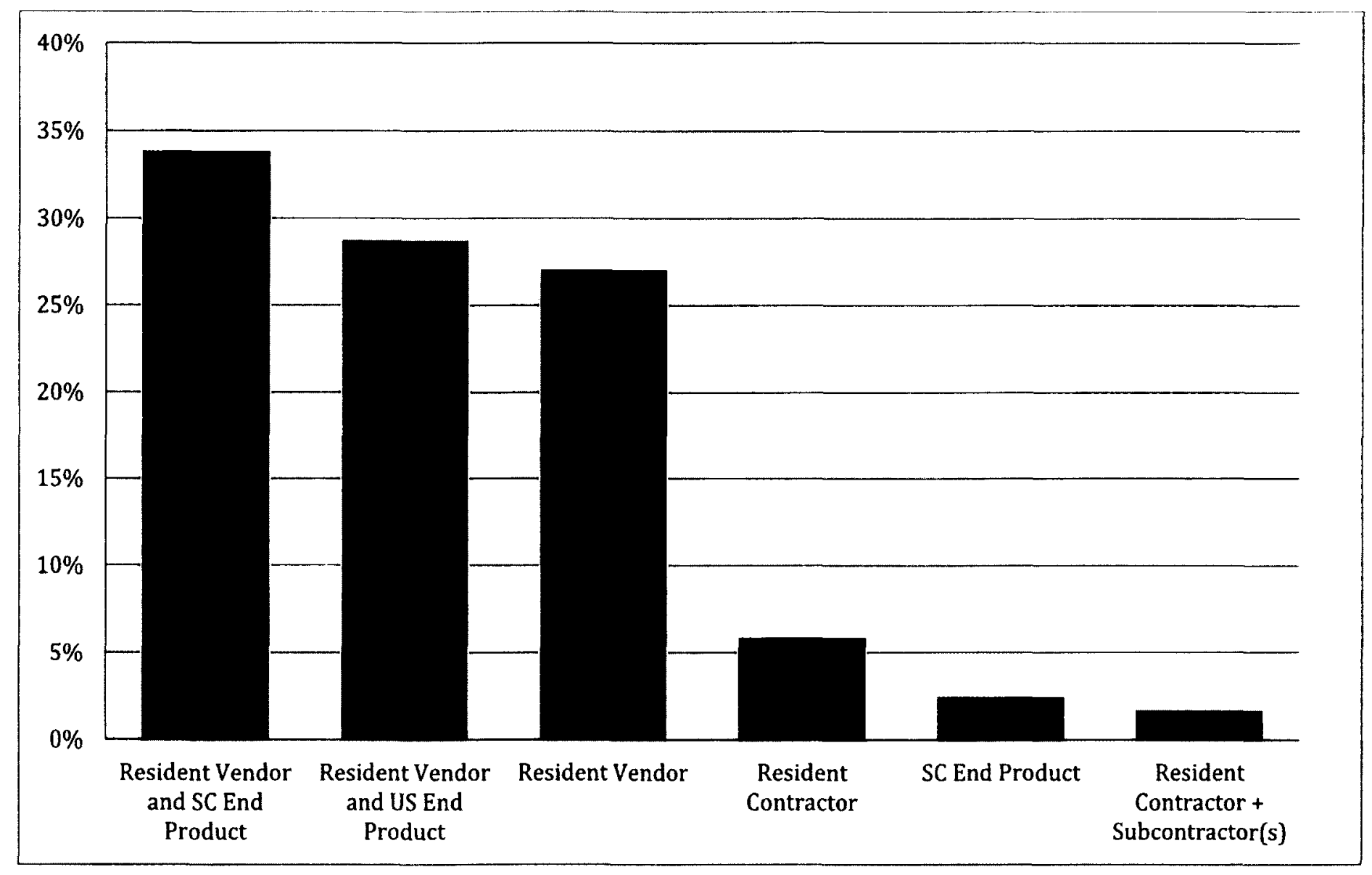


Profile of Industries Benefiting from Procurement Contracts

As mentioned before, the dollar values of the contracts were assigned according to the NAICS codes. After identifying the corresponding NAICS industries for the 118 contracts, eight industries that benefited from the procurement contracts that were awarded based on preference policies were identified. Table 4.1 (page 77) shows the names of the eight industries, the average of the dollar spending during 2010-2012 and the number of contracts that were awarded based on the preferences by industry. (Appendix D includes NAICS descriptions of the industries that were involved in this research). For clarifying purposes, Chart 4.3 (page 78 ) is also a visual representation of the dollar values of the top industries benefiting from procurement contracts. The eight industries are: retail trade, construction, administrative and support services, manufacturing, wholesale trade, professional, scientific, and technical services, transportation and warehousing, and other services (except public administration).

As a result of awarding preference contracts, state government agencies spent the most on the wholesale trade industry (an average of $\$ 657,248$ ). According to the NAICS, "the Wholesale Trade sector comprises establishments engaged in wholesaling merchandise, generally without transformation, and rendering services incidental to the sale of merchandise" (NAICS, 2013, par 4). For example, in 2010, the Transportation Department awarded a contract to a South Carolina vendor to buy safety vests. The extra sales from the safety vests contributed to the wholesale trade industry. In 2012, Lander University awarded a nearly $\$ 18,000$ contract to a South Carolina vendor to buy 
theater lighting fixtures and lamps. The $\$ 18,000$ sale added to the wholesale industry. The University of South Carolina bought cameras for its Law Enforcement and Safety Department from a resident vendor for $\$ 29,000$. A total of forty-one contracts (35\%) were attributed to the wholesale trade industry within the three-year period.

The second highest sector benefiting from procurement contracts is the manufacturing sector. Forty-two contracts were awarded to buy a South Carolina endproduct that was made, manufactured, or grown in South Carolina. According to the South Carolina Procurement Office, "Made means to assemble, fabricate, or process component parts into an end product, the value of which, assembly, fabrication, or processing is a substantial portion of the price of the end product. Manufactured means to make or process raw materials into an end product. Grown means to produce, cultivate, raise, or harvest timber, agricultural produce, or livestock on the land, or to cultivate, raise, catch, or harvest products or food from the water which results in an end product that is locally derived from the product cultivated, raised, caught, or harvested"'(South Carolina Budget and Control Board, 2009, p. 2).

Chart 4.4 (page 79) shows the names of the twelve manufacturing sectors and the percentage of total number of contracts that contributed to the various manufacturing industries. The twelve sectors are: miscellaneous manufacturing, printing and related support activities, computer and electronic product manufacturing, electrical equipment and appliance manufacturing, machinery manufacturing, furniture and related product manufacturing, other transportation equipment manufacturing, fabricated metal product manufacturing, primary metal manufacturing, paper 
manufacturing, wood product manufacturing, and petroleum and coal products manufacturing.

Thirty- nine percent of the manufacturing contracts were attributed to the miscellaneous manufacturing industry. For example, Midlands Technical College awarded a contract to buy dental workstations and dental equipment. The value of the contract was nearly $\$ 200,000$, and it contributed to the dental equipment and instruments manufacturing (miscellaneous manufacturing). The second highest manufacturing sector benefiting from procurement contracts was printing and related support activities. The Health and Environmental Control Department hired a resident vendor to print WIC food guide booklets. The contract, valued at $\$ 21,000$, was attributed to the printing industry. In 2011, the University of South Carolina awarded a contract to furnish and deliver Symetrix SymLink digital audio devices for $\$ 16,500$. The sales contributed to the computer and electronic product-manufacturing sector. In another example, in 2011, Francis Marion University bought portable concession stand stations for $\$ 26,304$, and this contributed to the furniture and related product manufacturing.

For the construction industry, state governments awarded 15 contracts that were based on preference policies for an average of $\$ 330,469$. The Vocational Rehabilitation Department awarded a contract to a South Carolina vendor for a loading dock area and paving improvements/repairs. In this case, the additional sales were added to the construction industry. In 2011, Juvenile Justice contracted with a resident contractor for dorm demolition, and this service was considered a contribution to the 
construction industry. The Transportation Department also awarded a $\$ 12,000$ contract to a resident vendor to install concrete piles.

In 2011, Trident Technical College awarded a contract to a resident vendor to buy multimeters for $\$ 225$, and the dollar value contributed to the retail sector. Coastal Carolina University awarded a contract to hire a resident contractor for landscaping services and paid $\$ 12,000$. This contract contributed to the administrative and support services industry. Midlands Technical College spent nearly $\$ 20,000$ for data processing, computer programming and software services by awarding the contract to a resident vendor. 
Table (4.1): Profile of Industries Benefiting from Procurement Contracts

\begin{tabular}{|l|c|c|}
\hline Name of the Industry & $\begin{array}{l}\text { Average } \\
(2010-2012)\end{array}$ & $\begin{array}{l}\text { Number of } \\
\text { the Contracts }\end{array}$ \\
\hline Wholesale Trade & $\$ 657,248$ & 41 \\
\hline Manufacturing & $\$ 412,090$ & 42 \\
\hline Construction & $\$ 330,469$ & 15 \\
\hline Administrative and Support and Waste Management and Remediation Services & $\$ 67,122$ & 8 \\
\hline Professional, Scientific, and Technical Services & $\$ 55,962$ & 6 \\
\hline Retail Trade & $\$ 17,456$ \\
\hline Other Services (except Public Administration) & $\$ 14,897$ \\
\hline Transportation and Warehousing & 2 \\
\hline Total & $\$ 10,994$ \\
\hline
\end{tabular}




\section{Chart (4.3): The Percentage of Procurement Contracts by Industry}

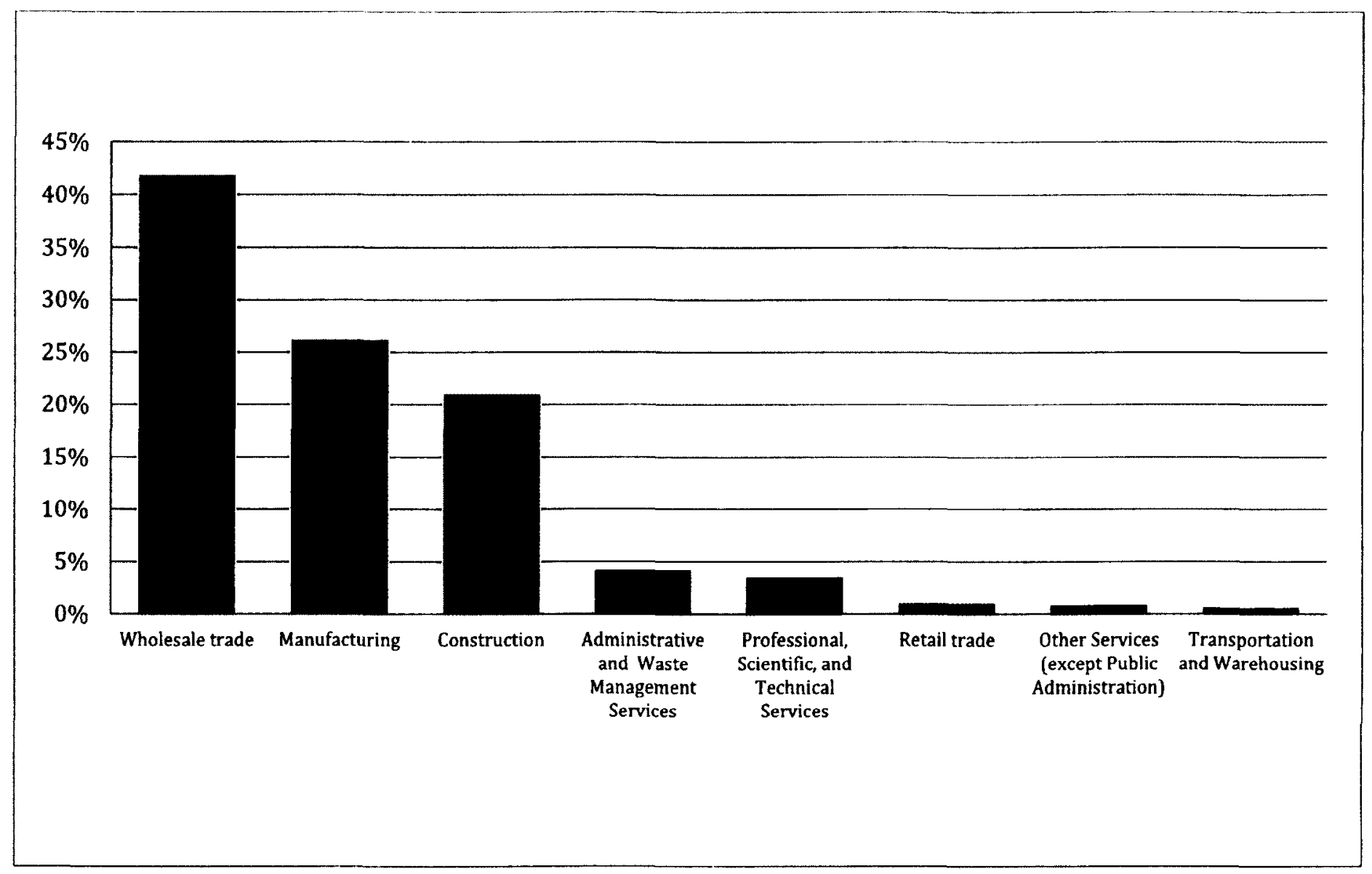


Chart (4.4) Manufacturing Sector

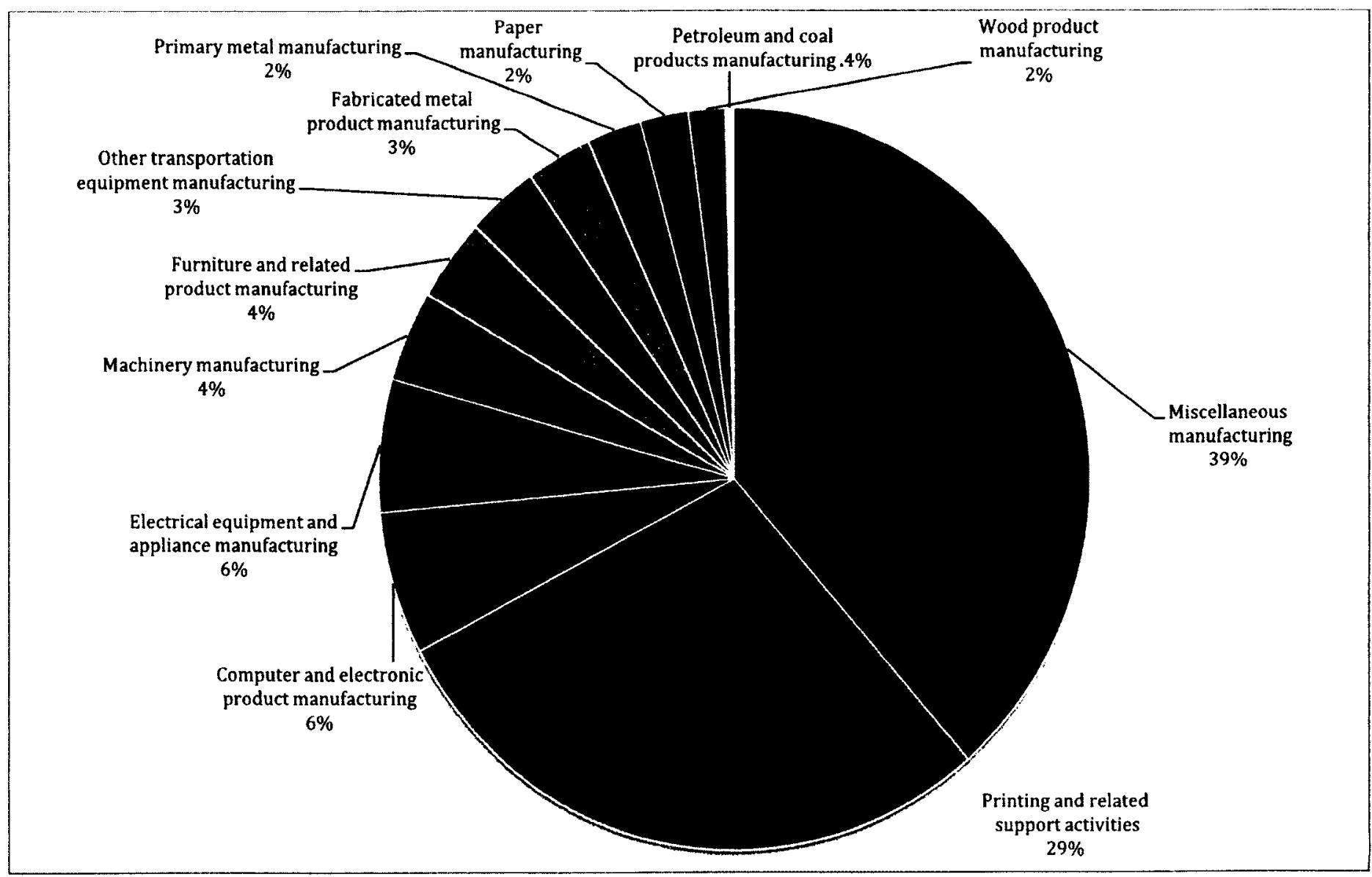


The Economic Impact Results

The researcher used the REMI PI+1.5.2, 70-sector, 1-region, model of the South Carolina economy to perform the impact study of the in-state preference policies. There are two main steps to study the effect of the preference policies on the economy and to obtain the results from REMI PIt. First, REMI Inc. developed the South Carolina version of the REMI PI+ model by using historical, estimated and forecasted data. The South Carolina REMI PI+ model contains the baseline value for all the economic indicators, which represents the values of the indicators without implementing the preference policy. Second, for each contract, the corresponding NAICS industry was determined, and the dollar values of the contracts were added to the model. Entering the dollar values of the contracts represents a shock in the economy and creates the alternative forecast for the model. The alternative forecast represents the value of the economic indicators when implementing the policy.

For each year, the difference between the baseline value and the alterative forecast represents the quantitative impact of the in-state preference policies (but without considering policy costs). If the difference between the baseline value and the alterative forecast is positive, the preference policies have a positive impact on the economy. If the difference between the baseline value and the alterative forecast is negative, the preference policies have a negative impact on the economy. If the difference between the baseline value and the alterative forecast is zero, the preference policies have no impact on the economy of South Carolina. 
The study uses seven economic indicators to measure the impact of the preference policies. These indicators are: total employment (includes the private nonfarm employment), output (business sales), value added, Gross State Product (GSP), personal income, real disposable personal income, and state's population.

After running the simulation, which is presented in detail in Chapter III, the results can be viewed in three different formats in the model. Each format represents a unique way to read the results. The discussion below consists of a combination of the three formats.

1. Difference: viewed as a numeric difference relative to the other forecast. In this research, difference represents the numeric difference between the baseline values (the control forecast) and the alternative forecast. Table 4.2 shows the results in "Difference" format.

2. Levels: gives the ability to view the actual numeric values for all the variables in the model. In this view, the numeric values for all the economic indicators with and without implementing the preference policies are provided. Charts $4.5,4.6$, $4.8,4.10-4.14$ illustrate the behavior of the main economic indicators. It is critical to mention that the above charts are drawn using 3-D line formatting, and the 3$D$ rotating is zero for the $X$ and $Z$ axis and ten for the $Y$ axis. Also, the chart perspective is ten. This type of formatting is used in order to show more clearly the small economic impacts of the in-state preference policies on the state economy. 
3. Percentage Change: viewed as a percentage change relative to another forecast (alternative forecast \% change compared to control forecast). Chart 4.15 shows the change in the economic indicators as a percentage of the estimated baseline.

The total quantitative impact of implementing the preference policies on the economic indicators is shown in Table 4.2. The increase or decrease in employment, personal income, GSP, output, value added and real disposable income measures the economic impact. All values in the table are positive which indicates an increase in the economic indicators as a result of implementing the preference policies. For the employment variable, the numeric values represent how many extra jobs are added to the economy. For GSP, output and real disposable income indicators, the numeric values represent how many extra dollars are added to the economy as a result of implementing the preference policies. The next section provides more details about each economic indicator. 
Table (4.2): Difference in Economic Indicators Compared to the Baseline Values

\begin{tabular}{|c|c|c|c|c|c|c|c|c|c|c|}
\hline Variable & Units & 2010 & 2011 & 2012 & 2013 & 2014 & 2015 & 2016 & 2017 & $\begin{array}{l}\text { Total of the } \\
\text { Differences }\end{array}$ \\
\hline Total Employment & Jobs & 14 & 18 & 24 & 18 & 17 & 16 & 15 & 14 & 135 \\
\hline $\begin{array}{c}\text { Private Non-Farm } \\
\text { Employment }\end{array}$ & Jobs & 12 & 16 & 21 & 16 & 15 & 14 & 13 & 12 & 119 \\
\hline Output/ Sale & Millions & 1.526 & 2.289 & 2.960 & 2.197 & 2.106 & 2.045 & 1.984 & 1.953 & 17.06 \\
\hline Personal Income & Millions & 0.595 & 0.839 & 1.175 & 0.961 & 0.961 & 0.992 & 1.007 & 0.992 & 7.52 \\
\hline $\begin{array}{l}\text { Real Disposable } \\
\text { Personal Income }\end{array}$ & Millions & 0.473 & 0.626 & 0.824 & 0.626 & 0.671 & 0.656 & 0.626 & 0.641 & 5.14 \\
\hline Gross State Product & Millions & 0.900 & 1.389 & 1.724 & 1.328 & 1.251 & 1.221 & 1.221 & 1.190 & 10.22 \\
\hline Value Added & Millions & 0.916 & 1.389 & 1.724 & 1.328 & 1.266 & 1.236 & 1.221 & 1.190 & 10.27 \\
\hline Population & People & 3 & 7 & 12 & 14 & 16 & 17 & 19 & 19 & 107 \\
\hline
\end{tabular}


The Economic Indicators

1. Employment:

REMI PI+ defines employment as "the number of jobs, full-time plus part-time, by place of work. Full-time and part-time jobs are counted at equal weight. Employees, sole proprietors, and active partners are included, but unpaid family workers and volunteers are not included" (REMI, 2013b, par 44). REMI adapted the Bureau of Economic Analysis's (BEA) definition of employment. According to the BEA's definition, the additional jobs "represented the number of "roster slots" available from business or government at the prevailing wage conditions during a time period". So, the definition of employment is a "labor demanded" concept rather than an idea of "how many people have a job" at a moment." (REMI, 2013a, p. 11).

Due to the sales increase from implementing in-state preference policies, employment is anticipated to increase above the baseline. In the REMI PI+ model, sales (output) and employment are connected because output influences private non-farm employment. As shown in Table 4.2, increased sales contributed 14, 18 and 24 jobs in $2010,2011, \& 2012$ to the economy of the state. The total increase in employment within the next 5 years (2013-2017) is 79 job-years greater than the baseline. REMI estimates that there are 135 more job-years available and occupied than in the baseline during the 8 years of the study. Table 4.2 also shows that on average more than $80 \%$ of the additional jobs were added to private industries. 
It is critical to emphasize the importance of interpreting the employment results correctly; the total employment in 2010 is 14 jobs greater than the baseline values. These jobs might be 14 new jobs starting in 2010 or 14 "more people have a job (when accounting for people who work multiple jobs or commute in or out of [South Carolina] for work), but it did mean there was more work in the state to such degree" (REMI, 2013a, p. 11).

Chart 4.5 shows the total employment impact to South Carolina between implementing and not implementing preference policies. The dashed line shows the total number of jobs in the state of South Carolina without implementing the preference policies. The solid line shows the total number of jobs in the state of South Carolina with implementing the preference policies. When South Carolina government agencies award preference contracts to South Carolina firms, the sales of the firms increase, and they need to hire more workers to increase production. For South Carolina the extra dollars generated additional jobs in the state. Furthermore, Chart 4.6 compares private non-farm employment before and after implementing the preference policies.

In addition to the number of jobs, the model provides employment by industrylevel within the private non-farm sector. Chart 4.7 shows that workers were able to work in the occupations demanded mainly by the following industries: construction, manufacturing, retail trade, wholesale trade, professional, scientific, and technical services, and administrative and waste management services. Twenty-five percent of the private non-farm jobs are in the construction industry, and $23 \%$ of the private nonfarm jobs are in the wholesale trade industry. 


\section{Chart (4.5): Employment}

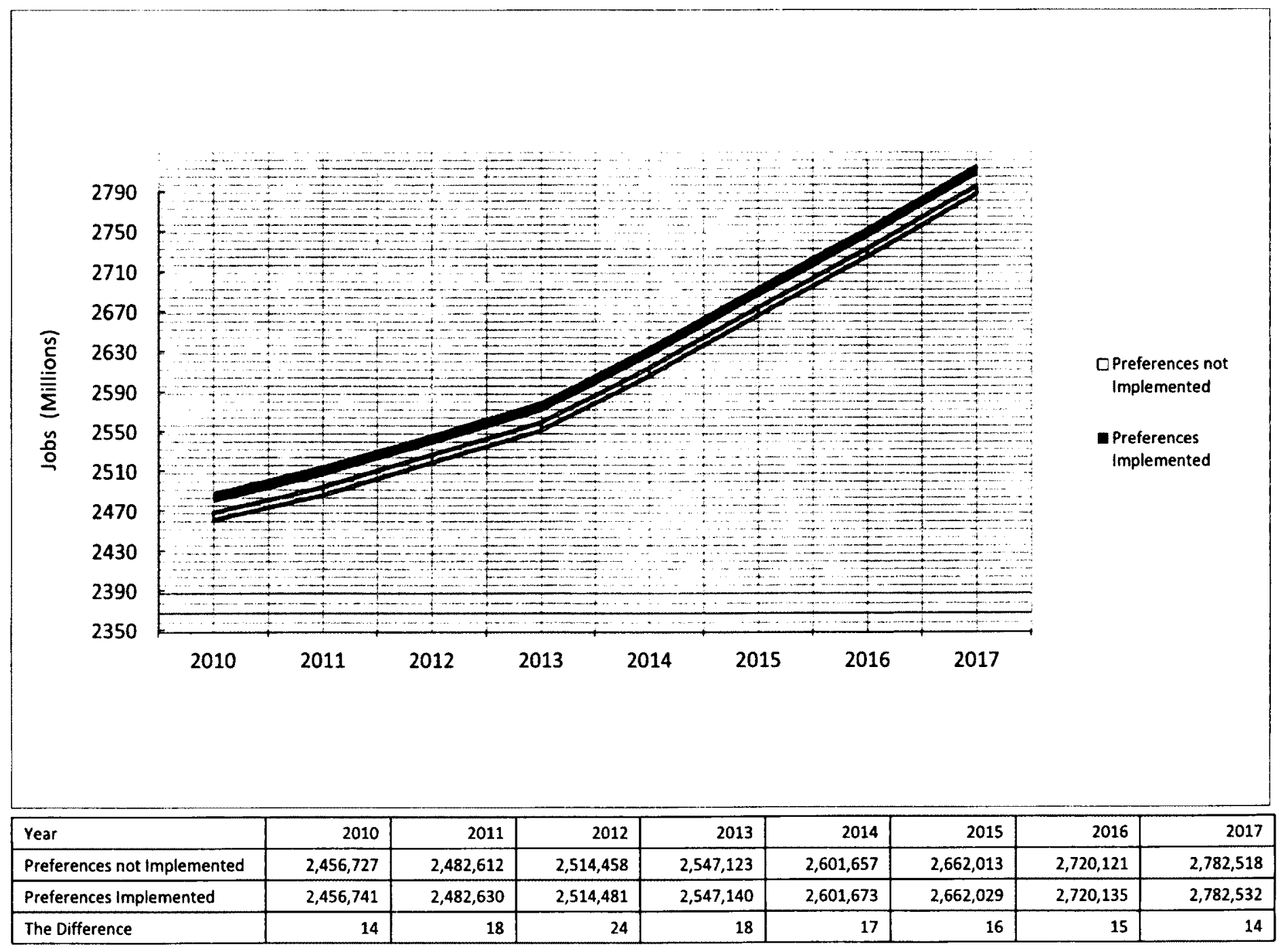




\section{Chart (4.6): Private Non-Farm Employment}

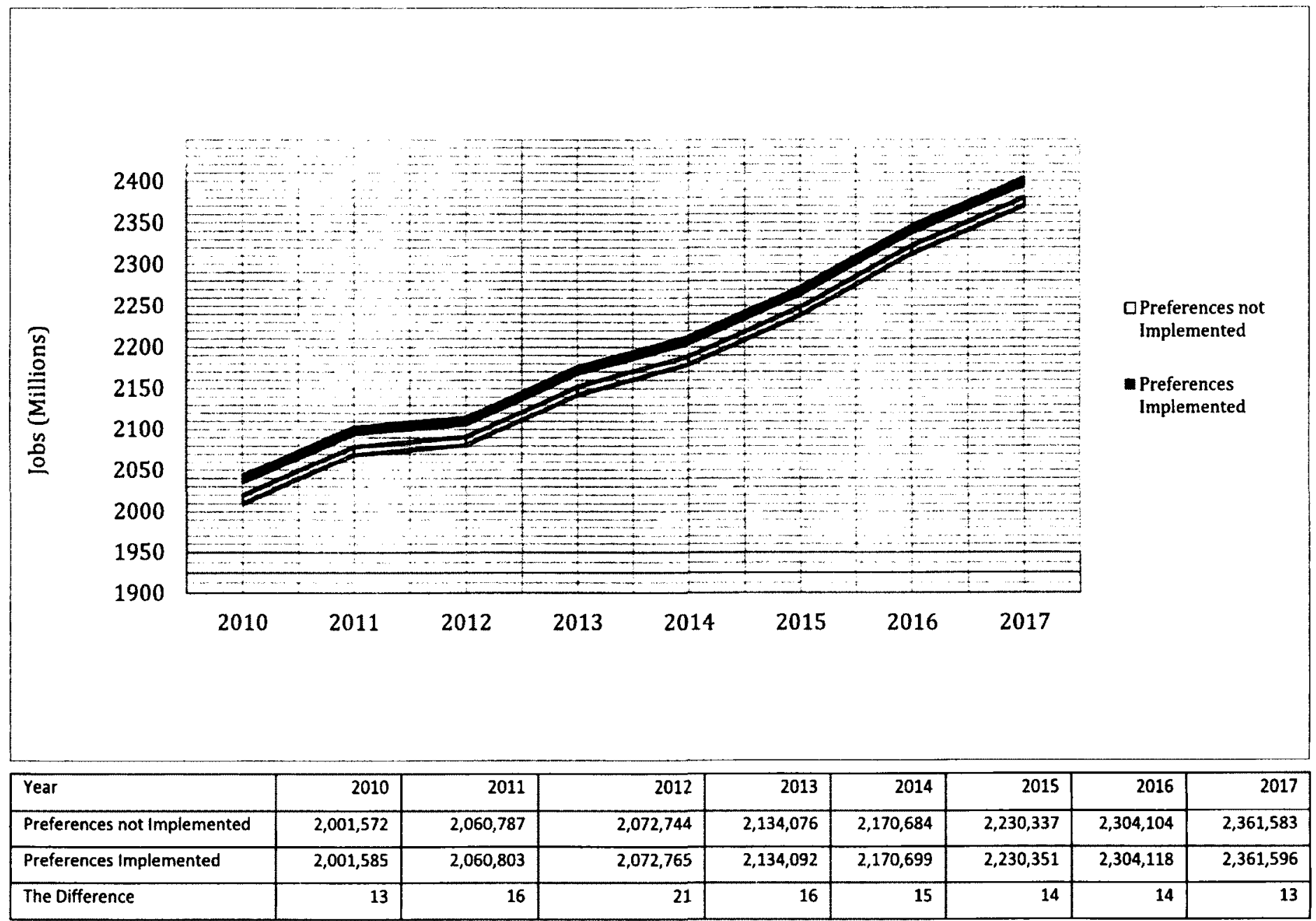




\section{Chart (4.7): Total Jobs by Industry}

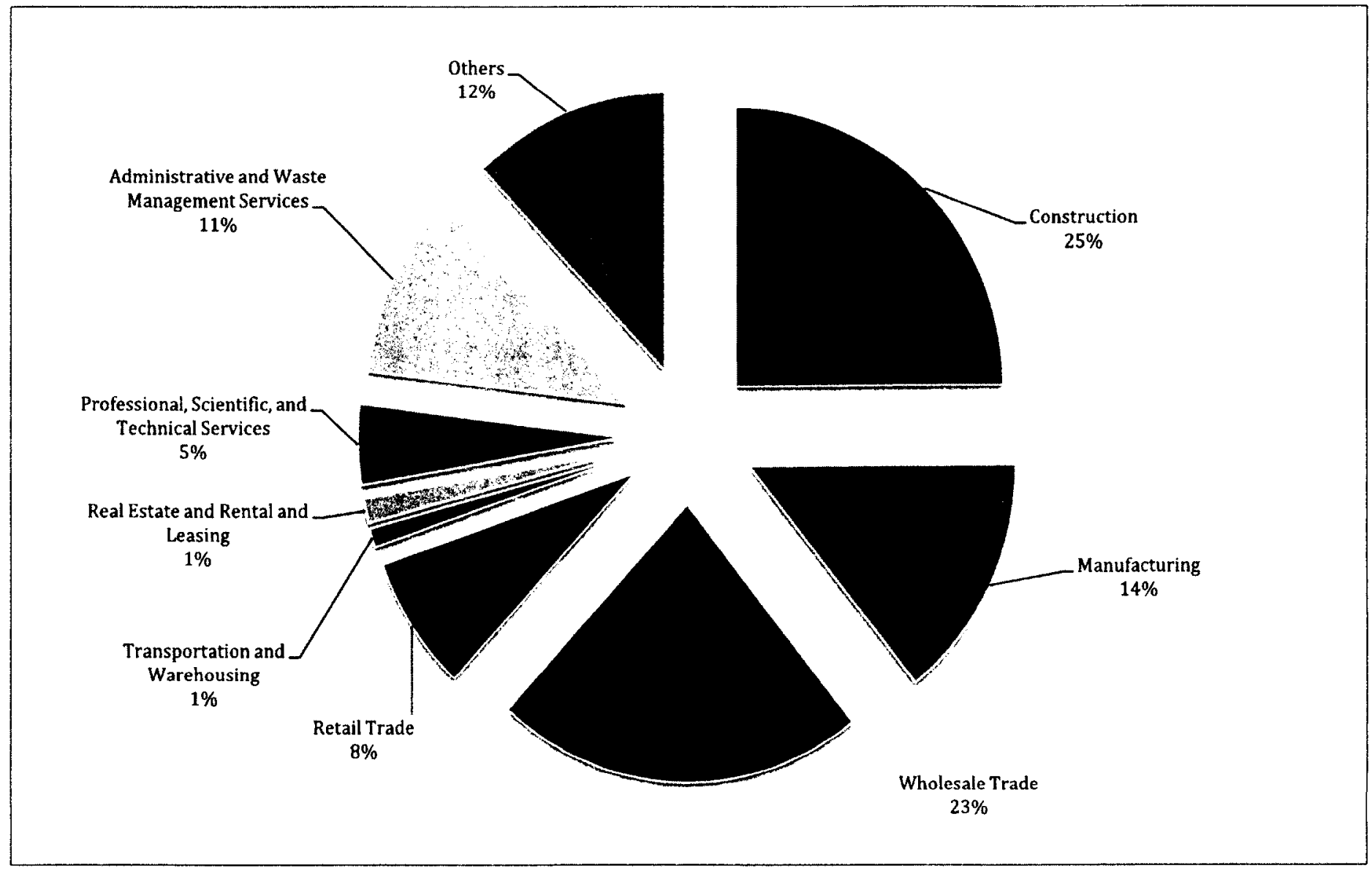


2. Total Output:

Output is "the sum of output for private non-farm industries, state and local government, federal civilian, federal military, and farm sectors" (REMI, 2013b, par 150). It is basically the additional sales or total production that was generated within the state because preference policies were implemented when awarding the contract to state vendors. The results show that when the contracts were awarded to in-state vendors, the sales /output for some industries increased by $\$ 1.5$ million in 2010 over the baseline simulation (the sales without implementing the preference policies), and are predicted to continue to increase on average by $\$ 2.1$ million for each year from 2010 until 2017 (see Table 4.2).

Chart 4.8 shows that the output impact for a variety of industries increased after implementing preference policies. The dashed line shows the total output in the state of South Carolina without implementing the preference policies. The solid line shows the total output in the state of South Carolina with implementing the preference policies. In 2012 , industry sales were $\$ 307.221$ billion (the baseline value); after implementing the preference policies, the output was $\$ 307.224$ billion. Therefore, the increase was estimated to be around three million dollars in 2012 . The total increase in sales within the eight-year period is expected to be around $\$ 17$ million.

As shown in Chart 4.9, the benefits of implementing the preference policies were concentrated in the industries related to wholesale trade, construction, and manufacturing. Sales in the wholesale trade industry increased the most during the eight years because of implementing the preference policies; it increased by $\$ 5.2$ million 
and represents $33.5 \%$ of the sales increase. While manufacturing and construction sales increased by $25 \%$ and $17 \%$ respectively during the eight-year period, all other sectors showed a sales increase of less than $6 \%$. The other industries in Chart 4.9 represent management of companies and enterprises, arts, entertainment and recreation, educational services, forestry, fishing and related activities, and mining. 


\section{Chart (4.8): Sales/ Output}

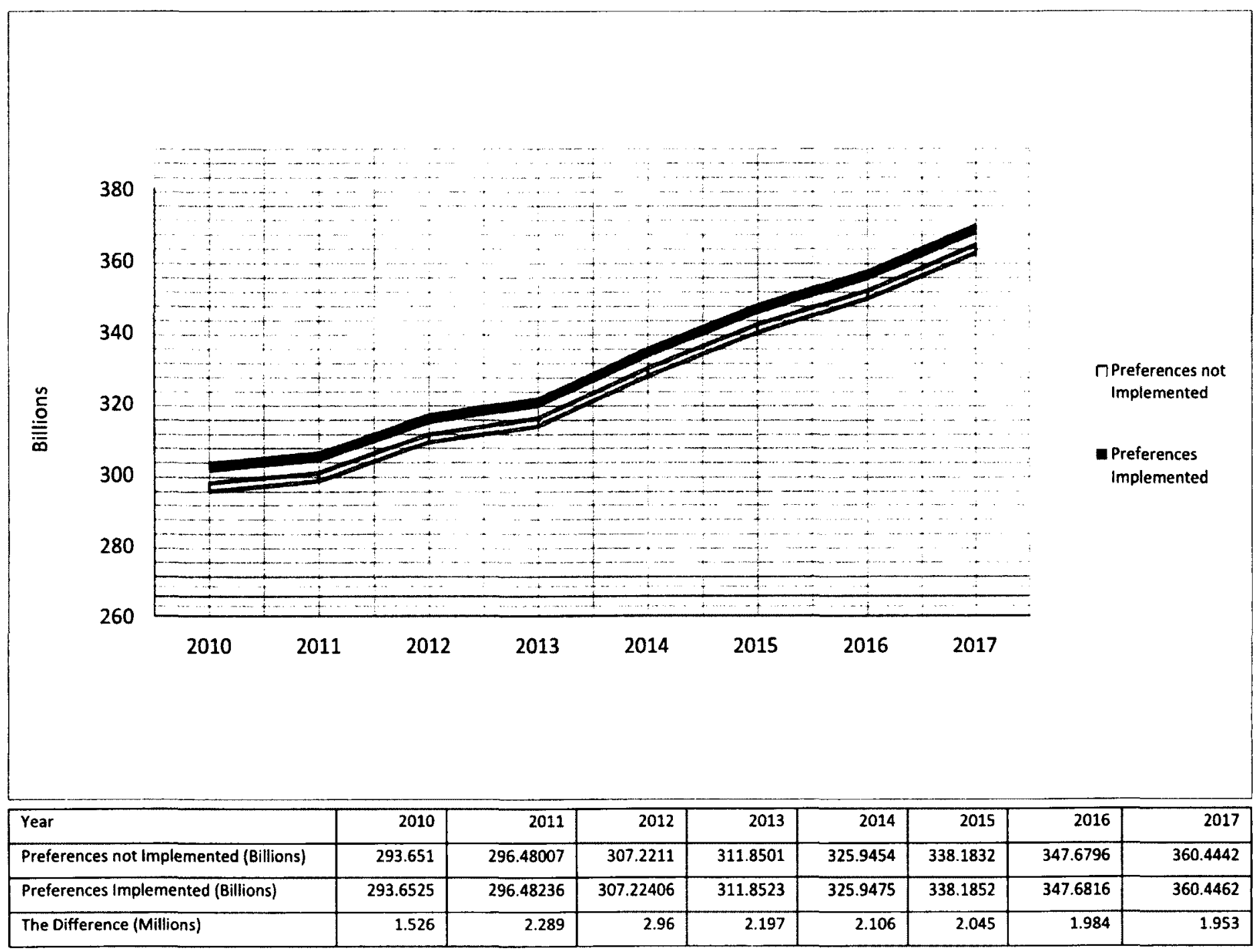


Chart (4.9): Sales by Industry

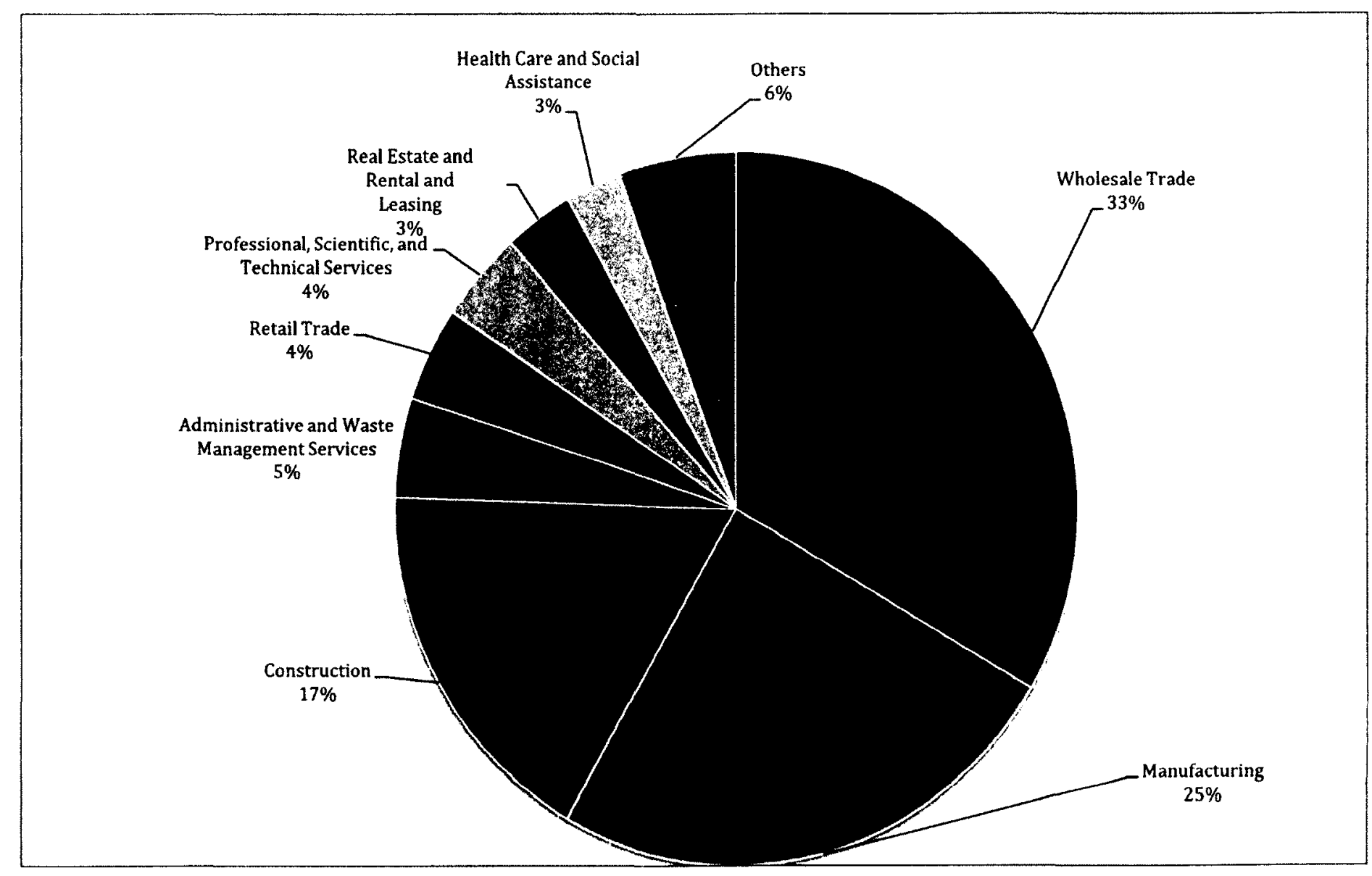


3. Value Added:

Value added represents " a measure of the contribution of each private industry and of government to a region's Gross Domestic Product" (REMI, 2013b, par 238). It represents the difference between industry's gross output (sales, commodity taxes and inventory change) minus its intermediate inputs (energy, raw materials, semi-finished goods and services that are purchased from domestic industries or from foreign resources). Demand affects the value added variable, so the value added variable increases as a result of an increase in demand. As Table (4.2) shows value added increased by $\$ .91, \$ 1.4, \$ 1.7$, and $\$ 1.3$ million for the years $2010,2011,2012,2013$ respectively, and increased by $\$ 1.2$ million for the years $2014-2017$. The state gained $\$ 10.27$ million in value added when implementing the preference policies.

Chart 4.10 shows the value added variable over the eight-year period. The dashed line shows the total value added in the state of South Carolina without implementing the preference policies. The solid line shows the total value added in the state of South Carolina with implementing the preference policies. The value added increased on average by $\$ 1.3$ million yearly. In 2012 , the value added baseline was $\$ 172.4546$ billion and the alternative forecast was $\$ 172.4563$ billion, so the difference between the baseline and the forecast represented the impact of implementing the preference policies; in this case, the difference for 2012 was $\$ 1.7$ million. 
Chart (4.10): Value Added

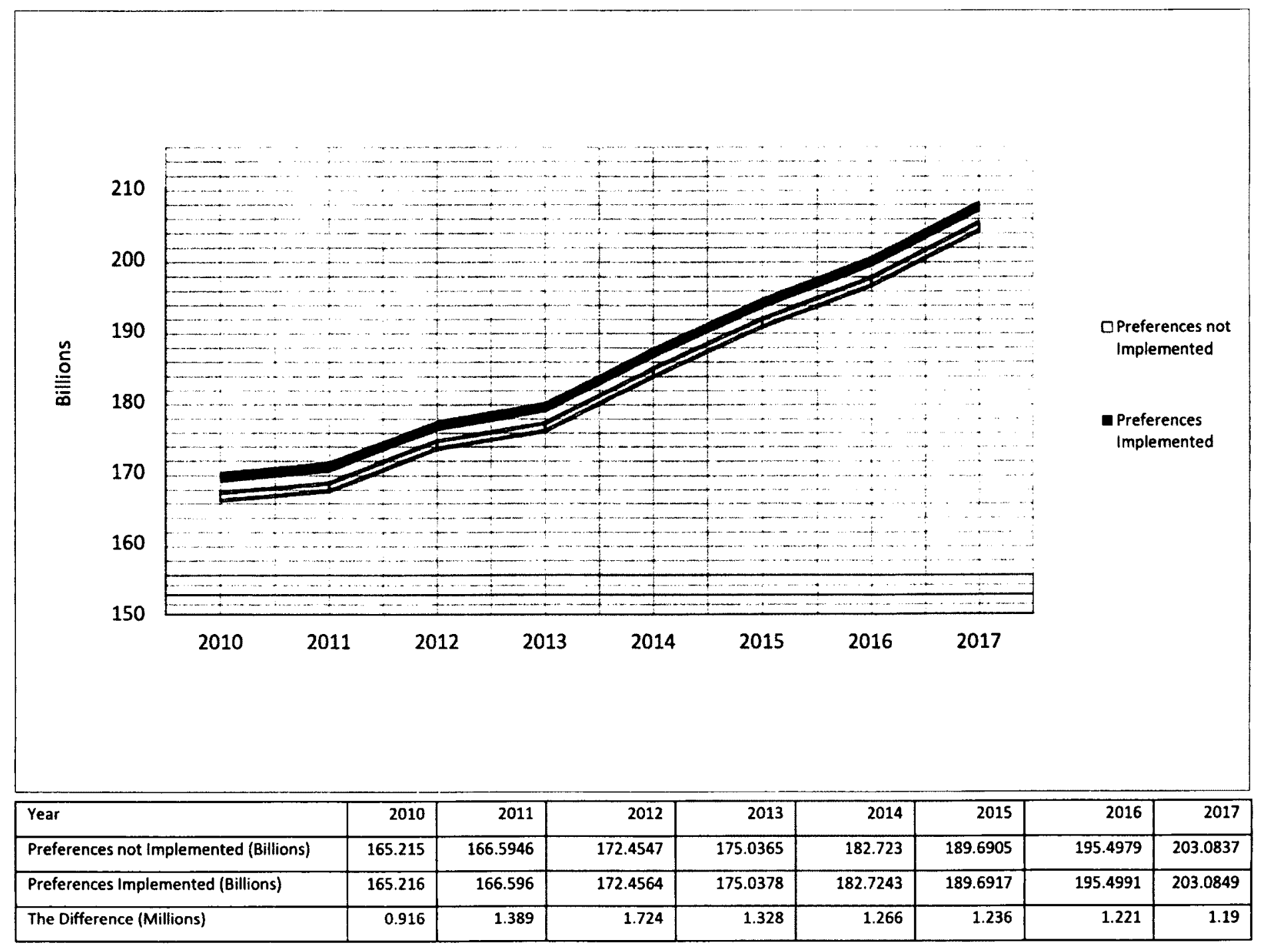


4. Gross State Product (GSP):

GSP represents "a comprehensive measure of economic activity in a state, and can provide important information about regional economic health" (Weber, 1979, p. 217). As Table (4.2) shows, in 2011, the economic impact of the in-state preference increased South Carolina GSP by $\$ 1.4$ million. In 2012 , the preference policies contributed $\$ 1.7$ million to GSP, which equals a $0.15 \%$ increase in GSP. When government awards the contracts to in-state vendors and buys their products, the demand for the products increases and as a result the GSP increases. The total estimated impact of the policy on GSP from 2010- 2017 is the summation of the difference between the baseline values and the alternative forecast values over the eight years of study. In this case, the sum of the impacts from 2010 through 2017 for GSP is $\$ 10.22$ million.

Chart 4.11 shows the GSP impact in South Carolina from implementing the preference policies. The change in GSP is similar to the change in employment. The difference between the dashed line (the baseline) and the solid line (the alternative forecast) represents the impact of the preference policies. When South Carolina government agencies award the preference contract to a South Carolina vendor, the extra dollars generated a positive impact in the state in terms of GSP. 


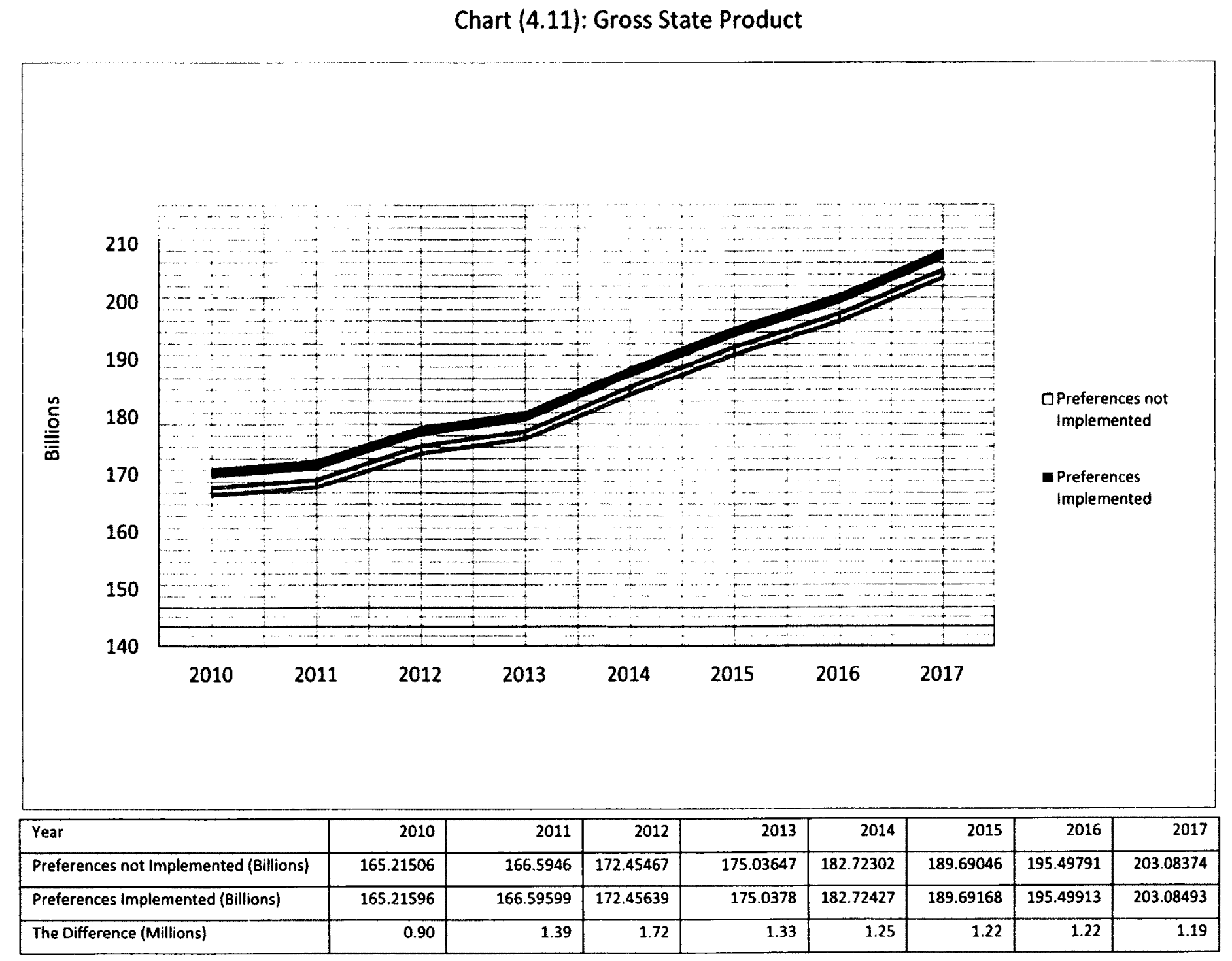


5. Personal Income:

Personal Income represents the "Income received by persons from all sources. It includes income received from participation in production as well as from government and business transfer payments. It is the sum of compensation of employees (received), supplements to wages and salaries, proprietors' income with inventory valuation adjustment (IVA) and capital consumption adjustment (CCAdj), rental income of persons with CCAdj, personal income receipts on assets, and personal current transfer receipts, less contributions for government social insurance" (REMI, 2013b, par 154). As Table 4.2 illustrates, on average personal income increased by one million dollars. In total, $\$ 7.52$ million was added to the economy as a result of implementing the preferences. Chart 4.12 shows the personal income associated with implementing the preference policies in South Carolina. It follows the same trend as employment. When South Carolina government agencies award a preference contract to a South Carolina vendor, the extra dollars generate more personal income.

6. Real Disposable Income:

Real disposable income reflects "total after-tax income received by persons; it is the income available to persons for spending or saving" (REMI, 2013b, par 169). Since output increases along with a rise in employment, real disposable personal income is estimated to increase. As a result of implementing the in-state preference, the annual real disposable personal income was estimated to increase about $\$ 5.14$ million during the years 2010 and 2017 (Table 4.2). Chart 4.13 shows trends similar to the personal income variable. 


\section{Chart (4.12): Personal Income}

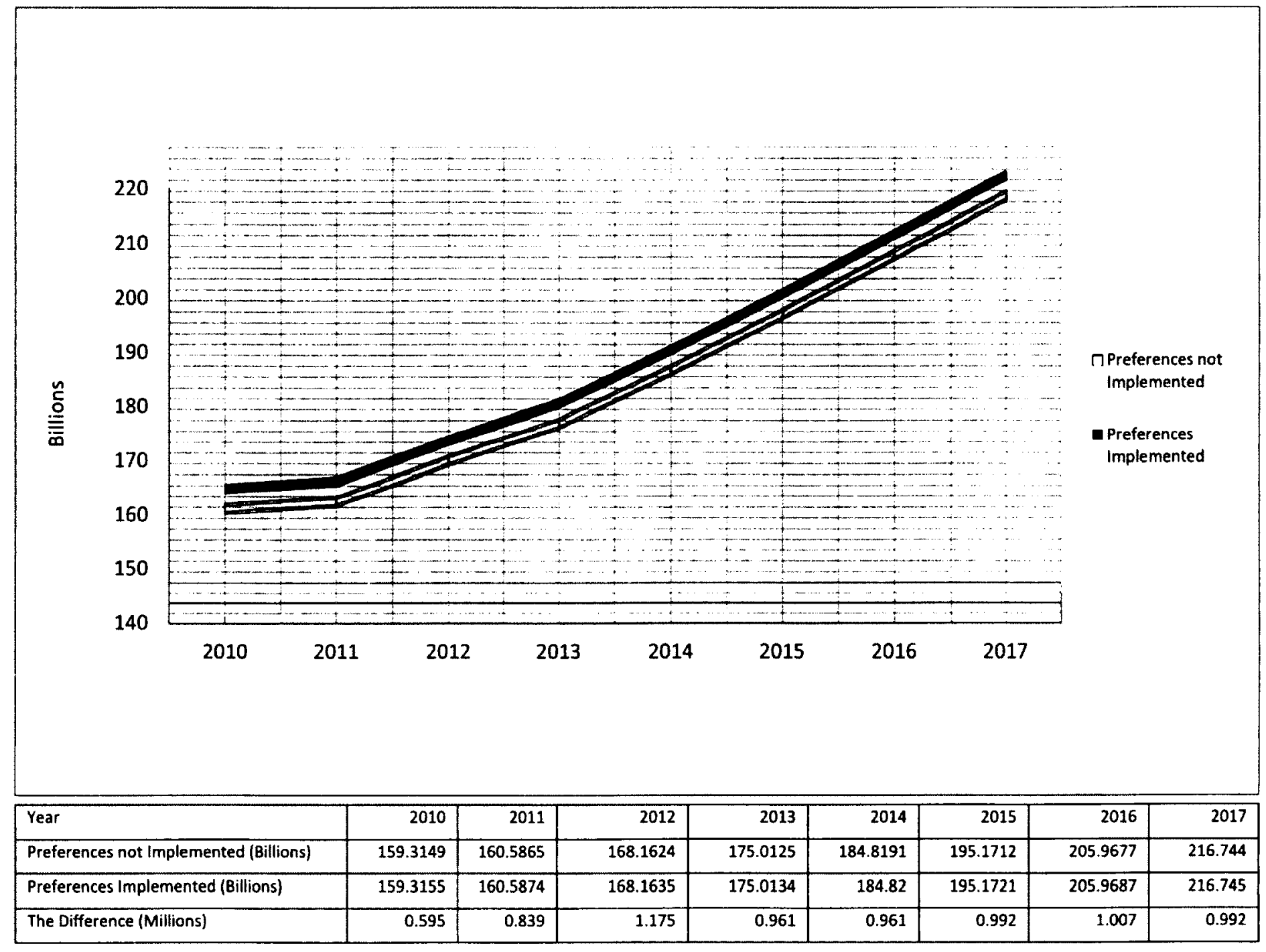




\section{Chart (4.13): Real Disposable Personal Income}

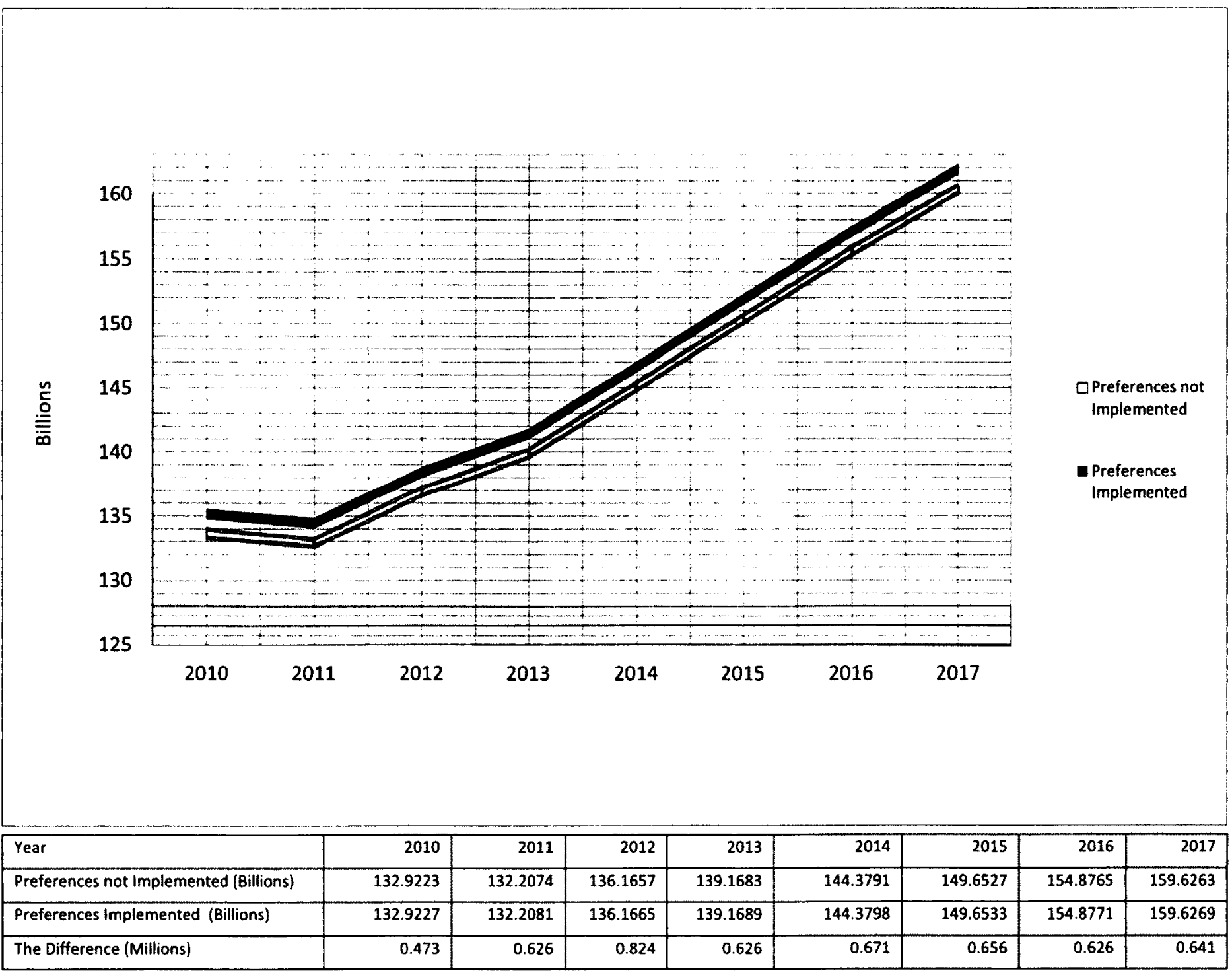


7. Population:

"Population reflects mid-year estimates of people, including survivors from the previous year, births, special populations, and three types of migrants (economic, international, and retired)" (REMI, 2013b, par 158). Workers might relocate if they find a job with higher wages somewhere else and migrate from one area to another. As Table (4.2) shows, the population of the state increased by only seven people in 2011 as a result of implementing the preference policies. With time, more people might move to the state; three people moved to the state in 2010 and an additional 19 people are expected to move in 2017. On average, population is predicted to increase by approximately 13 people yearly.

Chart 4.14 shows the population of the state variable over the eight-year period. The dashed line shows the population in the state of South Carolina without implementing the preference policies. The solid line shows the population of the state with implementing the preference policies. The population increased on average by 13 people yearly. For example, in 2016 , the population is estimated to be $4,850,119$ and the forecast was $4,850,138$. The difference between the baseline and the forecast represents the number of people who might relocate to the state to work in jobs as a result of implementing the preference policies, and in this case, that is 19 people. Therefore, along with the economic impacts associated with job growth, income, value added, and GSP, it is estimated that there would be a small effect on the state's population. 


\section{Chart (4.14): Population}

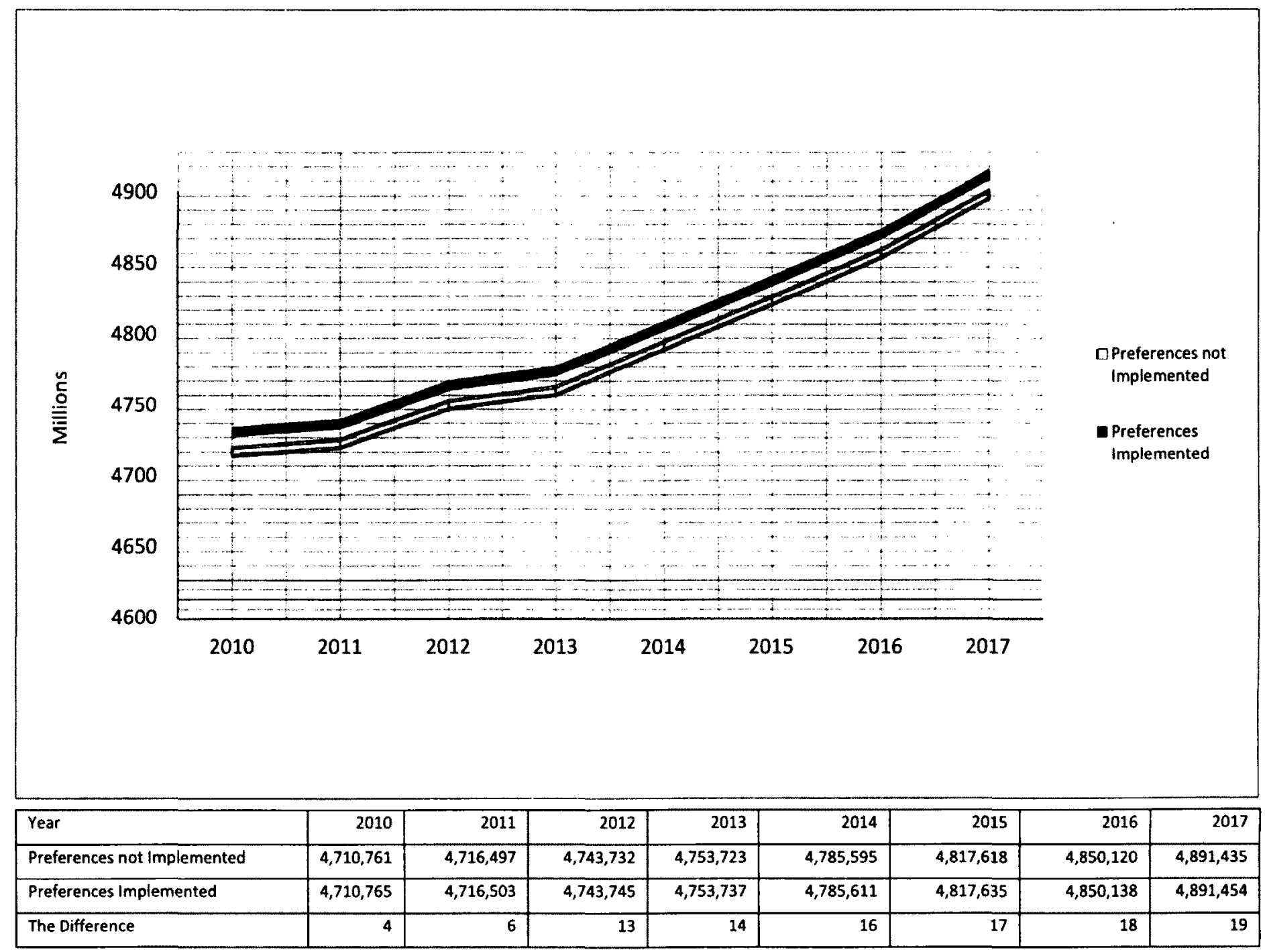


Chart (4.15) presents the percentage change of the main economic indicators in this study. As mentioned earlier in this chapter, the percentage change for every variable represents the percentage changes from the baseline values. These percentages indicate the extent to which the economic indicators increased, decreased, or remained the same as a result of implementing the preference policies. They also indicate if the impacts on the economy are considered large or small compared to the baseline. As shown in Table (4.2), implementing the preference policies contributed positively to the economy of the state. However, as shown in Chart (4.15), the percentage changes are relatively small.

The trend of the percentage impact is similar for all the economic indicators. The percentage impact increased in 2010 and 2011 and reached the highest percentage $(.001 \%)$ in 2014, but then the percentage decreased for all the economic indicators, except for the state's population, until 2017. For example, the percentage change in employment variable was nearly $.0006 \%$ in 2010 , increased to $.001 \%$ in 2012 and decreased to $.0005 \%$ by 2017 . Except for the state's population, the percentage impacts on personal income and real disposable income were lower than the other economic indicators. The percentage impact was around $.0004 \%$ for the eight-year period, except in 2012 when it was around .0006\%. 
Chart (4.15): Percentage Change

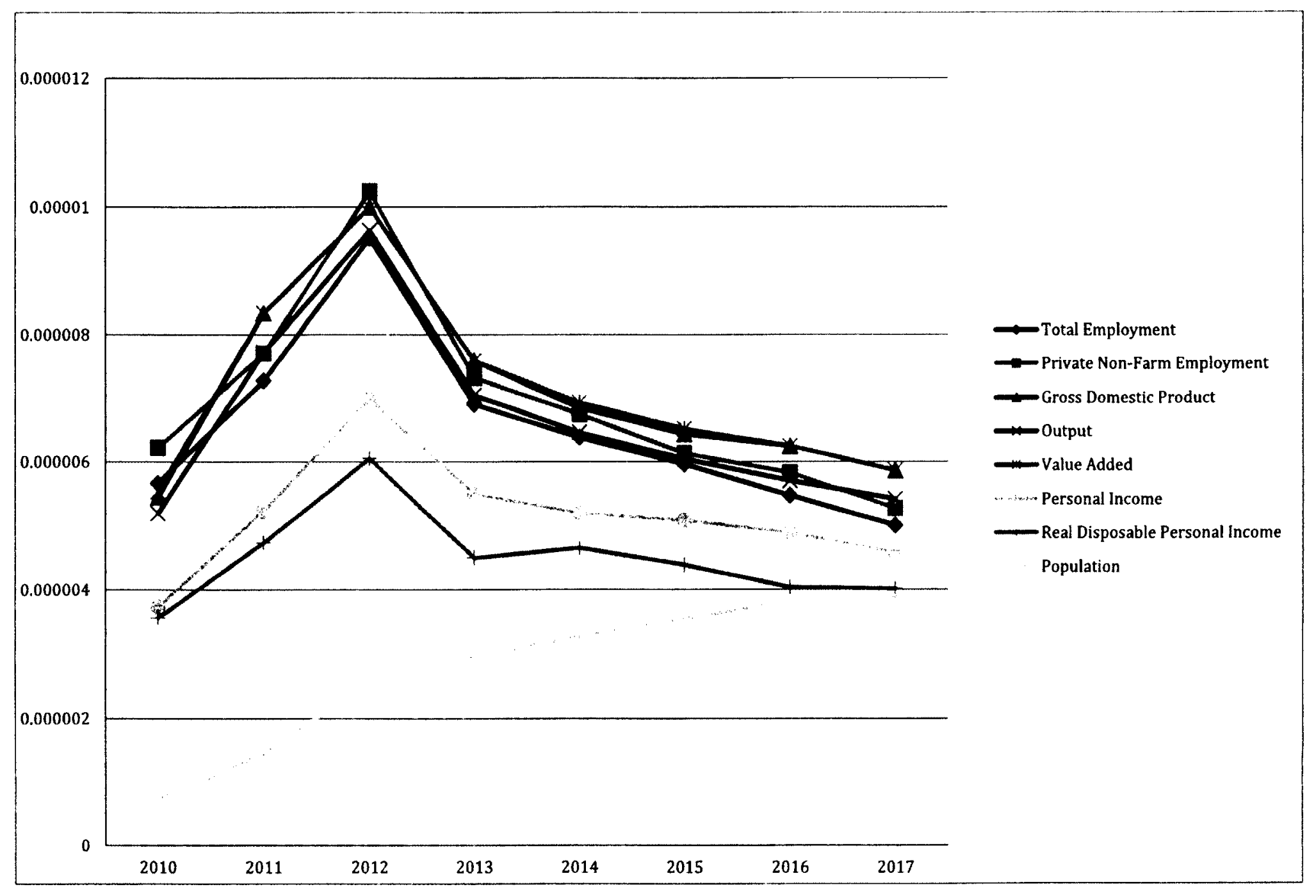




\section{Summary}

The previous sections in this chapter presented the results of this economic impact study. The impact is measured by the differences in the values of economic indicators with and without implementing the preference policies. Because the impact of the preference policies differs by industry, the sales (the dollar value of the contracts) are compiled into the North American Industry Classification System (NAICS), and then the dollar value of the contracts (output/ sales) awarded to South Carolina firms given the in-state preference policy was input into the model. REMI reported seven main economic indicators: employment, output/sales, personal income, real disposable income, Gross State Product (GSP), value added, and state's population.

As a result of implementing the in-state preference, 135 job-years are estimated to be added to the South Carolina economy with more than $80 \%$ of these jobs added to the private non-farm industries. Most of the jobs are in the construction (25\%), wholesale trade (23\%), and manufacturing (14\%) industries. Real disposable personal income is estimated to increase by $\$ 5.14$ million between 2010 and 2017 , and the South Carolina economy is estimated to gain $\$ 10.22$ million in GSP from 2010 through 2017. Sales are estimated to increase on average by $\$ 2.1$ million from 2010 through 2017 (total $\$ 17$ million). The sales benefits were concentrated in industries related to manufacturing, wholesale trade, construction, and administrative support services. The state gained $\$ 10.27$ million in value added when implementing the preference policies. 
Even though these benefits are relatively small compared to the size of South Carolina's economy, they outweigh the $\$ 179,332$ of preference costs, which represent the extra dollars that government pays when they award the contracts based on preferences. In conclusion, the results showed that the values of the economic indicators are positive and represent the estimated contributions to the state economy. Chapter IV presented details of how the sales from 118 contracts were classified within the NAICS system as well as a detailed explanation of the profiles of state government agencies, industries benefiting from procurement contracts, and the various preference types. The chapter concluded with a presentation of the values of the economic indicators and a summary of the results. 
Chapter V

Conclusion

This research examined the impact of in-state preference policies on the economy of South Carolina. Chapter IV discussed the data preparation, reported the profiles of state government agencies, preference types, and industries benefiting from procurement contracts, and presented the results of the economic impact on the state economy. The economic impact is measured using seven indicators: output (business sales), total employment (includes the private non-farm employment), real disposable personal income, Gross State Product (GSP), value added, personal income, and state's population. This chapter reports a summary of the research and the research results and presents study implications, limitations and delimitations of the study, and future research.

Summary of the Research

State governments have adopted a variety of procurement preference policies to achieve a variety of social, political and economic goals. This study focused on the economic goals by investigating the economic impact of implementing in-state preference policies on the economy of South Carolina. In-state preference policies promote state businesses and help them remain in their home state. According to economic theory, as a result of adding extra money to the economy, the preference 
policies would generate more jobs and an increase in production, sales, income and population. To investigate the benefits of implementing the preference policies, international trade theory was used as a guiding framework in this study.

Within the context of international trade, governments provide social, political, and economic arguments to justify their intervention in trade. Reviewing the literature revealed that the rationale for adopting procurement preference policies in the domestic context is similar to the rationale presented in support of government intervention in international trade. A significant amount of research has investigated the impact that protectionist instruments such as tariffs, import quotas, subsidies, and formal policies might have on a country's economy and trade, but the results from the research were not consistent. Deardorff and Stern (1981) and Lowinger (1976) used input-output models to analyze the impact of discriminatory policies on the economy of U.S., U.K. and EU member countries; Baldwin (1982), Breton and Salmon (1996) and Herander (1982) used supply-demand equations to estimate the impact of the Buy American Act on imports, output, and domestic prices, and a computable general equilibrium model was used by Herander (1982) to investigate the impact of government price discrimination and tariffs. Scholars showed that protectionist instruments might have some benefits to the economy, but there are costs associated with these benefits, and most of the time, the benefits are not large enough to outweigh the costs. 
Within the state context, state governments enact in-state preference policies hoping to help their own economy by increasing economic growth and bringing economic benefits to the state. However, there is a lack of research to prove these economic benefits. This research attempted to provide empirical evidence by answering the following research question: what are the impacts of implementing the in-state procurement preference policies on the economy of the state of South Carolina?

To estimate the economic impact of the South Carolina preference policies on the state economy, the Regional Economic Model Policy Insight (REMI PI+) was utilized in this study. REMI PI+ represents a traditional way to measure the impact of a variety of policies and programs. REMI PI+ consists of embedded mathematical equations that explain the relationships and the linkages among a variety of economic variables. The embedded relationships within these models trace the economic impacts generated by increasing sales as a result of implementing preference policies.

The REMI model is composed of three main components, which economists have used separately in impact studies involving international trade. Since trade theory was used as an overarching theory in this research, it seemed appropriate to select REMI as a research tool. Moreover, many scholars, researchers, practitioners and professionals from several private, public and nonprofit organizations have used REMI PI+ for over thirty years. Scholars have applied REMI to study a variety of policy issues at the state level. For example, Florida state used the model to investigate the impacts of the Florida Energy and Climate Change Action Plan (FECCAP) on the state's economy (Rose \& Wei, 2012) while in Michigan, the model was used to analyze the macroeconomic impact of 
the Michigan Climate Action Plan (Miller et al., 2010). Pennsylvania used the model to evaluate the impacts of the Pennsylvania Climate Action Plan on the state's economy for the period of 2009-2020 (Rose et al., 2011). However, although the repeated use of the model over time has established confidence in its reliability, there are some limitations in its use. These limitations are discussed later in this chapter.

In this study, South Carolina's version of the PI+ was applied to analyze the economic impacts of in-state preference policies on the economy of the state from 2010 through 2012 and to forecast the trends from 2013 to 2017. The overall structure of the REMI PI+ is divided into five major blocks, namely, output and demand, labor and capital demand, population and labor force, wages, prices, and profits, and market shares. The economic impacts were determined by measuring the most commonly reported economic indicators: output (business sales), total employment (includes the private non-farm employment), personal income, real disposable personal income, Gross State Product (GSP), value added, and state's population.

Two types of secondary data were used: 1) the values of the economic variables which were represented in all the underlying economic linkages, equations and estimated relationships of the economic structure in the PI+. This data were collected from the Bureau of Economic Analysis, the Bureau of Labor Statistics, and County Business Patterns. 2) quarterly procurement preference reports. The Procurement Services Office in South Carolina provided quarterly procurement preference reports each of which included the names of the South Carolina agencies that have awarded the 
contracts, the solicitation numbers, descriptions, NIGP commodity codes, lowest response amount, award amount, preference expenses, and preference categories.

To measure the economic indicators, REMI PI+ factors in the specific industry that each contract complies with, and therefore, the industry sector for each contract was identified to comply with NAICS. The dollar values of the contracts were added to the model before the researcher ran the simulation and generated the results. The results are presented in detail in the previous chapter, and they are presented briefly in the next section of this chapter.

\section{Summary of the Results}

This study assessed the economic impact of in-state preference policies using REMI PIt. A customized version of REMI PI+ model was developed for the state of South Carolina. Before running REMI, the researcher analyzed not only the profile of state government agencies that implement preference policies but also the preference types that were claimed by the vendors as well as the industries benefiting from procurement contracts.

Almost $31 \%$ of South Carolina government agencies have implemented the preference policies, and they award contracts mainly to buy products and services related to wholesale trade, manufacturing, and construction. Vendors, when bidding on contracts, claimed a variety of preference policies. Thirty-four percent of the vendors claimed that they qualified for resident vendor and South Carolina end-product 
preference. Twenty-seven percent of the vendors proved that they qualified for the resident vendor preference policy and twenty-nine percent of the contracts were awarded based on resident vendor and US end product. Less than $6 \%$ of the contracts were awarded based on resident contractor and subcontractor preferences and South Carolina end-product preferences.

The results from running the REMI model represent the quantitative difference between the baseline values and the alternative forecast values. The baseline values show the numerical values of the economic indicators before implementing the in-state preference policies. The alternative forecast values show the numerical values of the economic indicators after implementing the in-state preference policies. The difference between the baseline forecast and the alternative forecast could be positive, negative, or zero. If the difference is positive, implementing the in-state preference policies contributes positively to the state economy. If the difference is negative, implementing the in-state preference policies hurts the state economy, and if the difference is zero, implementing the in-state preference policies has no impact on the state economy.

Table (4.2) showed the expected amount of increase in the economic indicators due to the simulated economic shocks. The shock represents the extra sales that were added to the economy as a result of implementing the preference policies. The economic impact of implementing preference policies was $\$ 17$ million in total industry output (sales) over 8 years. On average the output increased by $\$ 2.1$ million from 2010 until 2017. In terms of sales, the wholesale industry's output increased the most compared with the other industries (34\%). The manufacturing and construction 
industries accounted for $25 \%$ and $17 \%$ of total sales and the value-added impact was \$10.27 million dollars.

Implementing preference policies also impacted total employment which increased by 135 job-years. Eighty percent of those total jobs (119 jobs) were in private industries, and they mainly appeared in the construction, wholesale trade, manufacturing, and administrative and waste management industries. The construction and wholesale trade industries were the largest component in terms of employment 30 jobs and 27 jobs respectively) followed by the manufacturing, and administrative and waste management industries (17 and 13 jobs respectively). Over 100 people were predicted to relocate to the state within the next 8 years and should that be the case there could be a gain of $\$ 5.14$ million in real disposable personal income.

\section{Policy Implications}

The results of this study showed that the numeric values of the economic indicators, which are GSP, employment, personal income, real disposable income, state's population, value added, and output, all increased when the state implemented the in-state preference policies. It is important to discuss the implications of implementing the preference policies on South Carolina, however, this research does not support a specific decision related to in-state preference policies for South Carolina. 
The findings have important implications for voters, taxpayers, public administrators, and policy makers. Voters and taxpayers are concerned about the effective use of their money by government. They want government to do great things for them and the society (Dye, 2012). Governments have the obligation to maximize the use of taxpayers' money, and in the case of in-state preference policies, governments spend more money when they award these policies. Citizens want to be informed about the impact of paying the extra money and have enough knowledge to understand government actions. The results from this study can help voters and taxpayers keep an eye on the impact of preference policies.

Furthermore, policymakers frequently enact policies to address an issue but, not in all cases, can they predict the consequences of implementing the policy. This study might help policymakers to confirm the need to continue the policy, to stop implementing the policy, and/ or to change the policy to make it more beneficial. The positive results indicate that the preference policies are beneficial to the state, but the volume/scale of the impacts could be large or small depending on the cost of implementing the preference policies. Policymakers and public officials should give more attention to the costs associated with implementing the preference policies, and they must find a balance between the benefits and the costs of preference policies since both issues are legitimate policy concerns.

This research starts the process of filling the gap in the literature by adding research related to preference policies to the body of knowledge of public procurement. Scholars confirmed the importance of analyzing preferences on many occasions. Qiao et 
al. $(2009$, p. 397$)$ mentioned that "the practical impact of preferences is worthy of much more analysis". Professional organizations and government officials also discussed preference policies and emphasized the need for more research-based answers to the benefits of preference policies. For example, "NASPO believes that more research and cost-benefit analysis studies are warranted to gauge success rates and gains, if any, or failures of preference programs and policies, including whether any state has realized any direct or indirect cost benefit or loss as a result due to a specific preference" (NASPO, 2012, p. 3). In addition, in its report on in-state preference policy in its procurements, the Connecticut Department of Administrative Services (2012, p. 6) stated that "[Preferences data] may be useful in the future in making a determination as to the economic impact of state contracting and any proposed policy changes in this area". These statements warn of the emergent need to have more data available regarding in-state preference policies in order to contribute to a better understanding of preference policies. This consideration is another implication of this study.

Since the economic impacts of preference policies on the South Carolina economy are shown by industry-level, the results give state agencies the opportunity to identify the sectors that state agencies want to support when they implement the preferences. In conclusion, the results from this study have shown that implementing preference policies does help the state economy, and the results provide the knowledge base for policymakers, voters and taxpayers in determining whether or not to adapt instate preference policies. 
Limitations are the factors that weaken the research and are out of the researcher's control to a certain extent. Creswell $(2005$, p. 198) defined limitations as the "potential weaknesses or problems with the study identified by the researcher". The researcher acknowledges such limitations to this study because they may have had the potential to influence the interpretation of the results, and they will be described below.

This research is limited in its results for several reasons. First, the results from this research cannot be generalized to other states because it focused on one state, South Carolina. In addition, REMI Inc. has provided access to PI+ for the state of South Carolina for the purpose of this research; however, due to lack of funding, it was not possible to purchase additional versions of the model. A second limitation is that the accuracy of the data collected from the Office of Audit and Certification, a subdivision of the Procurement Services Office in South Carolina Budget and Control Board, and the values of all the variables embedded in the REMI PI+ model cannot be verified. Third, this analysis does not factor in the effect of reciprocal policies on South Carolina vendors when they bid on contracts in states that apply the reciprocal policies. The negative effects of these reciprocal policies could be negative because South Carolina vendors might lose the opportunity to do business in the state that applies the reciprocal policy. Fourth, the economic costs (except the direct cost of preferences) of implementing the preference policies were not analyzed in this study. Identifying the costs and comparing them with the in-state preferences' benefits might impact the 
conclusions of this study. Fifth, since the study is an economic impact study, there is no attempt made to assess the social benefits gained from the preference policies.

In addition to the above limitations, there are also others, which are related to the REMI model itself. Since the model represents a variety of equations and relationships, it is possible that it could be viewed as a black box by those who are not familiar with the model. However on their website, REMI has provided users with their documents to review all underlying assumptions and the data sources on their website. Finally, given the way the REMI model is built, it can only provide impact for three years (2010 - 2012) because it does not run simulations in years with actual historical data (the last year of historical data is 2009).

\section{Delimitations of this Research}

Delimitations are defined by Plichta and Garzon (2009, p. 15) as the "boundaries in which the study was deliberately confined". This research is confined to one state only and does not attempt to study the rest of the twenty-four states that implement instate preference policies, and this constitutes a delimitation of this study. This study is also confined by an eight- year time frame and does not examine beyond the prescribed period. A final delimitation of this research is that it is confined to the twenty-nine state agencies that implemented in-state preferences policies and does not try to examine all of the contracts implemented by all South Carolina state agencies. 


\section{Future Research}

This research examined the economic benefits from implementing in-state preference policies in South Carolina by measuring quantitative changes in the economic indicators. The results showed that the value of the indicators increased when they are compared to the baseline value for each year for the state of South Carolina. The results have established a foundation for future investigations in five areas of research.

Since, there are 25 (including South Carolina) states which implement in-state preference policies, and since every state has its own unique demographics, industries, and economy, this leads to future investigation to explore the economic impacts of the preference policies on each of the $\mathbf{2 4}$ states applying in-state preferences. Some researchers and government officials have expressed the need to investigate the impact of in-state preferences; for example, the Connecticut Department of Administrative Services (2012), emphasized the importance of investigating the impact of Connecticut state preference policies. In addition, Moreland (2012) prepared a report for NASPO about in-state preference policies, and he highlighted the need to study the impact of preferences. "NASPO believes that more research and cost-benefit analysis studies are warranted to gauge success rates and gains, if any, or failures of preference programs and policies, including whether any state has realized any direct or indirect cost benefit or loss as a result due to a specific preference" (Moreland, 2012, p. 3). 
In addition to an investigation into the impacts of preference policies on the other 24 states, a comparative study to further understand the differences and the similarities of the impact of in-state preference policies on the states' economies would raise new questions and stimulate further discussion. Comparing the economic impact between the 25 states will add a new perspective to the analysis and stands as a topic for future research.

This study also highlighted the need to investigate reciprocal preferences. The reciprocal preference laws add a percentage to the out-of-state vendors when their own states impose preferences on out-of-state vendors, effectively working in the opposite direction of in-state preference policies. According to NASPO's survey in 2012, thirtyfive states apply reciprocal preference laws to achieve equal treatment for their interested vendors against the bidders who get preference treatment in their own states. If twenty-five states implement in-state preference policies and thirty-five states implement reciprocal policies, it might mean that there are some states implementing both policies. It is critical to understand why these states would implement the two policies which work against each other, and this is considered to be another area for future research.

Obviously, there are other costs related to implementing the in-state preference policies and these costs might outweigh the benefits from implementing the in-state preference policies. Some of the costs include the opportunity costs that governments could have lost by not awarding the contracts to out-of-state vendors, the administrative costs related to managing the contract and determining the eligibility to 
award the contracts, and costs related to reciprocal policies on South Carolina vendors. At this time, the data that is related to these costs is either not available or is not measured. This lack of study of the costs of implementing preferences creates another important area for future research.

Finally, although REMI is considered to be one traditional approach used to measure the economic impact of a variety of policies, scholars and researchers have used other types of input-output models and other methods to measure the economic impact of implementing preferences. Scholars have used ordinary least squares regression to study the impact of policies on the states' or localities' economy, and others have used the Regional Input-Output Modeling System (RIMS). Future research to determine if using different methods would yield similar or different findings would be beneficial. 


\section{References}

2009 Act No. 72. (2009). Preferences Law. from http://procurement.sc.gov/webfiles/MMO PREFS/Main/2009 Act $72 \% 28 \mathrm{~S} .116$ $\% 29 . \mathrm{pdf}$

Achille. (2011). Brief Guide to Public Sector European Union Procurement Legislation. Oxon, UK: Achille Information Limited

Audet, D. (2002). Government procurement: A synthesis report. OECD Journal on Budgeting, 2(3), 149-194.

Avalos, A., \& Birdyshaw, E. (2007). Assessing the Economic Impact of a Local Preference Ordinance in the City of Fresno.

Baldwin, R. (1982). The political economy of protectionism Import competition and response (pp. 263-292): University of Chicago Press.

Baldwin, R., \& Richardson, J. D. (1972). Government Purchasing Policies, Other NTBs, and the International Monetary Crisis. Ottawa: Carleton School of International Affairs.

Bates, T. (2001). Minority business access to mainstream markets. Journal of Urban Affairs, 23(1), 41-56.

Boffa, M., \& Olarreaga, M. (2012). Protectionism during the crisis: Tit-for-tat or chickengames? Economics Letters.

Breton, A., \& Salmon, P. (1996). Are discriminatory procurement policies motivated by protectionism? Kyklos, 49(1), 47-68.

Bureau of Economic Analysis. (2013). Real GDP by State. Retrieved from: http://www.bea.gov/newsreleases/regional/gdp state/gsp newsrelease.htm

Bureau of Labor Statistics. (2013). South Carolina at Glance. Retrieved from: http://www.bls.gov/eag/eag.sc.htm

Cassing, S., \& Giarratani, F. (1992). An evaluation of the REMI model for the south coast air quality management district. Environment and Planning A, 24, 15491549.

Census of Bureau. (2013). South Carolina Quick Facts. Retrieved from: http://quickfacts.census.gov/gfd/states/45000.html

Chambers, B. B. (1991). Looking Back at City of Richmond v. JA Croson Co.: Its Effects on State and Local Set-Aside Programs. BYU Law Review, 1633.

Connecticut Department of Administrative Services. (2012). Report on in-state preference policy in State Procurement.

Cox, A., \& Furlong, P. (1995). European procurement rules and national preference: explaining the local sourcing of public works contracts in the EU in 1993. Journal of Construction Procurement, 1(2), 87-99.

Creswell, J. W. (2005). Educational Research: Planning, Conducting, and Evaluating Quantitative and Qualitative Research. Upper Saddle River, NJ: Pearson

De Silva, D. G., Dunne, T., Kosmopoulou, G., \& Lamarche, C. (2011). Disadvantaged Business Enterprise Goals in Government Procurement Contracting: An Analysis of Bidding Behavior and Costs. Federal Reserve Bamk of Cleveland.

Deardorff, A. V., \& Stern, R. M. (1981). A disaggregated model of world production and trade: An estimate of the impact of the Tokyo Round. Journal of Policy Modeling, $3(2), 127-152$. 
Deltas, G., \& Evenett, S. (1997). Quantitative estimates of the effects of preference policies. Law and Policy in Public Purchasing. University of Michigan Press, Ann Arbor, 73-92.

Dye, T. R. (2012). Understanding public policy: Pearson.

Enchautegui, M. E., Fix, M. E., Loprest, P. J., Lippe, S. C. V. D., \& Wissoker, D. A. (1997). Do Minority-Owned Businesses Get a Fair Share of Government Contracts? Washington, D.C.: The Urban Institute.

Erridge, R., Fee, A., \& McIlroy, J. (1998). European Union public procurement policy and electronic commerce: problems and opportunities. European Business Review, 98(5), 252-259.

European Commission. (2004). A report on the functioning of public procurement markets in the EU: benefits from the application of EU directives and challenges for the future (pp. 1-24).

Federal Reserve Economic Data. (2013). Per Capita Personal Income in South Carolina (SCPCPI).

Feik, J. (2013). Economic Profile - South Carolina: The Federal Reserve Bank of Richmond

Ferrini, L. (2012). What are the Main Causes and Effects of Economic Protectionism? Retrieved from http://www.e-ir.info/2012/08/28/the-causes-and-effects-ofeconomic-protectionism/

Frederickson, H. G. (1990). Public administration and social equity. Public administration and law, 209.

Gelderman, C. J., Ghijsen, P. W., \& Brugman, M. J. (2006). Public procurement and EU tendering directives - explaining non-compliance. International Journal of Public Sector Management, 19(7), 702-714.

Gordon, H., Rimmer, S., \& Arrowsmith, S. (1998). The economic impact of the European Union regime on public procurement: lessons for the WTO. The World Economy, 21(2), 159-187.

Green, R. (1993). Human Rights and Most-Favored-Nation Tariff Rates for Products from the People's Republic of China. U. Puget Sound L. Rev., 17, 611.

Gregg, I., \& Karen, O. C. (1990). Minority Set-Aside Programs in the State After City of Richmond The Journal of Federalism.

Hefner, F. (1996). State Procurement Preferences: Evaluating their Economic Benefit. The Journal of State Government, 69(1), 33-38.

Herander, M. (1982). The Impact of Government Price Discrimination and Its Equivalence with the Tariff. Weltwirtschaftliches Archiv, 118(3), 525-545. doi: $10.2307 / 40439053$

Hickok, S. (1985). The consumer cost of US trade restraints. Federal Reserve Bank of New York Quarterly Review, 10(2), 1-12.

Hill, C. W. L. (2011). Global Business Today. New York, NY: McGraw-Hill/Irwin.

Hoekman, B. (1998). Using international institutions to improve public procurement. World Bank Research Observer, 13(2), 249.

Hufbauer, G. C., Berliner, D. T., \& Elliott, K. A. (1986). Trade protection in the United States: 31 case studies: Institute for international economics Washington, DC.

Hymans, S. H. (2008). Forecasting and Econometric Models. from http://www.econlib.org/library/Enc/ForecastingandEconometricModels.html 
Jensen, K. (2011). Assessing the Use of Local Preferences in Local Government Contracting. (Master of Public Administration), The University of North Carolina at Chapel Hill.

Krasnokutskaya, E., \& Seim, K. (2008). Bid preference programs and participation in highway procurement auctions. American Economic Review.

Krueger, A. O. (1991). Government failures in development: National Bureau of Economic Research.

Krugman, P. R., \& Obstfeld, M. (1991). International economics: Trade and policy: Harper Collins Publishers, New York.

Lowenstein, H. (2011). Economic development through local vendor preference policy: the case of Horry County, South Carolina. The Coastal Business Journal, 10(1).

Lowinger, T. C. (1976). Discrimination in government procurement of foreign goods in the US and Western Europe. Southern Economic Journal, 451-460.

MacManus, S. A., Watson, S. A., \& Blair, D. C. (1992). Doing business with government: Federal, state, local \& foreign government purchasing practices for every business and public institution: Paragon House Publishers.

Madsen, P. T. (2002). Re-opening the debate on the lack of impact of EU-tenders on the openness of public procurement. Public Procurement Law Review(5), 265-281.

Marion, J. (2007). Are bid preferences benign? The effect of small business subsidies in highway procurement auctions. Journal of Public Economics, 91(7-8), 15911624.

Martin, J. M. F. (1996). The EC public procurement rules: a critical analysis: Clarendon Press Oxford.

McAfee, R. P., \& McMillan, J. (1989). Government procurement and international trade Journal of International Economics (Vol. 26, pp. 291-308).

McCrudden, C. (2007). Buying Social Justice-Equality, Government Procurement \& Legal Change. New York.

McCue, C. P., \& Gianakis, G. A. (2001). Public Purchasing: Who's Minding the Store? Journal of Public Procurement, 1(1), 71-95.

Miller, S., Wei, D., \& Rose, A. (2010). The economic impact of the Michigan climate change Action Plan on the state's economy. Washington, DC: the Michigan Department of Environmental Quality, The Center for Climate Strategies.

Moreland, E. (2012). In-state Preferences. NASPO.

NAICS. (2013). Introduction to NAICS. from http://www.census.gov/eos/www/naics/

NASPO. (2012). 2011-2012 NASPO Survey of State Procurement Practices Summary Report.

Nielsen, J. U., \& Hansen, L. G. (2001). The EU Public Procurement Regime-Does It Work? Intereconomics, 36(5), 255.

OECD. (2011). Public Procurement in the EU: Legislative Framework, Basic Principles and Institutions.

OUSTR. (2012). WTO Government Procurement Agreement. from http://www.ustr.gov/trade-topics/government-procurement/wto-governmentprocurement-agreement

Pitzer, J. T., \& Thai, K. V. (2009). Introduction to Public Procurement Herndon: National Institute of Governmental Purchasing. Inc. 
Plichta, S. B., \& Garzon, L. S. (2009). Statistics for nursing and allied health: Lippincott Williams \& Wilkins.

Pregelj. V. N. (2001). Most-favored-nation Status of the People's Republic of China.

Qiao, Y., Thai, K. V., \& Cummings, G. (2009). State and local procurement preferences: a survey Journal of Public Procurement, 9(3 \& 4), 371-410.

Reinert, E. S. (1999). The role of the state in economic growth. Journal of economic Studies, 26(4/5), 268-326.

REMI. (2007). REMI Policy Insight User Guide.

REMI. (2011). REMI PI+ Model Document. from http://www.remi.com

REMI. (2012). The REMI Model. from http://www.remi.com/the-remi-model

http://www.remi.com/products/pi

REMI. (2013a). Contrast: Modeling The Macroeconomic Impact Of " Medicaid Expansion "In North Carolina.

REMI. (2013b). REMI Glossary. from http://www.remi.com/resources/glossary

REMI. (n.d.). What does REMI say?

Rice, M. F. (1991). Government set-asides, minority business enterprises, and the Supreme Court. Public Administration Review, 114-122.

Rickman, D. S., \& Schwer, R. K. (1995). A comparison of the multipliers of IMPLAN, REMI, and RIMS II: Benchmarking ready-made models for comparison. The Annals of Regional Science, 29(4), 363-374.

Rodriguez, H., \& Houston, D. (2007). Procurement Matters: The Economic Impact of Local Suppliers: Civic Economics Center.

Rolfstam, M. (2008). Public procurement of innovation: Centre for Innovation, Research and Competence in the Learning Economy (CIRCLE), Lund University.

Rose, A., \& Wei, D. (2012). Macroeconomic Impacts of the Florida Energy and Climate Change Action Plan. Climate Policy, 12(1), 50-69.

Rose, A., Wei, D., \& Dormady, N. (2011). Regional macroeconomic assessment of the Pennsylvania Climate Action Plan. Regional Science Policy \& Practice, 357-379.

Rose, A., Wei, D., \& Prager, F. (2010). Impacts of climate policy on the California economy. San Francisco, California: Next 10.

Shafaeddin, M. (2000). What did Frederick List actually say? Some clarifications on the infant industry argument: United Nations Conference on Trade and Development.

Short, J. E. (1992). Issues in public purchasing: a guidebook for policymakers: Council of State Government.

Snider, K. F., \& Rendon, R. G. (2008). Public procurement policy: implications for theory and practice Journal of Public Procurement, 8(3), 310-333.

South Carolina Budget and Control Board. (2009). Frequently Asked Questions From The Vendor's Perspective. from http://procurement.sc.gov/webfiles/MMO PREFS/Main/FAQ Preferences.htm

Strayer, C. (2011). Local Preference. from http://www.cityofmiddletown.org/docs/council/12202011 w.pdf

Svara, J. H., \& Brunet, J. R. (2004). Filling in the Skeletal Pillar: Addressing Social Equity in Introductory Courses in Public Administration. Journal of Public Affairs Education, 10(2), 99-109.

Tarr, D. G., \& Morkre, M. E. (1984). Aggregate costs to the United States of tariffs and quotas on imports: general tariff cuts and removal of quotas on automobiles, 
steel, sugar, and textiles: an economic policy analysis: Federal Trade Commission, Bureau of Economics.

Thai, K. V. (2001). Public procurement re-examined. Journal of Public Procurement, I(1), 9-50.

The Economist. (2009). The nuts and bolts come apart, as global demand contracts, trade is slumping and protectionism rising from http://www.economist.com/node/13362027

The South Carolina Department of Commerce Research Division. (2010). South Carolina Economic Indicator Report.

Treyz, G. I., Rickman, D. S., \& Shao, G. (1991). The REMI economic-demographic forecasting and simulation model. International Regional Science Review, 14(3), 221-253.

Trionfetti, F. (1999). Trade and Public Procurement: The Perspective of Small Open Economies. London, UK: International Trade Center

Trionfetti, F. (2000). Discriminatory public procurement and international trade. The World Economy, 23(1), 57-76.

Vitner, M., \& Silverman, S. (2013). South Carolina 2013 Economic Outlook: Game Changers, Catalysts and Hurdles

Ward, A. (2000). Most Favored Nation Status: China.

Weber, R. E. (1979). A Synthesis of Methods Proposed for Estimating Gross State Product. Journal of Regional Science, 19(2), 217-229. doi: 10.1111/j.14679787.1979.tb00587.x

Wood, G. E., \& Mudd, D. R. (1978). The recent US trade deficit-no cause for panic. Federal Reserve Bank of St. Louis Review(Apr), 2-7.

World Trade Organization. (2012). An economic perspective on the use of non-tariff measures. 


\section{APPENDICES}

\section{Appendix A}

LIST OF SOUTH CAROLINA STATE AGENCIES

1. Clemson University

1. Trident Technical College

2. Medical University of South Carolina

3. Coastal Carolina University

4. Juvenile Justice

5. Midlands Technical College

6. University of South Carolina

7. Parks, Recreation and Tourism

8. Health and Environmental Control

9. Materials Management Office

10. Transportation Department

11. Educational Television Commission

12. Aiken Technical College

13. Budget and Control Board

14. Education Lottery

15. Greenville Technical College

16. Winthrop University

17. Spartanburg Technical College

18. College of Charleston

19. Lander University

20. Piedmont Technical College

21. Central Carolina Technology

22. South Carolina Technical College

23. Northeastern Technical College

24. Spartanburg Community College

25. Public Safety

26. Natural Resources

27. Francis Marion University

28. The Adjutant General of South Carolina

29. The South Carolina Department of Mental Health 


\section{Appendix B}

\section{DROPPED PROCUREMENT CONTRACTS}

A total of six contracts were dropped from the analysis for a variety of reasons. The Parks, Recreation and Tourism Department awarded a contract based on resident vendor and South Carolina end-product preferences which means that the vendor is a resident of the state and produces the product in the state as well. The description of the contracts is "Propane Gas for South Carolina States Parks-Line 2 (Santee)" and the product in this case is "the gas". The value of the contract is $\$ 25$. This solicitation was dropped from the analysis for two reasons. First, from the contract description it is not clear if the vendor produces the gas itself in the state or not. The researcher attempted to contact the Parks, Recreation and Tourism Department but failed to get a response. Second, the dollar value of the contract is small compared to the value of the other contracts.

The remaining five contracts were dropped from the analysis because errors were discovered in the reports. Two of these contracts were for Trident Technical College. According to the preference report, both contracts were for computer software for microcomputers, and they were awarded based on preference type 2 (SC end product), but the Procurement Department confirmed that the two contracts were awarded based on US end product only. In this case, these contracts are not relevant to this study. The other three contracts were for Greenville Technical College to buy Surgical Instruments \& Cases, Self Contained Breathing Apparatus, and Welding 
Machines. According to Greenville Technical College's Procurement Office, in two of the contracts the resident SC vendor provided the lowest bid and the preference laws were not applicable/ relevant in these awards, and in the third contract the resident vendor was the only vendor to submit a bid, and the preference policies were not relevant. 
Appendix C

PROBLEMS IDENTIFYING NAICS CODES

\section{South Carolina Department of Mental Health}

In 2012, the South Carolina Department of Mental Health awarded a contract based on preference type 5 (Resident Vendor and US End Product). The description of the contract includes "Blast Cook-Chiller", which didn't provide enough information to identify the industry. Bid document for this solicitation was downloaded from the South Carolina Budget and Control Board website, and the description of the contract was:

"Item Description: Hurrichill Blast Chiller, Model \#BCIP or equal, Roll-in, remote refrigeration, (80) $12 \times 20 \times 21 / 2^{\prime \prime}$ or (40) 18" $\times 26^{\prime \prime}$ pan capacity, 500 lbs. from $160 \mathrm{~F}$ to $38 \mathrm{~F}$ blast chill capacity/ $90 \mathrm{~min}$., solid state electronic control panel with VFD display and alarms, two food probes, s/s interior and exterior, UL listed for safety \& sanitation to NSF standards."

According to the description above, the South Carolina Department of Mental Health bought the Blast Cook-Chiller from the resident vendor in 2012. Therefore, the dollar value of this solicitation contributed to the wholesale industry.

2. University of South Carolina

The researcher contacted the Purchasing Department at the University of South Carolina to request more information regarding three solicitations. The description of the first solicitation is "storage server", and it was awarded based on the preference type 4 (Resident Vendor and South Carolina End Product). The description provided doesn't give sufficient information to determine the NAICS industry, so in this case, it 
was not clear whether the vendor sells the storage servers and produces them in the State because the vendor was qualified for preference type 4. If the vendor sells the product only, the sales from this contract are attributed to the retail or wholesale industry. If the vendor sells and produces the product, the sales from this contract are attributed to the Computer servers manufacturing. The Purchasing Department of the University of South Carolina clarified that the vendor installed the storage server (this is why the vendor was qualified for the resident vendor preference), and sold the storage server which was assembled, fabricated or processed in the state.

The description of the second solicitation is "Music Instruments", and it was awarded based on the preference type 1 (Resident Vendor). In this case, the information provided is not sufficient to identify the correct NAICS. Upon the researcher's request, the Purchasing Department of the University of South Carolina sent the solicitation documents. The solicitation description is "Furnish and Deliver New Music Instruments". This description identifies that the correct NAICS for this solicitation is wholesale industry.

The description of the third solicitation is "Symetrix Digital Audio Devices", but the NIGP code is a service code (communications and media related services). This solicitation was awarded based on preference type 2 (SC End Product). The Purchasing Department of the University of South Carolina sent the solicitation document and the more detailed description was "Furnish and Deliver Symetrix SymLink Digital Audio Devices". Since the preference is type 2 , this solicitation contributes to the computer and electronic product manufacturing. 


\section{Clemson University}

'In 2012, Clemson University awarded a contract and the description

is "YMCA Fence Replacement", but the provided NIGP code is service code (roadside, grounds, recreational and park area services). The solicitation was awarded based on the preference type 4 (Resident Vendor and South Carolina End Product). In this case, since the category is 4 , it could indicate that the awarded company produced the fence and provided the service of fence replacement. According to the information provided by the Procurement Services Office at Clemson University, this solicitation was awarded based on preference type 5 (Resident Vendor and US End Product), and it should have been broken into two lines (material and labor). In this case, the NAICS industry is Electrical Equipment, Appliance, and Component Manufacturing.

This is the response from the Procurement Services Office at Clemson University: "Ideally we would have broken it out in two lines - one for material and one for labor. Since it was not bid that way but price/scope consisted of both, it appears the buyer applied the preference based on what they believed or understood to be the majority of the cost in this instance" 


\section{Appendix D}

\section{NAICS INDUSTRIES DEFINITIONS}

1. Wholesale Trade

The Wholesale Trade sector comprises establishments engaged in wholesaling merchandise, generally without transformation, and rendering services incidental to the sale of merchandise. The merchandise described in this sector includes the outputs of agriculture, mining, manufacturing, and certain information industries, such as publishing. The wholesaling process is an intermediate step in the distribution of merchandise. Wholesalers are organized to sell or arrange the purchase or sale of (a) goods for resale (i.e., goods sold to other wholesalers or retailers), (b) capital or durable nonconsumer goods, and (c) raw and intermediate materials and supplies used in production. Wholesalers sell merchandise to other businesses and normally operate from a warehouse or office. These warehouses and offices are characterized by having little or no display of merchandise. In addition, neither the design nor the location of the premises is intended to solicit walk-in traffic. Wholesalers do not normally use advertising directed to the general public. Customers are generally reached initially via telephone, in-person marketing, or by specialized advertising that may include Internet and other electronic means. Follow-up orders are either vendor-initiated or client-initiated, generally based on previous sales, and typically exhibit strong ties between sellers and buyers. In fact, transactions are 
often conducted between wholesalers and clients that have long-standing business relationships.

This sector comprises two main types of wholesalers: merchant wholesalers that sell goods on their own account and business-to-business electronic markets, agents, and brokers that arrange sales and purchases for others generally for a commission or fee.

(1) Establishments that sell goods on their own account are known as wholesale merchants, distributors, jobbers, drop shippers, and import/export merchants. Also included as wholesale merchants are sales offices and sales branches (but not retail stores) maintained by manufacturing, refining, or mining enterprises apart from their plants or mines for the purpose of marketing their products and group purchasing organizations (e.g., purchasing and selling goods on their own account). Merchant wholesale establishments typically maintain their own warehouse, where they receive and handle goods for their customers. Goods are generally sold without transformation, but may include integral functions, such as sorting, packaging, labeling, and other marketing services.

(2) Establishments arranging for the purchase or sale of goods owned by others or purchasing goods, generally on a commission basis are known as business-tobusiness electronic markets, agents and brokers, commission merchants, import/export agents and brokers, auction companies, group purchasing organization (e.g., purchasing or arranging for the purchases of goods owned by others), and manufacturers' representatives. These establishments operate from 
offices and generally do not own or handle the goods they sell.

Some wholesale establishments may be connected with a single manufacturer and promote and sell the particular manufacturers' products to a wide range of other wholesalers or retailers. Other wholesalers may be connected to a retail chain, or limited number of retail chains, and only provide a variety of products needed by that particular retail operation(s). These wholesalers may obtain the products from a wide range of manufacturers. Still other wholesalers may not take title to the goods, but act as agents and brokers for a commission. Although, in general, wholesaling normally denotes sales in large volumes, durable nonconsumer goods may be sold in single units. Sales of capital or durable nonconsumer goods used in the production of goods and services, such as farm machinery, medium- and heavy-duty trucks, and industrial machinery, are always included in wholesale trade.

2. Construction

The Construction sector comprises establishments primarily engaged in the construction of buildings or engineering projects (e.g., highways and utility systems). Establishments primarily engaged in the preparation of sites for new construction and establishments primarily engaged in subdividing land for sale as building sites also are included in this sector.

Construction work done may include new work, additions, alterations, or maintenance and repairs. Activities of these establishments generally are managed at a fixed place of business, but they usually perform construction 
activities at multiple project sites. Production responsibilities for establishments in this sector are usually specified in (1) contracts with the owners of construction projects (prime contracts) or (2) contracts with other construction establishments (subcontracts).

Establishments primarily engaged in contracts that include responsibility for all aspects of individual construction projects are commonly known as general contractors, but also may be known as design-builders, construction managers, turnkey contractors, or (in cases where two or more establishments jointly secure a general contract) joint-venture contractors. Construction managers that provide oversight and scheduling only (i.e., agency) as well as construction managers that are responsible for the entire project (i.e., at risk) are included as general contractor type establishments. Establishments of the "general contractor type" frequently arrange construction of separate parts of their projects through subcontracts with other construction establishments. Establishments primarily engaged in activities to produce a specific component (e.g., masonry, painting, and electrical work) of a construction project are commonly known as specialty trade contractors. Activities of specialty trade contractors are usually subcontracted from other construction establishments, but especially in remodeling and repair construction, the work may be done directly for the owner of the property.

Establishments primarily engaged in activities to construct buildings to be sold on sites that they own are known as for-sale builders, but also may be known as 
speculative builders or merchant builders. For-sale builders produce buildings in a manner similar to general contractors, but their production processes also include site acquisition and securing of financial backing. For-sale builders are most often associated with the construction of residential buildings. Like general contractors, they may subcontract all or part of the actual construction work on their buildings.

There are substantial differences in the types of equipment, work force skills, and other inputs required by establishments in this sector. To highlight these differences and variations in the underlying production functions, this sector is divided into three subsectors.

Subsector 236, Construction of Buildings, comprises establishments of the general contractor type and for-sale builders involved in the construction of buildings. Subsector 237, Heavy and Civil Engineering Construction, comprises establishments involved in the construction of engineering projects. Subsector 238, Specialty Trade Contractors, comprises establishments engaged in specialty trade activities generally needed in the construction of all types of buildings. Force account construction is construction work performed by an enterprise primarily engaged in some business other than construction for its own account, using employees of the enterprise. This activity is not included in the construction sector unless the construction work performed is the primary activity of a separate establishment of the enterprise. The installation and the ongoing repair and maintenance of telecommunications and utility networks is 
excluded from construction when the establishments performing the work are not independent contractors. Although a growing proportion of this work is subcontracted to independent contractors in the Construction sector, the operating units of telecommunications and utility companies performing this work are included with the telecommunications or utility activities.

3. Printing and Related Support Activities

Industries in the Printing and Related Support Activities subsector print products, such as newspapers, books, labels, business cards, stationery, business forms, and other materials, and perform support activities, such as data imaging, platemaking services, and bookbinding. The support activities included here are an integral part of the printing industry, and a product (a printing plate, a bound book, or a computer disk or file) that is an integral part of the printing industry is almost always provided by these operations.

Processes used in printing include a variety of methods used to transfer an image from a plate, screen, film, or computer file to some medium, such as paper, plastics, metal, textile articles, or wood. The printing processes employed include, but are not limited to, lithographic, gravure, screen, flexographic, digital, and letterpress.

In contrast to many other classification systems that locate publishing of printed materials in manufacturing, NAICS classifies the publishing of printed products in Subsector 511, Publishing Industries (except Internet). Though printing and publishing are often carried out by the same enterprise (a newspaper, for 
example), it is less and less the case that these distinct activities are carried out in the same establishment. When publishing and printing are done in the same establishment, the establishment is classified in Sector 51 , Information, in the appropriate NAICS industry even if the receipts for printing exceed those for publishing.

This subsector includes printing on clothing because the production process for that activity is printing, not clothing manufacturing. For instance, the printing of T-shirts is included in this subsector. In contrast, printing on fabric (or grey goods) is not included. This activity is part of the process of finishing the fabric and is included in the NAICS Textile Mills subsector in Industry 31331, Textile and Fabric Finishing Mills.

4. Administrative and Support Services Industries in the Administrative and Support Services subsector group establishments engaged in activities that support the day-to-day operations of other organizations. The processes employed in this sector (e.g., general management, personnel administration, clerical activities, cleaning activities) are often integral parts of the activities of establishments found in all sectors of the economy. The establishments classified in this subsector have specialization in one or more of these activities and can, therefore, provide services to clients in a variety of industries and, in some cases, to households. The individual industries of this subsector are defined on the basis of the particular process that they are engaged in and the particular services they provide. 
Many of the activities performed in this subsector are ongoing routine support functions that all businesses and organizations must do and that they have traditionally done for themselves. Recent trends, however, are to contract or purchase such services from businesses that specialize in such activities and can, therefore, provide the services more efficiently.

The industries in this subsector cannot be viewed as strictly "support." The Travel Arrangement and Reservation Services industry group includes travel agents, tour operators, and providers of other travel arrangement services, such as hotel and restaurant reservations and arranging the purchase of tickets, serving many types of clients, including individual consumers. This group was placed in this subsector because the services are often of the "support" nature (e.g., travel arrangement) and businesses and other organizations are increasingly the ones purchasing such services.

The administrative and management activities performed by establishments in this sector are typically on a contract or fee basis. These activities may also be performed by establishments that are part of the company or enterprise.

However, establishments involved in administering, overseeing, and managing other establishments of the company or enterprise are classified in Sector $\mathbf{5 5}$, Management of Companies and Enterprises. Establishments in Sector 55 normally undertake the strategic and organizational planning and decision making role of the company or enterprise. Government establishments engaged 
in administering, overseeing, and managing governmental programs are classified in Sector 92, Public Administration.

5. Professional, Scientific, and Technical Services

The Professional, Scientific, and Technical Services sector comprises establishments that specialize in performing professional, scientific, and technical activities for others. These activities require a high degree of expertise and training. The establishments in this sector specialize according to expertise and provide these services to clients in a variety of industries and, in some cases, to households. Activities performed include: legal advice and representation; accounting, bookkeeping, and payroll services; architectural, engineering, and specialized design services; computer services; consulting services; research services; advertising services; photographic services; translation and interpretation services; veterinary services; and other professional, scientific, and technical services.

This sector excludes establishments primarily engaged in providing a range of day-to-day office administrative services, such as financial planning, billing and recordkeeping, personnel, and physical distribution and logistics. These establishments are classified in Sector 56, Administrative and Support and Waste Management and Remediation Services.

6. Miscellaneous Manufacturing Industries in the Miscellaneous Manufacturing subsector make a wide range of products that cannot readily be classified in specific NAICS subsectors in 
manufacturing. Processes used by these establishments vary significantly, both among and within industries. For example, a variety of manufacturing processes are used in manufacturing sporting and athletic goods that include products such as tennis racquets and golf balls. The processes for these products differ from each other, and the processes differ significantly from the fabrication processes used in making dolls or toys, the melting and shaping of precious metals to make jewelry, and the bending, forming, and assembly used in making medical products. The industries in this subsector are defined by what is made rather than how it is made. Although individual establishments might be appropriately classified elsewhere in the NAICS structure, for historical continuity, these product-based industries were maintained. In most cases, no one process or material predominates for an industry.

Establishments in this subsector manufacture products as diverse as medical equipment and supplies, jewelry, sporting goods, toys, and office supplies.

7. Machinery Manufacturing Industries in the Machinery Manufacturing subsector create end products that apply mechanical force, for example, the application of gears and levers, to perform work. Some important processes for the manufacture of machinery are forging, stamping, bending, forming, and machining that are used to shape individual pieces of metal. Processes, such as welding and assembling are used to join separate parts together. Although these processes are similar to those used in metal fabricating establishments, machinery manufacturing is different 
because it typically employs multiple metal forming processes in manufacturing the various parts of the machine. Moreover, complex assembly operations are an inherent part of the production process.

In general, design considerations are very important in machinery production. Establishments specialize in making machinery designed for particular applications. Thus, design is considered to be part of the production process for the purpose of implementing NAICS. The NAICS structure reflects this by defining industries and industry groups that make machinery for different applications. A broad distinction exists between machinery that is generally used in a variety of industrial applications (i.e., general purpose machinery) and machinery that is designed to be used in a particular industry (i.e., special purpose machinery). Three industry groups consist of special purpose machinery--Agricultural, Construction, and Mining Machinery Manufacturing; Industrial Machinery Manufacturing; and Commercial and Service Industry Machinery Manufacturing. The other industry groups make general-purpose machinery: Ventilation, Heating, Air-Conditioning, and Commercial Refrigeration Equipment Manufacturing; Metalworking Machinery Manufacturing; Engine, Turbine, and Power Transmission Equipment Manufacturing; and Other General Purpose Machinery Manufacturing.

8. Furniture and Related Product Manufacturing Industries in the Furniture and Related Product Manufacturing subsector make furniture and related articles, such as mattresses, window blinds, cabinets, and 
fixtures. The processes used in the manufacture of furniture include the cutting, bending, molding, laminating, and assembly of such materials as wood, metal, glass, plastics, and rattan. However, the production process for furniture is not solely bending metal, cutting and shaping wood, or extruding and molding plastics. Design and fashion trends play an important part in the production of furniture. The integrated design of the article for both esthetic and functional qualities is also a major part of the process of manufacturing furniture. Design services may be performed by the furniture establishment's work force or may be purchased from industrial designers.

Furniture may be made of any material, but the most common ones used in North America are metal and wood. Furniture manufacturing establishments may specialize in making articles primarily from one material. Some of the equipment required to make a wooden table, for example, is different from that used to make a metal one. However, furniture is usually made from several materials. A wooden table might have metal brackets, and a wooden chair a fabric or plastics seat. Therefore, in NAICS, furniture initially is classified based on the type of furniture (application for which it is designed) rather than the material used. For example, an upholstered sofa is treated as household furniture, although it may also be used in hotels or offices.

When classifying furniture according to the component material from which it is made, furniture made from more than one material is classified based on the material used in the frame, or if there is no frame, the predominant component 
material. Upholstered household furniture (excluding kitchen and dining room chairs with upholstered seats) is classified without regard to the frame material. Kitchen or dining room chairs with upholstered seats are classified according to the frame material.

Furniture may be made on a stock or custom basis and may be shipped assembled or unassembled (i.e., knockdown). The manufacture of furniture parts and frames is included in this subsector.

Some of the processes used in furniture manufacturing are similar to processes that are used in other segments of manufacturing. For example, cutting and assembly occurs in the production of wood trusses that are classified in Subsector 321, Wood Product Manufacturing. However, the multiple processes that distinguish wood furniture manufacturing from wood product manufacturing warrant inclusion of wooden furniture manufacturing in the Furniture and Related Product Manufacturing subsector. Metal furniture manufacturing uses techniques that are also employed in the manufacturing of roll-formed products classified in Subsector 332, Fabricated Metal Product Manufacturing. The molding process for plastics furniture is similar to the molding of other plastics products. However, plastics furniture producing establishments tend to specialize in furniture.

NAICS attempts to keep furniture manufacturing together, but there are two notable exceptions: seating for transportation equipment and specialized hospital furniture (e.g., hospital beds and operating tables). These exceptions are 
related to the fact that some of the aspects of the production process for these products, primarily the design, are highly integrated with the other manufactured goods, namely motor vehicles and health equipment.

\section{Computer and Electronic Product Manufacturing}

Industries in the Computer and Electronic Product Manufacturing subsector group establishments that manufacture computers, computer peripherals, communications equipment, and similar electronic products, and establishments that manufacture components for such products. The Computer and Electronic Product Manufacturing industries have been combined in the hierarchy of NAICS because of the economic significance they have attained. Their rapid growth suggests that they will become even more important to the economies of all three North American countries in the future, and in addition their manufacturing processes are fundamentally different from the manufacturing processes of other machinery and equipment. The design and use of integrated circuits and the application of highly specialized miniaturization technologies are common elements in the production technologies of the computer and electronic subsector. Convergence of technology motivates this NAICS subsector. Digitalization of sound recording, for example, causes both the medium (the compact disc) and the equipment to resemble the technologies for recording, storing, transmitting, and manipulating data. Communications technology and equipment have been converging with computer technology. When technologically-related components are in the same sector, it makes it easier to 
adjust the classification for future changes, without needing to redefine its basic structure. The creation of the Computer and Electronic Product Manufacturing subsector assists in delineating new and emerging industries because the activities that will serve as the probable sources of new industries, such as computer manufacturing and communications equipment manufacturing, or computers and audio equipment, are brought together. As new activities emerge, they are less likely therefore, to cross the subsector boundaries of the classification.

10. Wood Product Manufacturing Industries in the Wood Product Manufacturing subsector manufacture wood products, such as lumber, plywood, veneers, wood containers, wood flooring, wood trusses, manufactured homes (i.e., mobile homes), and prefabricated wood buildings. The production processes of the Wood Product Manufacturing subsector include sawing, planning, shaping, laminating, and assembling of wood products starting from logs that are cut into bolts, or lumber that then may be further cut, or shaped by lathes or other shaping tools. The lumber or other transformed wood shapes may also be subsequently planed or smoothed, and assembled into finished products, such as wood containers. The Wood Product Manufacturing subsector includes establishments that make wood products from logs and bolts that are sawed and shaped, and establishments that purchase sawed lumber and make wood products. With the exception of 
sawmills and wood preservation establishments, the establishments are grouped into industries mainly based on the specific products manufactured.

11. Electrical Equipment, Appliance, and Component Manufacturing Industries in the Electrical Equipment, Appliance, and Component Manufacturing subsector manufacture products that generate, distribute and use electrical power. Electric Lighting Equipment Manufacturing establishments produce electric lamp bulbs, lighting fixtures, and parts. Household Appliance Manufacturing establishments make both small and major electrical appliances and parts. Electrical Equipment Manufacturing establishments make goods, such as electric motors, generators, transformers, and switchgear apparatus. Other Electrical Equipment and Component Manufacturing establishments make devices for storing electrical power (e.g., batteries), for transmitting electricity (e.g., insulated wire), and wiring devices (e.g., electrical outlets, fuse boxes, and light switches). 
Appendix $E$

\section{SOUTH CAROLINA ECONOMIC OVERVIEW}

South Carolina is the 40th largest state with an area of 30,060 square miles and an estimated population of $4,723,723$ (Census of Bureau, 2013). The population per square mile is 153.9. The data shows that South Carolina's population has grown since 2009. According to The South Carolina Department of Commerce Research Division (2010, p. 9), "Between 2000 and 2009 the population in South Carolina increased 13.4\%, $13.1 \%$ for the southeast, and $8.8 \%$ for the US". In 2012, South Carolina's unemployment rate was 8.6 ranking 10th highest among the other states (Bureau of Labor Statistics, 2013). Compared to the national unemployment rate of 7.8 , South Carolina has a higher rate than the national average. GSP for 2011 is $\$ 385,092$, for 2010 is $\$ 378,131$, for 2009 is $\$ 368,963$, for 2008 is $\$ 377,869$ (Bureau of Economic Analysis, 2013). Personal income per capita in 2011 is $\$ 33,636$, in 2010 is $\$ 32,193$ (Federal Reserve Economic Data, 2013). Durable goods manufacturing contributed the most to the increase in the GSP (added $.82 \%)$. "The large gains in the durable goods sector likely reflect rising output at BMW's operations in the Upstate and the ramp up of Boeing's operations in North Charleston" (Vitner \& Silverman, 2013, p. 3). In addition to the durable goods, nondurable goods manufacturing, wholesale trade, government and real estate contributes to the GSP by a quarter of a percentage point (The South Carolina Department of Commerce Research Division, 2010). In 2012, the State added 32,400 jobs, and most of the jobs were in leisure and hospitality and retail trade. Construction firms added 4,200 jobs in 2012 as well (Feik, 2013). 


\section{SOUTH CAROLINA 2012 ECONOMIC PROFILE}

Area

- 30,060 square miles

Population

- 4.7 million residents

Employment

- $2,514,481$

Gross State Product

- $\$ 176.2$ billion

Manufacturing

- textile, clothing, wood, tourism

Services

- wholesale and retail trade 
Appendix $F$

\section{ABBREVIATION TABLE}

\begin{tabular}{|l|l|}
\hline BEA & Bureau of Economic Analysis \\
\hline BLS & Bureau of Labor Statistics \\
\hline CAP & Common Agricultural Policy \\
\hline CBP & County Business Patterns \\
\hline FASA & European Union \\
\hline FECCAP & Federal Acquisition Streamlining Act \\
\hline GATT & Florida Energy and Climate Change Action Plan \\
\hline GPA & General Agreement on Tariffs and Trade \\
\hline GSP & Government Procurement Agreement \\
\hline IMPLAN & Gross State Product \\
\hline MAPE & Impact Analysis for Planning \\
\hline NAICS & Mean Absolute Percentage Error \\
\hline NASPO & The North American Industry Classification System \\
\hline NIGP & The National Association of State Procurement Officials \\
\hline RCP & The National Institute of Governmental Purchasing \\
\hline REND-PRODUCTP & Resident Subcontractor Preference \\
\hline REMI & Regional Economic Model \\
\hline
\end{tabular}




\begin{tabular}{|l|l|}
\hline REMI PI+/PI+ & Regional Economic Model the Policy Insight Model \\
\hline RIMS II & Regional Input-Output Modeling System \\
\hline RSCP & Resident Subcontractor Preference \\
\hline RSQE & Research Seminar in Quantitative Economics \\
\hline RVP & Resident Vendor Preference \\
\hline SCEPP & South Carolina end-product preference \\
\hline USEPP & United States end-product preference \\
\hline Wist & Wist Office Products \\
\hline WTO & World Trade Organization \\
\hline
\end{tabular}


Sawsan A. Abutabenjeh

Department of Urban Studies and Public Administration

Strome College of Business

2084 Constant Hall

Old Dominion University

Norfolk, Virginia 23529

E-mail Address: sabutabenjeh@gmail.com

\section{EDUCATION}

Doctor of Philosophy, Public Administration and Urban Policy (2014), Urban Studies and Public Administration Department, Strome College of Business, Old Dominion University, Norfolk, Virginia.

Cognate area: Econometrics

Dissertation: The Impacts of In-State Procurement Preference Policies on the South Carolina Economy Dissertation Committee Chair: Professor Berhanu Mengistu.

Dissertation Committee Members: Dr. Stephen B. Gordon (Old Dominion University), Dr. David Selover (Old Dominion University) and Dr. Cliff McCue (Florida Atlantic University).

Master of Business Administration (2006), Banking and Financial Sciences Department, College of Economics and Administrative Sciences, The Hashemite University, Zarqa, Jordan.

Bachelor of Science, Finance and Banking Sciences (2004), Banking and Financial Sciences Department, College of Economics and Administrative Sciences, The Hashemite University, Zarqa, Jordan.

RESEARCH \& TEACHING AREAS

- Public Finance

- Quantitative Methods

- Research Methods and Design

- Policy Analysis and Evaluation

- Public Procurement

- Public Administration Theories

- American Public Administration 
Aug 11 - May 12

May 13- Aug 14

May 12- Aug 12

May 11- Aug 11

May 10-Aug 10

May 09-Aug 09

Aug 08 - May 13

Sep 04 - June 06

Aug 04 - Jan 07
Instructor of Record, PAS 300: Foundation of Public Service, Urban Studies and Public Administration Department, Strome College of Business, Old Dominion University.

Teaching Assistant, Finance and Accounting Departments, Strome College of Business, Old Dominion University. Teaching Assistant / Courses: Introduction to Financial Management, Intermediate Financial Management and Principles of Managerial Accounting.

Teaching and Research Assistant, Urban Studies and Public Administration Department, Strome College of Business, Old Dominion University.

Teaching Assistant / Courses: Introduction to Public Procurement, Public Sector Contract Planning and Formation, Social Entrepreneurship.

Graduate Research and Teaching Assistant, Banking and Financial Sciences Department, College of Economics and Administrative Sciences, The Hashemite University, Zarqa, Jordan.

Teaching Assistant / Courses: Research Methods and Design in Finance, Principles of Finance, Principles of Public Finance and Financial Management.

Senior Financial Analyst, Jordan Mortgage Refinance Company, Amman, Jordan.

Journal Publications (Peer Reviewed)

- Al Rjoub, S.A.M and Abutabenjeh, S. (2009). Price limits and stock returns volatility in Jordanian banks. Int. J. Monetary Economics and Finance, Vol. 2, No. 2, pp.144-165.

- Juita-Elena Yusuf, Lenahan O'Connell, and Sawsan Abutabenjeh. (2011). Paying for locally owned roads: A crisis in local government highway finance. Public Works Management \& Policy, Vol. 16, 3, pp. 250-269. 
- Abutabanjeh, S., Calida,N., and Jaradat, R. A. (2012). Collective Reflection on the PhD Student's Journey: Shades of "Techniques" and "Epistemic pluralism". Administrative Theory \& Praxis, Vol. 34, 2, pp. 274-278.

- Abutabanjeh, S, and Jaradat, R. Comparative Investigation for Research Design. Administration \& Society. (Manuscript is under review).

- Bishu, S., Abutabenjeh, S., and Alkadry, M. Public Procurement and Economic Development (Manuscript in progress).

- Abutabanjeh, S., and Alkadry, M. Fraud in Public Procurement (Manuscript in progress).

- Abutabanjeh, S. A Comparative Study of the Impact of State Preference Policies in Procurement (Manuscript in progress).

\section{CONFERENCES}

- Yusuf, J., Abutabenjeh, S. and L. O'Connell. (2009). The State of Transportation Finance since ISETA: A 15-year Analysis. Paper presented in poster session at the Association for Budgeting and Financial Management Annual Conference, DC.

- Yusuf, J. and S. Abutabenjeh. (2009). Evaluation of Entrepreneurial Assistance Programs: The State of the Research. Paper presented at the Mason Entrepreneurship Research Conference.

- Williams, A., Taylor, J., Kenter, R., Abutabenjeh, S., and Bishu, S. (2010). Nonprofit Accountability; Negotiating the Network. Paper presented at International Research Society for Public Management, Berne, Switzerland

- Yusuf, J., L. O'Connell, and Abutabenjeh,S. (2010). An Unfunded Mandate by Any Other Name? State-Local Ownership and Financing of Roads. Paper presented at the Annual Western Social Science Association (Public Finance and Budgeting) Conference, Reno, Nevada.

- Yusuf, J., L. O'Connell, and Abutabenjeh, S. (2010). State-Local Ownership and Financing of Roads Post-ISTEA: No Longer Business as Usual? Paper is presented at The Southeast Conference on Public Administration (SECOPA), Wilmington, North Carolina.

- Melkie, G., Abutabenjeh, S., and Morris, J. (2010). Are There Economic Gains from privatization of Public Services? Paper is presented at The Southeast Conference on Public Administration (SECOPA), Wilmington, North Carolina.

- Calida, B., Jaradat, R., and Abutabanjeh, S. (2011). Shifting governance symbols the "myth of control" from a systems view. Paper is presented at 24th Public Administration Theory NetworkConference (PAT-NET): Mythologies of Governing: Symbols, Stories, and Narratives, Norfolk, Virginia.

- Abutabanjeh, S. and Jaradat, R. (2011). Imaginations cross Disciplines: Public Administration and Engineering Management. Paper is presented at 24th Public 
Administration Theory Network Conference (PAT-NET): Mythologies of Governing: Symbols, Stories, and Narratives, Norfolk, Virginia.

- Bishu, S., Abutabenjeh, S., and Alkadry, M. (2011). Public Procurement and Economic Development. Paper is presented at The Southeast Conference on Public Administration (SECOPA), New Orleans, Louisiana.

- Abutabanjeh, S., and Jaradat, R. (2011). The Role of Imagination in the Organization: Public Administration and System of Systems (SoS) Perspectives. Paper is presented at The Southeast Conference on Public Administration (SECOPA), New Orleans, Louisiana.

- Abutabanjeh, S., Alkadry, M. and Jaradat, R. (2012). Fraud in Public Procurement. Paper is presented at the American Society for Public Administration Conference (ASPA 2012), Las Vegas, Nevada.

- Bishu, S., Abutabenjeh, S., and Alkadry, M. (2012). Public Procurement and Economic Development. Paper is presented at the American Society for Public Administration Conference (ASPA 2012), Las Vegas, Nevada.

- Abutabanjeh, S., Vellalos, J.,Gordon, S., and Gokhale, S. (2012). Politics in State and Local Government Design and Construction. Paper is presented at the 70th Annual MPSA Political Science Conference, Chicago, Illinois.

- Abutabanjeh, S. (2012). An Empirical Examination of the Impact of State Preference Policies in Procurement. Paper is presented at 5th International Public Procurement Conference (IPPC5), Seattle, Washington.

- Abutabanjeh, S. (2013). Government, Money and Fraud. Paper is presented at the Association for Budgeting and Financial Management Annual Conference, DC.

- Abutabanjeh, S, and Jaradat, R. (2014). Tool to Navigate the Public Procurement Problems Domains. Paper is presented at the 72nd Annual MPSA Political Science Conference, Chicago, Illinois.

- Member, the Economic Development Team for Franklin, Virginia (2010-2011).

- Committee Member, Public Administration Theory Network Conference; PATNet 2011.

- Conference Reviewer, 33rd National ASEM Conference, Agile Management, Virginia Beach, VA, Oct 17-20, 2012.

- Committee Member, Preparing Future Faculty Program (2013).

- Member, the Armed Forces Communications-Electronics Association (AFCEA) international, Hampton Roads Chapter, and Old Dominion University.

- President, the Women in Transportation (WTS) student chapter at Old Dominion University. 
- Excellence Award for ranking $1^{\text {nd }}$ in class, Bachelor of Science, Finance and Banking Sciences, Banking and Financial Sciences Department for five semesters, Hashemite University, Zarqa, Jordan.

- Excellence Award for graduating $1^{\text {st }}$ in class, Master of Business Administration, Banking and Financial Sciences Department. Hashemite University, Zarqa, Jordan

- Administrative Sciences College Dean's Honor List, Hashemite University, Zarqa, Jordan for five semesters.

- Urban Studies and Public Administration Department Fellowship (2009-2010), College of Business and Public Administration, Old Dominion University.

- Student Success Award, Old Dominion University, August 2009.

- Jesse and Sue Hughes International Scholarship (2011, 2012, 2014), College of Business and Public Administration, Old Dominion University.

- Academic scholarship (2012), the National Institute of Governmental Purchasing (NIGP).

- The Armed Forces Communications and Electronics Association Hampton Roads Chapter Scholarship (2013). 